\title{
Kyiv Institutional Buildings Sector Energy Efficiency Program: Technical Assessment
}

\section{August 1997}

$$
\begin{aligned}
& \text { sep } 02197 \\
& \text { Q STI }
\end{aligned}
$$

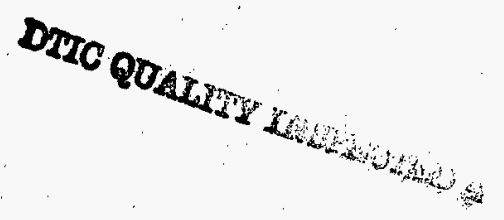




\title{
DISCLAIMER
}

This report was prepared as an account of work sponsored by an agency of the United States Government. Neither the United States Government nor any agency thereof, nor Battelle Memorial Institute, nor any of their employees, makes any warranty, express or implied, or assumes any legal liability or responsibility for the accuracy, completeness, or usefulness of any information, apparatus, product, or process disclosed, or represents that its use would not infringe privately owned rights. Reference herein to any specific commercial product, process, or senvice by trade name, trademark, manufacturer, or otherwise does not necessarily constitute or imply its endorsement, recommendation, or favoring by the United States Government or any agency thereof, or Battelle Memorial Institute. The views and opinions of authors expressed herein do not necessarily state or reflect those of the United States Government or any agency thereof.

\author{
PACIFIC NORTHWEST NATIONAL LABORATORY \\ operated by \\ BATTELLE \\ for the \\ UNITED STATES DEPARTMENT OF ENERGY \\ under Contract DE-AC06-76RLO 1830
}

Printed in the United States of America
Available to DOE and DOE contractors from the
Office of Scientific and Technical Information, P.O. Box 62, Oak Ridge, TN 37831;
prices available from (615) 576-8401.

Available to the public from the National Technical Information Service, U.S. Department of Commerce, 5285 Port Royal Rd., Springfield, VA 22161 


\section{Kyiv Institutional Buildings Sector Energy Efficiency Program: \\ Technical Assessment}

T. J. Secrest

S. L. Freeman.

A. Popelka ${ }^{(a)}$

P. A. Shestopal ${ }^{(\text {b) }}$

E. V. Gagurin ${ }^{(b)}$

August 1997



Prepared for

the U.S. Department of Energy

under Contract DE-AC06-76RLO 1830

Pacific Northwest National Laboratory

Richland, Washington 99352

(a) Tysak Engineering.

(b) Agency for Rational Energy Use and Ecology. 


\section{Summary}

The government of Ukraine, through the State Committee of Energy Conservation (State Committee), is considering the implementation of energy efficiency measures in state and municipal institutional buildings in the city of Kyiv. The State Committee entered into an agreement with the U.S. Department of Energy to assess the efficiency potential of the institutional buildings sector in Kyiv. Results of this assessment would support a loan by the World Bank for implementing an institutional buildings sector efficiency improvement program in Kyiv.

This report documents the assessment of the institutional buildings sector efficiency resource conducted by Pacific Northwest National Laboratory (PNNL) and its subcontractors, Tysak Engineering and the Agency for Rational Energy Use and Ecology (ARENO-ECO). The assessment consists of three primary tasks: evaluation of the institutional sector building stock in Kyiv, estimation of heat energy consumption in this building stock, and assessment of the cost-effective energy efficiency potential through retrofits to the buildings.

Buildings suitable for inclusion in a potential loan program were identified by means of a survey of owning organizations. Of the 1,678 buildings identified by the survey, education buildings make up the largest category with 1,296 buildings and a total of 6 million square meters of floorspace. There are an estimated 339 healthcare buildings having about 1 million square meters of floorspace. Forty three cultural buildings were also included in the survey with a total of 113 thousand square meters of floorspace. Total floorspace included in the survey for the institutional sector is 7.2 million square meters.

Of $17.7 \mathrm{Gcal}$ of heat energy supplied to the buildings sector in the form of hot water for space heating and domestic hot water purposes, the share by sector is estimated as follows: residential sector $68 \%$, institutional sector $16 \%$, and commercial sector $16 \%$. Although a literature review and professional experience indicate these estimates to be reasonable, uncertainty is high for these estimates. Of the institutional buildings included in this assessment, the educational category was estimated to represent about $84 \%$ of the total energy consumption.

Building types were analyzed by size and age subcategories to determine the cost-effective energy efficiency potential. Measures to improve energy efficiency were selected and applied to each subcategory to reduce space heating and domestic hot water energy use. Measures were selected based on the economic criterion of a 5-year or less simple payback. The measures include insulation (exterior, roof, attic, and pipe), weatherstripping, storm windows, radiator reflectors, controls (building and radiator level), low-flow showerheads, and faucet aerators. After measures were selected, the performance of the measure package was evaluated based on simple payback, internal rate of return, and net present value. 
The estimated efficiency potential ranges from $20 \%$ of baseline energy use for art galleries and museums to $29 \%$ for theaters, or a weighted average efficiency potential of $26 \%$ for all buildings. The investment levels associated with the efficiency improvements range from $\$ 3.47$ per square meter for schools to $\$ 6.21$ per square meter for hospital administration buildings, or a weighted average investment of $\$ 4.31$ per square meter. The total cost to install the efficiency measures is $\$ 31.1$ million.

As a result of energy efficiency improvements, a reduction in energy bills of $\$ 1.7$ million is estimated in the first year, increasing to over $\$ 9$ million annually when the installation of efficiency measures is completed in the fifth year of the program. In addition to energy use reductions, annual emissions are expected to be reduced as follows: 332 metric tons of $\mathrm{NO}_{x}, 232$ metric tons of $\mathrm{SO}_{\mathrm{x}}$, and 85,427 metric tons of $\mathrm{CO}_{2}$. None of the measures considered are expected to have negative health impacts or other environmental impacts. 


\section{Abbreviations and Acronyms}

\begin{tabular}{|c|c|}
\hline $\mathrm{A} / \mathrm{C}$ & air conditioning \\
\hline AISU & Advanced International Studies Unit \\
\hline ARENA-ECO & Agency for Rational Energy Use and Ecology \\
\hline ASEAM5 & A Simplified Energy Analysis Method, Version 5 \\
\hline ASHRAE & American Society for Heating, Refrigeration, and Air Conditioning. Engineers \\
\hline CFC & chlorofluorocarbon \\
\hline CHP & combined heat and power \\
\hline $\mathrm{CO}_{2}$ & carbon dioxide \\
\hline $\mathrm{dm}^{3}$ & cubic decimeters \\
\hline DOE & U.S. Department of Energy \\
\hline DWH & domestic water heating \\
\hline ECOs & energy conservation opportunities \\
\hline EHDP & Enterprise Housing Divestiture Project \\
\hline FLEOH & full load equivalent operating hours \\
\hline Gcal & gigacalories \\
\hline GJ & gigajoules \\
\hline GWh & gigawatt-hours \\
\hline IEA & International Energy Agency \\
\hline IRR & internal rate of return \\
\hline $\mathbf{K}$ & degrees Kelvin \\
\hline kcal & kilocalories \\
\hline KGTKE & Kyiv Municipal District Heat Company \\
\hline km & kilometer \\
\hline KRB & Hryvna \\
\hline kWh & kilowatt-hours \\
\hline m & meter \\
\hline MJ & megajoule \\
\hline $\mathrm{NO}_{\mathrm{x}}$ & oxides of nitrogen \\
\hline NPV & net present vàlue \\
\hline O\&M & operations and maintenance \\
\hline ODS & ozone depleting substances \\
\hline PNNL & Pacific Northwest National Laboratory \\
\hline R-Value & resistance to heat flow, defined as thickness/thermal conductivity \\
\hline RRR & required rate of return \\
\hline SCEC & State Committee for Energy Conservation \\
\hline $\mathrm{SO}_{\mathrm{x}}$ & oxides of sulfur \\
\hline TETS & combined heat and power station \\
\hline TMY & typical meteorological year \\
\hline
\end{tabular}




$\begin{array}{ll}\text { U-Value } & \text { overall heat transfer coefficient } \\ \text { VAT } & \text { value added tax } \\ \text { W } & \text { watt }\end{array}$

\section{Conversion Factors}

$$
\begin{aligned}
1 \mathrm{Gcal} & =1163 \mathrm{kWh} \\
1 \mathrm{Gcal} & =4.186 \mathrm{GJ} \\
1 \mathrm{GJ} & =278 \mathrm{kWh}
\end{aligned}
$$




\section{Acknowledgments}

This assessment was made possible by funding provided by the U.S. Department of Energy (DOE) under a Memorandum of Cooperation between the DOE and the Ukrainian State Committee for Energy Conservation (SCEC). Recognition is provided to Brian Castelli and Elizabeth Arner of DOE's Office of Energy Conservation and Renewable Energy for their perseverance and leadership in this effort. Appreciation is extended to Carolyn Gochenour and Pentti Aro of the World Bank and Tord Holmstrom of Energi Planerarna $\mathrm{AB}$ for their coaching and many suggestions and comments. Appreciation is extended to Mykhailo Kovalko, Nikolai Raptsoun, and Georgy Panchenko of the SCEC for their in-country leadership to facilitate data collection and agreements with Ukrainian participants. 


\section{Contents}

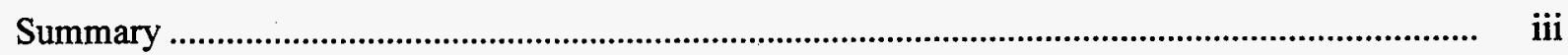

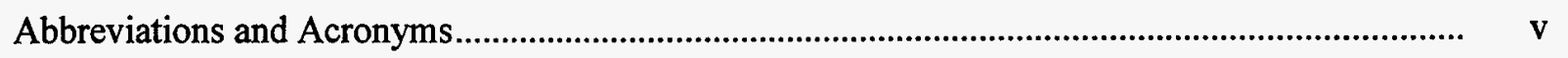

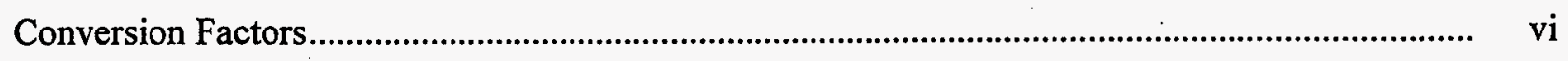



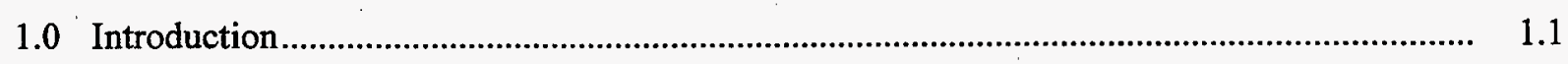



1.2 Report Organization ..................................................................................... 1.2



2.0 Energy Use Baseline Assessment ........................................................................... 2.1

2.1 Sector and Subsector Definitions ...................................................................... 2.1



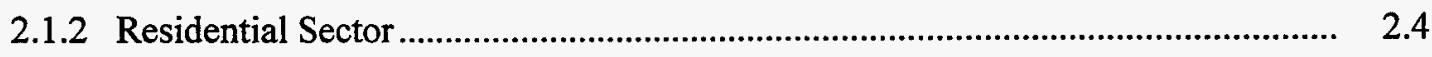

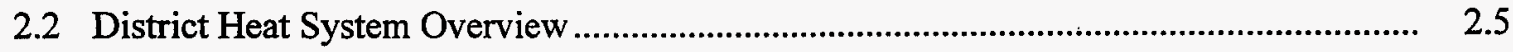

2.3 Thermal Energy Consumption Baseline .............................................................. 2.7

2.3.1 Building Sector Heat and Hot Water Consumption ........................................... 2.13



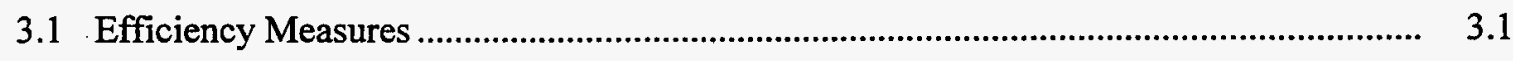

3.1.1 Efficiency Measures Considered ................................................................ $\quad 3.1$

3.1.2 Efficiency Measures Not Considered ............................................................ 3.22 
3.1.3 Summary of Efficiency Measures Considered .................................................. 3.26

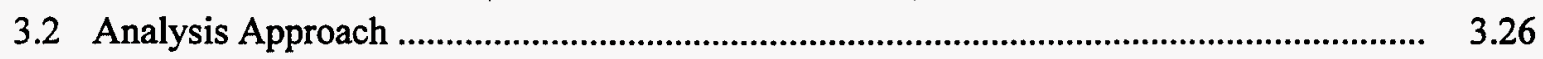



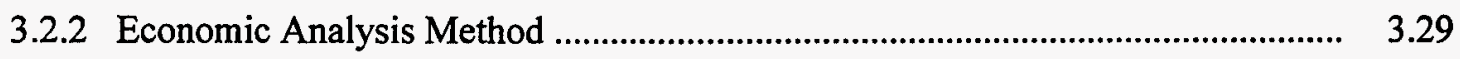

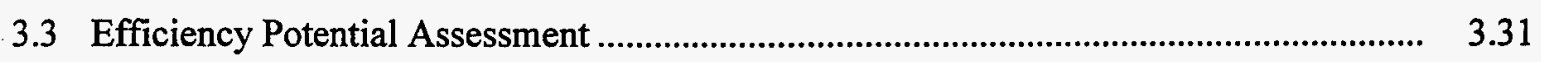

3.3.1 Institutional Sector Efficiency Potential..................................................... 3.32

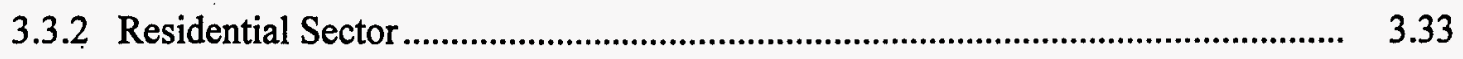

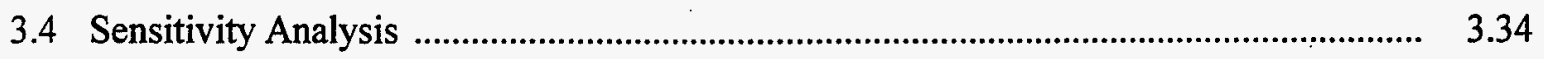

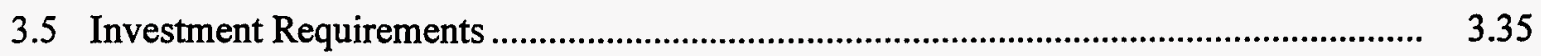

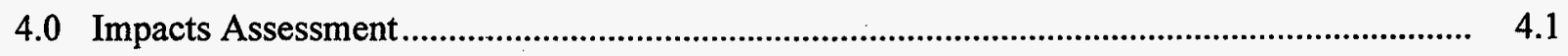

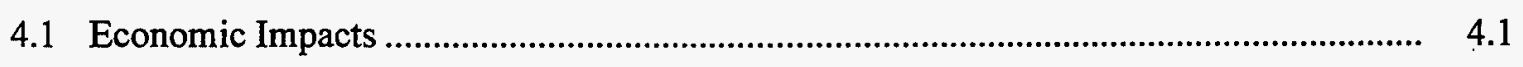

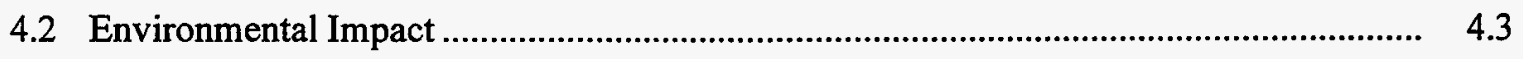



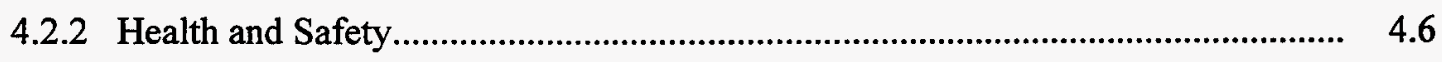

4.2.3 Indoor Air Quality ................................................................................. 4.6

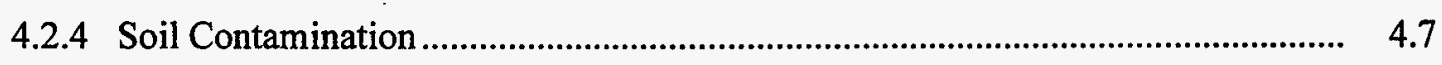

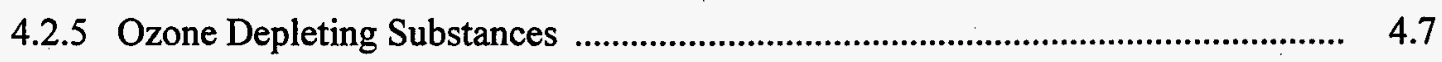

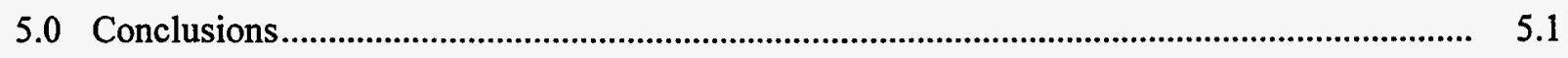

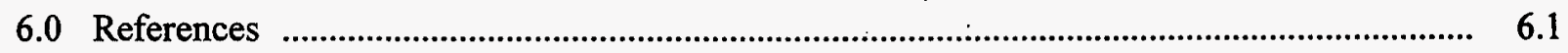

Appendix A - Institutional Building Stock Survey and Data Collection ..................................... A.1




Appendix C - Efficiency Measure Cost Data................................................................................ C.1

Appendix D - Efficiency Measure Performance Analysis .............................................................. D.1

Appendix E - Investment Requirements ............................................................................... E. E.1

Appendix F - Review of Literature ................................................................................. F.1 


\section{Figures}

2.1 District Heating Regions in Kyiv ...................................................................................... 2.6

2.2 Estimated Energy Flow of Kyiv District Heating System, 1995 ……................................... 2.12 


\section{Tables}

2.1 Number and Floorspace of Institutional Buildings by Type and Subsector, 1996................. 2.4

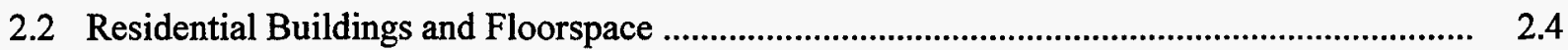

2.3 Hot Water Capacity of the Kyiv District Heating System ................................................. 2.6

2.4 Estimated Fuel Consumption by District Heat Suppliers in Kyiv, 1995 ............................. 2.9

2.5 Estimated Heat and Electricity Supply to the District Heating System in Kyiv, $1995 \ldots \ldots \ldots . . . . \quad 2.10$

2.6 Estimated Heat and Electricity Consumption from the District Heating System

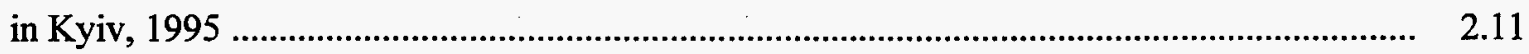

2.7 Institutional Sector Baseline Heat and Hot Water Energy Consumption Supplied by District Heat

2.8 Residential Sector Baseline Heat and Hot Water Energy Consumption Supplied by District Heat.

3.1 Efficiency Measures Considered and Installed Cost Per Unit

3.2 Institutional Sector Efficiency Potential

3.3 Residential Sector Efficiency Potential

3.4 Internal Rate of Return Switching Valve for Energy Savings and Installed Costs - Institutional Buildings

3.5 Internal Rate of Return Switching Valve for Energy Savings and Installed Costs - Residential Buildings

3.6 Investment Requirements for the Institutional Buildings Sector

3.7 Investment Requirements for the Residential Buildings Sector.

4.1 Secondary Impacts

4.2 Boiler Plant Permissible Air Pollutant Emission Levels 


\subsection{Introduction}

The government of Ukraine, through the State Committee of Energy Conservation (State Committee), is considering the implementation of energy efficiency measures in state and municipal institutional buildings in the city of Kyiv. The State Committee entered into an agreement with the U.S. Department of Energy to assess the efficiency potential of the institutional buildings sector in Kyiv. Results of this assessment would support a loan by the World Bank for implementing an institutional buildings sector efficiency improvement program in Kyiv.

This report documents the assessment of the institutional buildings sector efficiency resource conducted by the Pacific Northwest National Laboratory (PNNL) and its subcontractors, Tysak Engineering, a U.S.-based engineering consultancy; and the Agency for Rational Energy Use and Ecology (ARENAECO), a Ukrainian nongovernmental organization that specializes in energy efficiency assessments. Companion assessments of the central district heat supply resources (combined heat and power plants) and distribution system (distributed heat generation plants and thermal distribution system) were conducted by Joseph Technology Corporation (JTC 1996) and Ekono Energy (1996), respectively.

\subsection{Scope and Approach}

The purpose of this assessment is to characterize the economic energy efficiency potential and investment requirements for space heating and hot water provided by district heat in the stock of state and municipal institutional buildings in the city of Kyiv. The assessment involves three activities. The first is a survey of state and municipal institutions to characterize the stock of institutional buildings. The second is to develop an estimate of the cost-effective efficiency potential. The third is to estimate the investment requirements to acquire the efficiency resource.

Institutional buildings are defined as nonresidential buildings owned and occupied by state and municipal organizations. General categories of institutional buildings are education, healthcare, and cultural. The characterization activity provides information about the number of buildings, building floorspace, and consumption of space heating and hot water energy provided by the district system.

Because of the desire to limit the potential loan program to a small number of owing organizations, this assessment focused on those organizations expected to have large numbers of buildings and floorspace under their subordination. These organizations include the Municipal Department of Health, the Ministry of Health, the Municipal Department of Education, the Ministry of Education, and the Municipal Department of Culture. The building stock data are thus most complete for the categories of healthcare, education, and cultural buildings. Data were not collected for building types, such as office buildings, that are widely distributed among state and municipal organizations. 
The analysis adopts simple payback as the primary metric for determining the suitability of efficiency measures for the loan program. This reflects the desire for the project savings to pay back the loan in a short timeframe. The basic economic requirement is for the installed cost of the energy efficiency measures to have a simple payback of 5 years or less. The economic analysis also examines the costs from net present value (NPV) and internal rate of return (IRR) standpoints. The efficiency potential is developed to provide estimates of the reduction in total annual energy consumption. The sensitivity of the investment is also examined with respect to costs of efficiency measures and energy savings.

Although other buildings served by the district heating system in Kyiv are not the focus of a planned investment program, an estimate of the efficiency potential and cost is also developed for the residential sector.

\subsection{Report Organization}

The efficiency assessment is presented in the following four chapters:

- Chapter 2 provides a characterization of the building sector and the baseline heat and hot water energy supplied by the district heating system.

- Chapter 3 presents the energy conservation opportunities (ECOs) and the estimated economic efficiency resource along with investment requirements. This includes an analysis of the sensitivity of the cost-effectiveness of the investment to key factors.

- Chapter 4 presents the estimated secondary economic and environmental impacts analysis of the efficiency resource. Secondary economic impacts include employment, balance of payments, and potential domestic manufacture of equipment and materials. Environmental impacts include reductions in emissions and worker exposure to hazardous materials.

- Chapter 5 contains a summary and conclusions.

Appendix A describes the stock of institutional buildings and the data collection methodology. Appendix $B$ describes baseline energy consumption. Appendix $C$ contains the efficiency measure cost data. Appendix D describes the efficiency measure performance analysis. Appendix E describes investment requirements. Appendix $\mathrm{F}$ is a review of the literature. These appendices are referenced in the applicable chapters.

\subsection{Study Participants}

PNNL, one of DOE's five multiprogram research laboratories, conducts a significant number of programs in the area of energy efficiency and integrated resource planning. PNNL's Advanced International Studies Unit (AISU) conducts research on global climate change and manages cooperative 
programs to transfer energy efficiency practices and technologies to other countries. PNNL provided technical and management oversight for this effort and contributed to the analysis.

PNNL/AISU contracted with Tysak Engineering and ARENA-ECO to support the assessment activities. Tysak Engineering specializes in buildings efficiency assessments and implementation projects, with substantial experience in Central and Eastern Europe. Tysak provided direct oversight for and was directly responsible for the conduct of the majority of the analysis.

ARENA-ECO is a Ukrainian nongovernmental, nonprofit organization dedicated to improving economic development and the environment through energy efficiency. ARENA-ECO provided the in-country coordination for the assessment and contributed to all aspects of the analysis. 


\subsection{Energy Use Baseline Assessment}

This chapter presents a baseline assessment of the consumption of district heat energy by building sector. Although the focus of this assessment is the institutional buildings sector, the baseline is also provided for the residential sector. Section 2.1 describes the building sectors defined for this assessment and characterizes the sectors by number of buildings and square meters of floorspace. Information on institutional buildings in this section is based on a survey carried out for the project, which is described in detail in Appendix A. Section 2.2 describes the district heating system in Kyiv. Section 2.3 provides estimates of the baseline space heat and hot water energy provided to each building sector by the district heating system.

\subsection{Sector and Subsector Definitions}

Three building sectors were defined in this analysis: institutional, residential, and commercial. Of these three sectors, residential buildings are the most precisely characterized in the literature. Little information exists on the number, size, and types of buildings in the institutional and commercial sectors. Characterization of the institutional buildings sector, the primary focus of this study, was carried out by means of a survey, which is described in detail in Appendix A. This survey was not comprehensive, but instead was intended to identify and characterize those categories of buildings (by type and ownership) most suitable for the potential loan program. No building stock information was available for the commercial sector.

The primary descriptors used to characterize institutional buildings are function, age, and size (number of floors), each of which has an impact on thermal performance. The building age categories used are buildings constructed prior to 1958 , those constructed from 1958 to 1980, and those constructed after 1980. These age groups conform roughly to periods with particular architectural styles and building codes that impact the thermal performance and applicability of energy efficiency measures (e.g., roof construction impacts the choice of roof or attic insulation as an efficiency measure). Building size categories were selected based on the available data. For institutional buildings these are 1 to 2 story buildings, 3 to 4 story buildings, and buildings 5 stories and greater. For residential buildings the categories are 1 to 4 story buildings, 5 to 9 story buildings, and buildings 10 stories and greater. The institutional and residential building sectors are described in more detail below.

\subsubsection{Institutional Sector}

The characterization of the institutional buildings sector was developed by surveying the state and municipal organizations that own and occupy buildings in this sector. More detailed information on the state and municipal organizations surveyed for the information in this section is presented in Appendix A. 
Institutional buildings are defined as nonresidential buildings owned and occupied by state and municipal government organizations. There are three types (subsectors) of institutional buildings: healthcare, education, and cultural. Each of these types is described below.

\section{Healthcare}

Healthcare buildings include only those buildings under the direction of the Municipal Department of Health and the Ministry of Health. There are a number of healthcare facilities under the direction of other organizations. The majority of buildings in the survey are owned by the Municipal Department of Health.

The healthcare subsector is divided into four building types as follows:

- Hospitals. Hospitals provide in-patient care and medical services. In-patient hospitals are widely distributed by size with about one-third of the 160 buildings being 1 to 2 stories, 3 to 4 stories, and greater than 4 stories. In terms of floorspace, however, about two-thirds is in the $>4$ stories category, about half of which was built between 1958 and 1980, the other half after 1980. Hospitals are the largest subsector of healthcare buildings.

- Polyclinics. Polyclinics provide out-patient medical services. Polyclinics are widely distributed by both age and size. More than $45 \%$ of polyclinic floorspace is in the size category $>4$ stories and of post- 1980 construction. About $35 \%$ of floorspace is in the categories of 3 to 4 story polyclinics built between 1958 to 1980 and after 1980 . There are a total of 110 buildings in this category.

- Hospital Administration and Support Buildings. The healthcare sector includes a number of buildings that serve exclusively for administration and support activities. Though about $50 \%$ of the 69 hospital administration buildings are 1 to 2 story buildings and pre-1958 construction, the largest concentration of floorspace (44\%) is found in newer (post-1958) buildings $>4$ stories.

- Other Healthcare Buildings. Though there are a large number of "other" healthcare-related buildings (136), they represent only $6 \%$ of the total healthcare floorspace. In addition, 64 buildings that are not primarily dedicated to healthcare have some floorspace used for healthcare activities. Again, this floorspace represents a small fraction of total floorspace in healthcare facilities. These buildings were not included in the analysis.

\section{Education}

The education subsector is divided into four building types. Kindergartens and schools are under the direction of the Municipal Department of Education. Higher education facilities and student hostels are under the direction of the Ministry of Education. A number of additional education buildings not included in this analysis are under the direction of several other organizations. A description of the four building types follows. 
- Kindergartens. Public kindergartens serve a broader function in Ukraine and many other Eastern European countries than in the United States. After childbirth, mothers are allowed paid leave (currently 3 years, previously 1.5 years) to care for their child. An additional unpaid leave of the same duration is also available if they choose to remain in the home, with a guarantee of their old job when they return. Kindergartens thus serve a preschool/daycare function for children anywhere from 1.5 to 6 years of age. The kindergartens are generally small, with about 100-200 students, and are dispersed throughout the residential districts. In total there are approximately 600 state-owned kindergartens in Kyiv, all of them less than 5 stories high. More than half of the buildings and floorspace were built between 1958 and 1980 and are 1 to 2 stories high. The bulk of the remainder are also 1 to 2 stories and were built since 1980 .

- Schools. Primary schools are also of small size and are distributed throughout the residential districts. The 389 school buildings are also less than 5 stories, with the majority (94\%) being 3 to 4 stories high. About half of the buildings were constructed between 1958 and 1980. Along with buildings constructed since 1980 , there is also a sizable population of pre-1958 buildings. Schools are the largest single institutional building category in the survey, by area, comprising about 2.8 million square meters of floorspace.

- Higher Education. This building type includes technical institutes and universities. Of the 174 higher education buildings, more than $50 \%$ of buildings and floorspace were constructed in the period 1958-1980. About $25 \%$ of the floorspace is in the post- 1980 category. This floorspace is accounted for by $19 \%$ of the buildings, reflecting a trend toward larger buildings in this period.

- Hostels. The Ministry of Education also operates a significant number of residential buildings for students. As with other higher education buildings, most hostels are greater than 5 stories, accounting for nearly $90 \%$ of total floorspace for hostels. About three quarters of this floorspace was built from 1958 to 1980 .

\section{Cultural}

The cultural buildings included in the survey are owned by the Municipal Department of Culture. The cultural buildings category is divided into two building types as follows:

- Theaters. Most of the 12 theaters included in the survey are of pre-1958 construction and have 3 to 4 stories. Pre- 1958 buildings also make up $85 \%$ of floorspace.

- Art Galleries/Museums. Information was collected for 31 art galleries and museums. About $84 \%$ of these (26) are of pre-1958 construction.

The estimated number of institutional buildings and floorspace by building category and ownership is shown in Table 2.1. A more detailed listing is provided in Appendix A. 
Table 2.1. Number and Floorspace of Institutional Buildings by Type and Subsector, 1996

\begin{tabular}{||l|l|c|c||}
\hline \multicolumn{2}{|c|}{ Institutional Buildings } & \multicolumn{1}{|c|}{$\begin{array}{c}\text { Number of } \\
\text { Buildings }\end{array}$} & $\begin{array}{c}\text { Floorspace } \\
\left(\mathbf{m}^{2} \mathbf{)}\right.\end{array}$ \\
\hline \multirow{3}{*}{ Subsector } & \multicolumn{1}{|c|}{ Type } & 160 & 637,125 \\
\hline \multirow{4}{*}{ Educatthcare } & Hospitals & 110 & 293,867 \\
\cline { 2 - 4 } & Polyclinics & 69 & 92,245 \\
\cline { 2 - 4 } & Administration & 600 & $1,312,326$ \\
\hline \multirow{3}{*}{ Cultural } & Kindergartens & 389 & $2,804,268$ \\
\cline { 2 - 4 } & Schools & 174 & $1,228,765$ \\
\cline { 2 - 4 } & Higher Education & 133 & 730,614 \\
\cline { 2 - 4 } & Hostels & 12 & 48,043 \\
\hline Total & Theaters & 31 & 65,358 \\
\cline { 2 - 4 } & Art Galleries/Museums & 1,678 & $7,212,611$ \\
\hline
\end{tabular}

\subsubsection{Residential Sector}

The characterization of the residential sector building stock in Kyiv is derived primarily from a report on building sector efficiency potential in Kyiv (TACIS 1994) and the more recent studies by Joseph Technologies and Ekono Energy (JTC 1996; Ekono Energy 1996). These reports are reviewed in detail in Appendix F. Total estimates of residential floorspace for the past 16 years are presented in Table 2.2.

Table 2.2. Residential Buildings and Floorspace ${ }^{(a)}$

\begin{tabular}{|c|c|c|c||}
\hline Year & Number Dwellings & Average Area $\left.\mathbf{( m}^{2}\right)$ & $\begin{array}{c}\text { Floorspace } \\
\left(\mathbf{m i l l i o n} \mathbf{~ m}^{\mathbf{2}}\right)\end{array}$ \\
\hline 1980 & 620,400 & 53.4 & 33.1 \\
\hline 1985 & 701,300 & 54.4 & 38.1 \\
\hline 1990 & 807,300 & 54.0 & 43.6 \\
\hline 1991 & (b) & (b) & 44.5 \\
\hline 1992 & (b) & (b) & 45.5 \\
\hline 1993 & (b) & (b) & 46.3 \\
\hline 1994 & (b) & (b) & 47.2 \\
\hline 1995 & (b) & (b) & 48.1 \\
\hline 1996 & 889,400 & 55.1 & 49.0 \\
\hline
\end{tabular}

(a) Estimates for 1980-1990 are from TACIS (1994). Total floorspace estimates from 1991-1996 are from Ekono Energy (1996). Number of dwellings in 1996 is from JTC (1996). Average area in 1996 is estimated from the total floorspace and number of dwellings and is consistent with the trend toward larger apartments.

(b) No data available. 
In $1990,99.7 \%$ of buildings used for public housing were connected to the district heating network, and public-owned buildings made up $95.5 \%$ of total dwellings (TACIS 1994). Hence, descriptions of the residential housing sector describe, to a large degree, the residential sector demand on the district heating system.

The stock of residential buildings is divided into age categories depending on location either in the city center or the periphery as follows (TACIS 1994):

- Residential buildings located in the city center compose less than $5 \%$ of the floorspace. Of these, the distribution by construction time period is:

constructed before $1917 \quad 61 \%$

constructed from $1917-1961 \quad 34 \%$

constructed after 1961

- Residential buildings located on the periphery compose more than $95 \%$ of the floorspace. Of these, the distribution by construction time period is:

constructed before $1961 \quad 0 \%$

constructed from $.1961-1975 \quad 31 \%$

constructed after $1975 \quad 69 \%$

Multifamily residential buildings can also be described according to the number of building stories, which has a strong correlation with thermal performance. In Kyiv the housing floorspace is divided as $8.3 \%$ in buildings 1 to 4 stories, $67.9 \%$ in buildings 5 to 9 stories, and $23.8 \%$ in buildings over 9 stories (Ekono Energy 1996). While a more precise description of the building size categories would be useful, this characterization will suffice for a first order approximation of the residential buildings efficiency resource because it is not the focus of this assessment.

\subsection{District Heat System Overview}

The district heating system in Kyiv consists of six heating regions, with the addition of two heating regions planned. Heating regions 1,2, and 3 are located on the west side of the Dnieper River, and regions 4,5 , and 6 on the east side of the river. The layout of the six heating regions is shown in Figure 2.1. The two planned regions are to the south of region 6. 


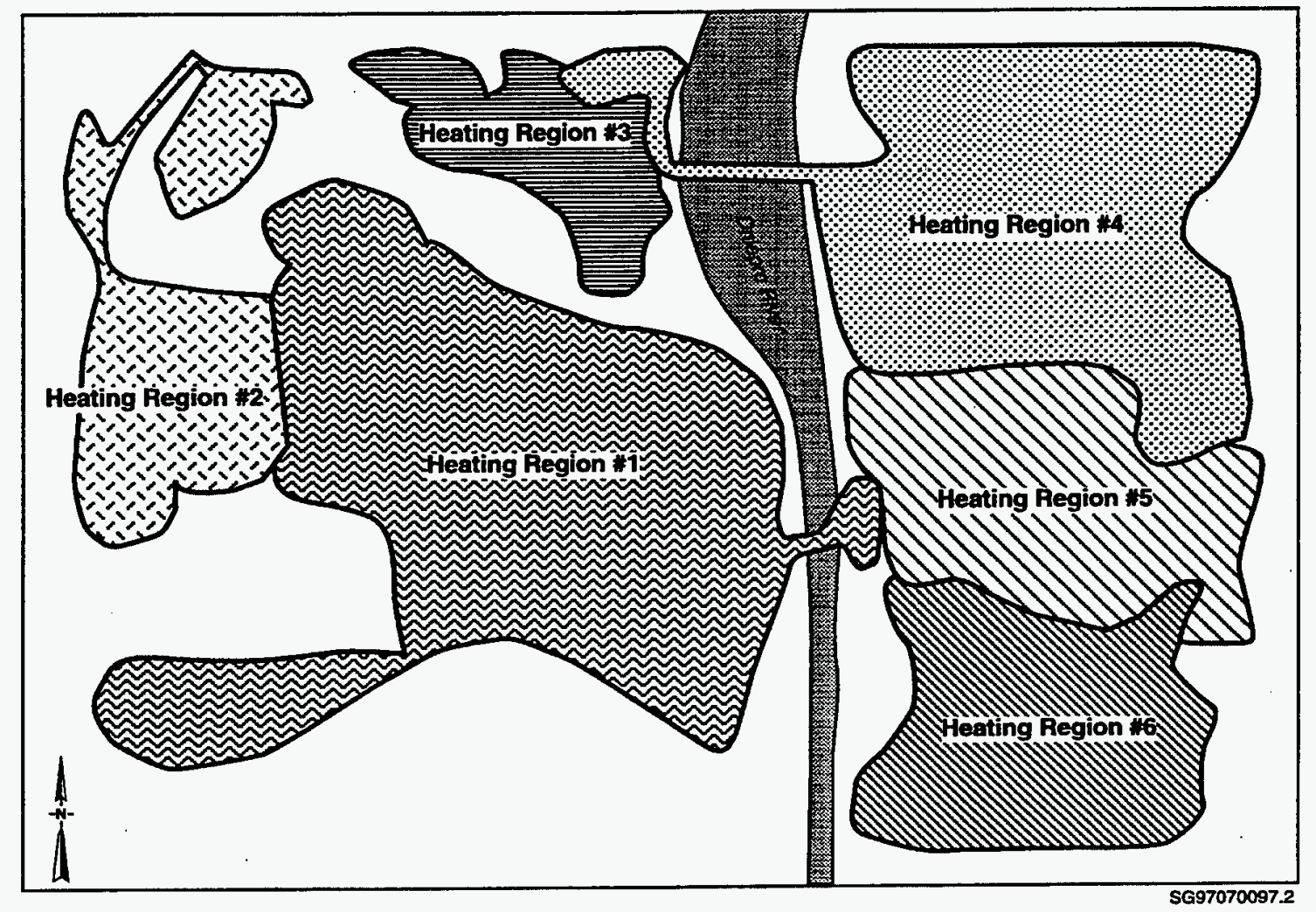

Figure 2.1. District Heating Regions in Kyiv

Hot water is supplied from a number of sources with capacities shown in Table 2.3.

Table 2.3. Hot Water Capacity of the Kyiv District Heating System

\begin{tabular}{||l|r|r|r||}
\hline \multicolumn{1}{|c|}{ Source } & Gcal/Hr & MW & \multicolumn{1}{c|}{ \% } \\
\hline Kievenergo & 5,667 & 6,591 & 60.1 \\
Kyiv Municipal District Heating Company & 511 & 594 & 5.4 \\
Akademteploenergo & 250 & 291 & 2.7 \\
Industrial Boilers & 2,221 & 2,583 & 23.5 \\
Other Boilers & 783 & 911 & 8.3 \\
\hline Total Capacity & 9,432 & 10,969 & 100 \\
\hline
\end{tabular}

Kievenergo owns and operates two combined heat and power (CHP) plants, purchases heat from a CHP supplier, and owns and operates nine large heat-only boiler plants. The Kyiv Municipal District Heat Company (KGTKE) owns and operates 112 heat-only boiler plants, Akademteploenergo owns and operates two heat-only boiler plants, and industrial sources provide heat from about 350 plants. Industrial boiler capacity also includes 1,601 Gcal steam/hour, which is consumed primarily for process uses. 
The primary heat transmission network (transmission system) is about $1,000 \mathrm{~km}$ in length, about $768 \mathrm{~km}$ of which Kievenergo owns and maintains. The KGTKE is responsible for about $232 \mathrm{~km}$. KGTKE also owns and maintains 2,206 substations and an estimated $662 \mathrm{~km}$ of secondary network (distribution system) [estimated assuming $300 \mathrm{~m}$ per substation]. The other heat suppliers also own and maintain sections of piping and substations.

Hot water is supplied to the network in a constant flow configuration, with heat delivery regulated by hot water supply temperatures having a design temperature of $150^{\circ} \mathrm{C}$. Hot water for space heat is supplied directly to most buildings through a hydroelevator system located in the basement. In this system, entering water is cooled to appropriate levels by mixing with the return water in a venturi nozzle.

Buildings operators purchase heat from the system based on estimated consumption rather than actual consumption. Because of the lack of heat metering in buildings, there is no way to verify that charges match consumption, and hence there is no incentive to conserve energy. Buildings also lack functional controls, so temperature regulation is carried out by opening windows. Though radiators are sometimes equipped with shut-off valves, the poor quality of the valves recommends against their use. In normal conditions, significant overheating occurs early and late in the heating season and during warm periods in the middle of the winter. In recent years, however, fuel supply and capacity constraints have reduced service levels, resulting more commonly in under-heating than over-heating. Lack of effective controls also results in poor heat distribution, so that some rooms, zones, or buildings may be underheated while others are adequately or over-heated.

\subsection{Thermal Energy Consumption Baseline}

In this study, the energy efficiency potential is estimated from baseline energy consumption estimates, which are developed from a combination of simulation modeling estimates, actual system performance data, and design performance estimates. Efficiency potential is expressed as a percentage of this baseline. Because of this, the magnitude of the baseline energy consumption plays a critical role in the estimation of the cost-effective resource potential. Lacking a significant amount of metered data, these baseline energy consumption estimates are at best approximate. Though a wide variety of sources exist, the information contained in these sources is not always consistent. For some parameters, such as transmission and distribution system performance, the actual efficiency is only an educated estimate. Baseline energy consumption estimates are presented below.

This section presents estimates of the consumption of energy in the district heating system in the city of Kyiv for 1995 and estimates of the consumption of heat and hot water in the buildings sector by building category. Because of the poor economic situation in Ukraine in 1995, the district heat energy production was depressed relative to normal conditions due to fuel shortages and capacity constraints. The 1995 energy flow estimates are used primarily to illustrate the relative importance of the various heat supply sources and heat consuming sectors. The efficiency resource assessment is based on design 
heat consumption estimates and modeled performance in normal heat supply conditions. Hence, the building sector level heat consumption estimates used in assessing the efficiency potential will differ from the 1995 heat consumption estimates.

Estimates of energy flows in the district heating system are largely based upon the reports prepared by Joseph Technologies and Ekono Energy for the rehabilitation of the heat generation and distribution components of the Kyiv District Heating System (JTC 1996; Ekono Energy 1996). The baseline and forecast heat consumption estimates in these reports are based primarily on a master plan developed by Ukrenergoprom in 1995 in close cooperation with Kievenergo, Energoproject, and Kievproject (Ukrenergoprom 1995).

In addition, the Joseph Technologies report contains detailed operations and accounting information for Kievenergo and KGTKE both for the year 1995 and, in the case of Kievenergo, for estimated 1996 operations. The Ekono Energy report also contains fuel energy use data for Kievenergo and KGTKE.

Estimates of building sector level energy flows in the district heating system are difficult to make because of the lack of metered energy consumption data for the system and for Kyiv buildings. Estimates of the distribution of heat energy consumption are generally derived in terms of capacity demand data (usually given as Gcal/hour). Though some limited metering has been done to calibrate building energy demand models (e.g., TACIS 1994), estimates of specific energy consumption in buildings must often be developed from rough estimates of system performance, and rough descriptions of the supply system connections to buildings' floorspace. A more detailed evaluation of the various specific energy consumption estimates found in the literature is presented by building sector in Appendix B.

City-level heat and energy flow estimates for 1995 are presented in Tables 2.4 through 2.6, and are summarized in Figure 2.2. Values used to generate Figure 2.2 are shaded in the respective tables.

Fuel consumption (Table 2.4) is presented only as the city-level total, and is assumed to be split as $85 \%$ natural gas and $15 \%$ mazut. This estimate is based on Kievenergo accounting data (JTC 1996) and is consistent with the dominant use of natural gas for boiler fuel in Kyiv.

Heat and electricity production are presented by supplier in Figure 2.2. These values can be found by supplier in the bottom two rows of Table 2.5. In Figure 2.2, the category "other" includes heat produced by heat-only boiler plants and individual heat generators.

Heat and electricity consumption estimates in Figure 2.2 are from the right-hand column of Table 2.6. The public sector total (4.2 million Gcal) is split into commercial and institutional sectors in Figure 2.2. Because there is no actual data on energy consumption in public buildings, this value is split evenly between the two sectors. The estimated energy consumption of $1.1 \mathrm{Gcal}$ for education, cultural, and healthcare buildings suggests that this assumption is reasonable. Energy flows for Kievenergo and KGTKE are based on actual 1995 fuel consumption and heat production data reported in Ekono Energy 
Table;2:4.; Estimated:Fuel Consumption (thousand Gcal) by District Heat Suppliers in Kyiv, 1995

\begin{tabular}{|c|c|c|c|c|c|c|c|c|c|c|c|c|c|c|c|}
\hline \multirow{4}{*}{\multicolumn{2}{|c|}{ Consumer Groups }} & \multicolumn{14}{|c|}{ Estimated Fuel Consumption By Heat Suppliers } \\
\hline & & \multirow{2}{*}{\multicolumn{3}{|c|}{ Kievenergo }} & \multicolumn{6}{|c|}{ Heat-Only Boiler Plants } & & & \multirow{3}{*}{\begin{tabular}{|c|} 
Industrial \\
Boiler Plants \\
and \\
Secondary \\
Energy \\
Resources \\
(SER)
\end{tabular}} & \multirow{3}{*}{$\begin{array}{l}\text { Individual } \\
\text { Heat } \\
\text { Generators }\end{array}$} & \multirow{3}{*}{$\begin{array}{c}\text { Total for } \\
\text { All } \\
\text { Suppliers }\end{array}$} \\
\hline & & & & & \multicolumn{3}{|c|}{ Akademteploenergo } & \multicolumn{3}{|c|}{ Kievzhilteplokommunenergo } & \multirow{2}{*}{$\begin{array}{l}\text { Heat-Only } \\
\text { Boiler Plants } \\
\text { of Other } \\
\text { Owners }\end{array}$} & \multirow{2}{*}{$\begin{array}{l}\text { Total for } \\
\text { Heat-Only } \\
\text { Boiler } \\
\text { Plants }\end{array}$} & & & \\
\hline & & TETS $^{(a)}$ & $\begin{array}{l}\text { District } \\
\text { Boiler } \\
\text { Plants } \\
\end{array}$ & Total & $\begin{array}{l}\text { District } \\
\text { Boiler } \\
\text { Plants } \\
\end{array}$ & $\begin{array}{l}\text { Other } \\
\text { Boiler } \\
\text { Plants } \\
\end{array}$ & Total & $\begin{array}{l}\text { District } \\
\text { Boiler } \\
\text { Plants }\end{array}$ & $\begin{array}{l}\text { Other } \\
\text { Boiler } \\
\text { Plants }\end{array}$ & Total & & & & & \\
\hline \multicolumn{2}{|c|}{1} & 2 & 3 & 4 & 5 & 6 & 7 & 8 & 9 & 10 & 11 & 12 & 13 & 14 & 15 \\
\hline \multirow{3}{*}{$\begin{array}{l}\text { Residential } \\
\text { and Public } \\
\text { Sector }\end{array}$} & Total incl.: & 8,845 & 4,576 & 13,422 & 266 & 153 & 419 & 105 & 1,360 & 1,465 & 2,142 & 17,447 & 382 & 784 & 18,613 \\
\hline & Residential & 6,115 & 3,164 & 9,279 & 167 & 87 & 254 & 87 & 773 & 860 & 1,177 & 11,570 & 284 & 763 & 12,617 \\
\hline & Public & 2,730 & 1,412 & 4,142 & 98 & 66 & 165 & 17 & 587 & 604 & 965 & 5,876 & 98 & 21 & 5,995 \\
\hline \multirow[t]{2}{*}{ Industry } & Water & 2,075 & 1,073 & 3,148 & 151 & 2 & 153 & - & 20 & 20 & 31 & 3,353 & 5,991 & - & 9,344 \\
\hline & Steam & 602 & - & 602 & - & - & - & - & - & - & - & - & 6,267 & - & 6,869 \\
\hline \multicolumn{2}{|c|}{ Total for Electricity } & 7,471 & - & 7,471 & - & - & - & - & - & - & - & - & - & - & 7,471 \\
\hline \multicolumn{2}{|c|}{ Total for Heat } & 11,522 & 5,650 & 17,172 & 417 & 156 & 572 & 105 & 1,380 & 1,485 & 2,173 & 20,800 & 12,640 & 784 & 34,827 \\
\hline \multicolumn{2}{|c|}{ Total for All Consumers } & 18,993 & 5,650 & 24,643 & 417 & 156 & 572 & 105 & 1,380 & 1,485 & 2,173 & 20,800 & 12,640 & 784 & 42.298 \\
\hline \multicolumn{16}{|c|}{$\begin{array}{l}\text { (a) TETS refers to combined heat and power plants. } \\
\text { Total fuel use estimates for Kievenergo and Kievzhilteplokommunenergo from Ekono Energy (1996). Sector splits for Kievenergo from Ekono Energy (1996) and for Kievzhilteplokommunenergo from } \\
\text { capacity demand splits from Ukrenergoprom data. Fuel use estimates for other boiler owners estimated from heat production estimates based on an estimated average boiler efficiency of } 88 \% \text {. Fuel use for } \\
\text { electricity estimated from electricity supply data and Kievenergo estimates of } 1996 \text { heat rate (JTC 1996). }\end{array}$} \\
\hline
\end{tabular}


Table 2.5: Estimated Heat; and Electricity Supply.(thousand Gcal) to the District Heating System in Kyiv, 1995

\begin{tabular}{|c|c|c|c|c|c|c|c|c|c|c|c|c|c|c|c|}
\hline & & \multicolumn{14}{|c|}{ Estimated Heat and Electricity Supply by Heat Suppliers } \\
\hline \multirow{3}{*}{\multicolumn{2}{|c|}{ Consumer Groups }} & TETS $^{(\mathbf{a})}$ & \multicolumn{10}{|c|}{ Heat-Only Boiler Plants } & \multirow{3}{*}{\begin{tabular}{|c} 
Industrial \\
Boiler Plants \\
and \\
Secondary \\
Energy \\
Resources \\
(SER)
\end{tabular}} & \multirow{3}{*}{$\begin{array}{c}\text { Individual } \\
\text { Heat } \\
\text { Generators }\end{array}$} & \multirow{3}{*}{$\begin{array}{l}\text { Total for } \\
\text { All } \\
\text { Suppliers }\end{array}$} \\
\hline & & \multicolumn{3}{|c|}{ Kievenergo } & \multicolumn{3}{|c|}{ Akademteploenergo } & \multicolumn{3}{|c|}{ Kievzhilteplokommunenergo } & \multirow{2}{*}{$\begin{array}{l}\text { Heat-Only } \\
\text { Boiler Plants } \\
\text { of Other } \\
\text { Owners }\end{array}$} & \multirow{2}{*}{$\begin{array}{l}\text { Total for } \\
\text { Heat-Only } \\
\text { Boiler } \\
\text { Plants }\end{array}$} & & & \\
\hline & & TETS $^{(\boldsymbol{a})}$ & $\begin{array}{c}\text { District } \\
\text { Boiler } \\
\text { Plants }\end{array}$ & Total & $\begin{array}{l}\text { District } \\
\text { Boiler } \\
\text { Plants }\end{array}$ & $\begin{array}{l}\text { Other } \\
\text { Boiler } \\
\text { Plants }\end{array}$ & Total & $\begin{array}{l}\text { District } \\
\text { Boiler } \\
\text { Plants }\end{array}$ & $\begin{array}{l}\text { Other } \\
\text { Boiler } \\
\text { Plants }\end{array}$ & Total & & & & & \\
\hline \multicolumn{2}{|c|}{1} & 2 & 3 & 4 & 5 & 6 & 7 & 8 & 9 & 10 & 11 & 12 & 13 & 14 & 15 \\
\hline \multirow{3}{*}{$\begin{array}{l}\text { Residential } \\
\text { and Public } \\
\text { Sector }\end{array}$} & Total incl.: & 7,804 & 4,038 & 11,842 & 234 & 135 & 370 & 89 & 1,154 & 1,243 & 1,890 & 15,344 & 337 & 692 & 16,373 \\
\hline & Residential & 5,395 & 2,791 & 8,187 & 147 & 77 & 224 & 74 & 656 & 730 & 1,039 & 10,180 & 251 & 673 & 11,103 \\
\hline & Public & 2,409 & 1,246 & 3,655 & 87 & 59 & 145 & 15 & 498 & 513 & 851 & 5,164 & 86 & 19 & 5,269 \\
\hline \multirow[t]{2}{*}{ Industry } & Hot Water & 1,831 & 947 & 2,778 & 133 & 2 & 135 & 0 & 17 & 17 & 27 & 2,958 & 5,286 & 0 & 8,244 \\
\hline & Steam & 512 & $\cdot$ & 512 & - & - & - & - & - & - & - & - & 5,327 & - & 5,839 \\
\hline \multirow{2}{*}{\multicolumn{2}{|c|}{$\begin{array}{l}\text { Total Electricity (Gwh) } \\
\text { Total El. (thousand Gcal) }\end{array}$}} & 5,049 & - & 5,049 & - & $\cdot$ & - & - & - & - & - & - & - & - & 5,049 \\
\hline & & 4,341 & - & 4,341 & - & - & - & - & $\cdot$ & - & $\cdot$ & - & - & - & 4,341 \\
\hline \multicolumn{2}{|c|}{ Total Heat (thousand Gcal) } & 10,147 & 4,985 & 15,132 & 368 & 137 & 505 & 89 & 1,171 & 1,260 & 1917 & 18,302 & 10,950 & 692 & 30,456 \\
\hline \multicolumn{16}{|c|}{$\begin{array}{l}\text { (a) TETS refers to combined heat and power plants. } \\
\text { Heat production for Kievenergo and Kievzhilteplokommunenergo estimated from energy use data and boiler performance estimates (Ekono Energy 1996). Total heat production for heat-only boiler plants, industrial } \\
\text { boilers and secondary sources, and individual heat generators from Ekono Energy (1996), allocated by sector based on heat demand estimates (Gcal/hour) from Ukrenergoprom. Electricity production from } \\
\text { Kievenergo data (JTC 1996). }\end{array}$} \\
\hline
\end{tabular}


Table 2.6. Estimated Heat and Electricity Consumption (thousand Geal) from the District Heating System in Kyiv, 1995

\begin{tabular}{|c|c|c|c|c|c|c|c|c|c|c|c|c|c|c|c|}
\hline & & \multicolumn{14}{|c|}{ Estimated Heat and Electricity Consumption } \\
\hline \multirow{3}{*}{\multicolumn{2}{|c|}{ Consumer Groups }} & TETS $^{(a)}$ & \multicolumn{10}{|c|}{ Heat-Only Boiler Plants } & \multirow{3}{*}{$\begin{array}{c}\text { Industrial } \\
\text { Boiler Plants } \\
\text { and } \\
\text { Secondary } \\
\text { Energy } \\
\text { Resources } \\
\text { (SER) }\end{array}$} & \multirow{3}{*}{$\begin{array}{c}\text { Individual } \\
\text { Heat } \\
\text { Generators }\end{array}$} & \multirow{3}{*}{$\begin{array}{l}\text { Total for } \\
\text { All } \\
\text { Suppliers }\end{array}$} \\
\hline & & \multicolumn{3}{|c|}{ Kievenergo } & \multicolumn{3}{|c|}{ Akademteploenergo } & \multicolumn{3}{|c|}{ Kievzhilteplokommunenergo } & \multirow{2}{*}{$\begin{array}{l}\text { Heat-Only } \\
\text { Boiler Plants } \\
\text { of Other } \\
\text { Owners }\end{array}$} & \multirow{2}{*}{$\begin{array}{l}\text { Total for } \\
\text { Heat-Only } \\
\text { Boiler } \\
\text { Plants }\end{array}$} & & & \\
\hline & & TETS $^{(a)}$ & $\begin{array}{l}\text { District } \\
\text { Boiler } \\
\text { Plants }\end{array}$ & Total & $\begin{array}{l}\text { District } \\
\text { Boiler } \\
\text { Plants }\end{array}$ & $\begin{array}{l}\text { Other } \\
\text { Boiler } \\
\text { Plants }\end{array}$ & Total & $\begin{array}{l}\text { District } \\
\text { Boiler } \\
\text { Plants }\end{array}$ & $\begin{array}{l}\text { Other } \\
\text { Boiler } \\
\text { Plants }\end{array}$ & Total & & & & & \\
\hline \multicolumn{2}{|c|}{1} & 2 & 3 & 4 & 5 & 6 & 7 & 8 & 9 & 10 & 11 & 12 & 13 & 14 & 15 \\
\hline \multirow{3}{*}{$\begin{array}{l}\text { Residential } \\
\text { and Public } \\
\text { Sector }\end{array}$} & Total incl.: & 6,243 & 3,230 & 9,473 & 187 & 108 & 296 & 71 & 923 & 994 & 1,512 & 12,275 & 269 & 554 & 13,098 \\
\hline & Residential & 4,316 & 2,233 & 6,550 & 118 & 61 & $179-$ & 59 & 525 & 584 & 831 & 8,144 & 201 & 538 & 8,883 \\
\hline & Public & 1,927 & 997 & 2,924 & 69 & 47 & 116 & 12 & 398 & 410 & 681 & 4,131 & 69 & 15 & 4,215 \\
\hline \multirow[t]{2}{*}{ Industry } & Hot Water & 1,464 & 758 & 2,222 & 107 & 2 & 108 & - & 14 & 14 & 22 & 2,366 & 4,229 & - & 6.595 \\
\hline & Steam & 410 & - & 410 & - & - & - & - & - & - & - & - & - & - & 5,053 \\
\hline \multicolumn{2}{|c|}{ Total Electricity (Gwh) } & 4,628 & - & 4,628 & - & - & $\cdot$ & - & - & - & - & - & - & - & 4,628 \\
\hline \multicolumn{2}{|c|}{ Total El. (thousand Gcal) } & 3,979 & - & 3,979 & - & - & - & - & $\cdot$ & - & - & - & - & - & 3,979 \\
\hline \multicolumn{2}{|c|}{ Total Heat (thousand Gcal) } & 8,117 & 3,988 & 12,105 & 294 & 110 & 404 & 71 & 937 & 1,008 & 1,534 & 14,641 & 4,498 & 554 & 24,746 \\
\hline \multicolumn{16}{|c|}{$\begin{array}{l}\text { (a) TETS refers to combined heat and power plants. } \\
\text { Heat supply estimated from heat production assuming } 20 \% \text { losses of heat and steam in the transmission and distribution system (Ekonon Energy 1996), and assuming electricity transmission losses of } 8.3 \% \text { based on } \\
\text { Kievenergo data (JTC 1996). }\end{array}$} \\
\hline
\end{tabular}




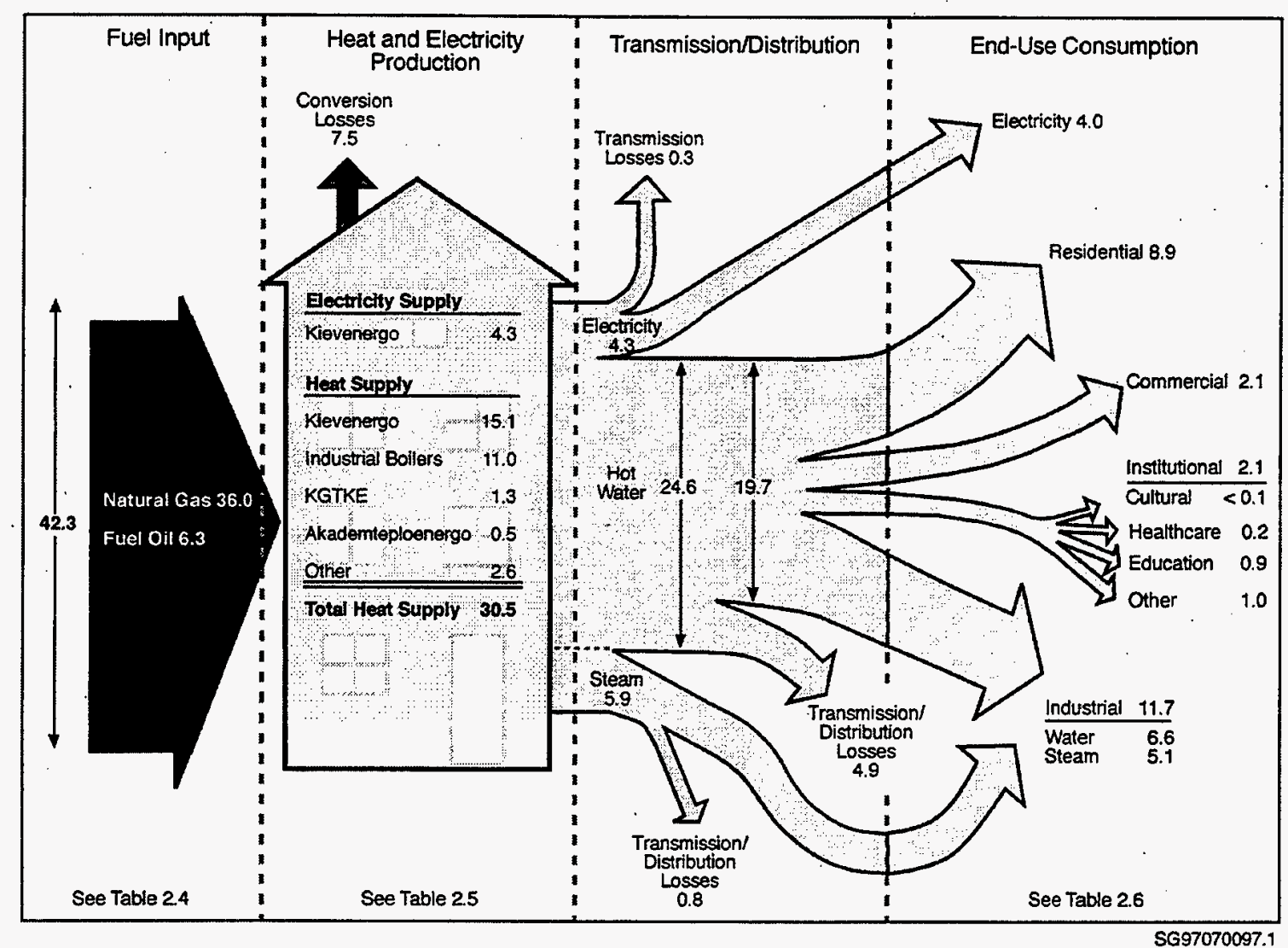

Figure 2.2. Estimated Energy Flow of Kyiv District Heating System (million Gcal), 1995

(1996). Energy flows for Kievenergo are distributed by building sector according to building sector shares given in Ekono Energy (1996), and are consistent with Ukrenergoprom estimates. Energy flow shares by building sector for KGTKE are taken from capacity demand shares from Ukrenergoprom.

Energy flow estimates for other heat suppliers are taken from annual heat production estimates in Ekono Energy (1996) distributed by building sector using Ukrenergoprom capacity demand shares. Energy use for these suppliers is back-calculated based on an estimated boiler performance of $88 \%$, the approximate value for Kievenergo boilers (Ekono Energy 1996; JTC 1996).

Heat supply to buildings is estimated from heat production by assuming an average of $20 \%$ transmission and distribution system losses, taken from Ekono Energy (1996). This value is higher than both the Joseph Technology estimate (12\%) and the annual average values in Kievenergo documents ${ }^{(a)}(13 \%)$ presented in Joseph Technologies (JTC 1996). These values appear low considering the poor condition of the transmission and distribution system. This is illustrated by the high level of water leakage from the system, estimated at from 5 to 45 times system volume annually depending on the network (Ekono

(a) Kievenergo loss estimates vary by quarter from $10 \%$ (first quarter) to $33 \%$ (third quarter) for annual average losses of $13 \%$. 
Energy 1996). By comparison, Ekono Energy cites normal replacement volumes for a well-maintained system of 1 to 2 times system volume per year.

The energy flow diagram (Figure 2.2) also shows fuel use in the production of electricity by combined heat and power plants. Fuel-use estimates are taken from Kievenergo accounting data presented in Joseph Technologies (JTC 1996). Power production is estimated using a heat rate of $1,480 \mathrm{kcal} / \mathrm{kWh}$, which is derived from detailed power generation estimates for Kievenergo in 1996 (JTC 1996), and includes power purchases by Kievenergo. Net electricity supply is estimated assuming $8.3 \%$ transmission losses, also from the same source.

Annual energy-flow estimates shown in Figure 2.2 are based on actual conditions in 1995, and hence cannot be compared directly with annual energy-flow estimates from Ukrenergoprom and Ekono Energy, which are based on estimated energy flow in normal fuel supply and capacity conditions. It is estimated, however, that in 1995 the heat supply was about $74 \%$ of the expected supply in normal conditions (Ekono Energy 1996). Using this ratio, the total residential sector heat supply (1995 actual) of $8,883 \mathrm{Gcal}$ (Table 2.6) leads to an estimated $12,084 \mathrm{Gcal}$ in normal supply conditions. This value can be compared to the Ekono Energy and Ukrenergoprom estimates of 11,314 and 15,080 Gcal, respectively. By comparison, estimated heat consumption based on design data and residential floorspace data is $11,685 \mathrm{Gcal}$ (see Table 2.6 and Appendix B for derivation of this estimate).

Including energy used in the production of electricity, Kievenergo accounts for $58 \%$ of the total 42.3 million Gcal of fuel consumption. After conversion losses, this amounts to a production of 24.6 million Gcal of hot water, 5.9 million Gcal of steam, and 4.3 million Gcal ( $5049 \mathrm{GWh}$ ) of electricity. Total supply of heat energy after transmission and distribution losses is 24.8 million Gcal, of which $47 \%$ is for industry (including hot water and steam), $36 \%$ for residential buildings, and $17 \%$ for institutional and commercial buildings. The residential sector is estimated to account for over two-thirds of building sector heat consumption, with the remaining one-third split about equally between the institutional and commercial sectors.

\subsubsection{Building Sector Heat and Hot Water Consumption}

Heat and hot water energy consumption provided by district heat is estimated in this section for each of the three building categories discussed in Section 2.1. As noted above, these estimates are based on the assumption of normal heat supply, and hence cannot be compared directly to the building level heat supply values in Figure 2.2, which are estimated to be about $74 \%$ (based on 1995 data) of normal supply conditions. Heat consumption for other building sectors can be estimated by dividing the values in Figure 2.2 by 0.74 .

\section{Institutional Sector}

The heat consumption estimates for the institutional sector were based on floorspace data from the survey discussed in Section 2.1, design heat consumption estimates for representative buildings in each 
subsector, and a sample of metered information taken in December of 1996. Additional detail on the estimation of institutional sector heat and hot water consumption is provided in Appendix B.

The estimates of institutional sector heat and hot water consumption are shown in Table 2.7 by building type and subsector. Institutional sector energy use is dominated by education, which has the largest amount of floorspace.

Table 2.7. Institutional Sector Baseline Heat and Hot Water Energy Consumption Supplied by District Heat

\begin{tabular}{|c|c|c|}
\hline \multicolumn{2}{|c|}{ Institutional Buildings } & \multirow{2}{*}{$\begin{array}{c}\text { Baseline Energy Use } \\
\text { (thousand Gcal) }\end{array}$} \\
\hline Subsector & Type & \\
\hline \multirow[t]{3}{*}{ Healthcare } & Hospitals & 157 \\
\hline & Polyclinics ${ }^{-}$ & 59 \\
\hline & Administration & 16 \\
\hline \multirow[t]{4}{*}{ Education } & Kindergartens & 329 \\
\hline & Schools & 470 \\
\hline & Higher Education & 240 \\
\hline & Hostels & 154 \\
\hline \multirow[t]{2}{*}{ Cultural } & Theaters & 10 \\
\hline & Art Galleries/Museums & 12 \\
\hline Total & & 1,446 \\
\hline
\end{tabular}

\section{Residential Sector}

The baseline heat consumption estimates for the residential sector are based in part on analysis conducted for a recent World Bank report (World Bank 1996) and in part on a recent study conducted in the Czech Republic (PNNL 1996). Additional detail for the residential sector baseline is located in Appendix B.

The estimates of residential sector heat and hot water consumption are shown by building type in Table 2.8. The total energy use estimate closely approximates the value of $8.9 \mathrm{Gcal}$ as shown in Figure 2.2 adjusted by the factor 0.74 . Residential sector energy use is largest in the 5 and 9 story building types, which dominate total floorspace. Five story buildings also have a relatively high estimated specific energy use.

\section{Commercial Sector}

No attempt was made to characterize the commercial sector building stock. Baseline energy consumption by this sector is estimated to be 2.8 million Gcal annually based on the values in Figure 2.2 and the adjustment factor of 0.74 . 
Table 2.8. Residential Sector Baseline Heat and Hot Water Energy Consumption Supplied by District Heat

\begin{tabular}{||c|c|}
\hline Building Type & $\begin{array}{c}\text { Baseline Energy Use } \\
\text { (thousand Gcal/year) }\end{array}$ \\
\hline 2-story & 2,569 \\
\hline 5-story & 3,545 \\
\hline 9-story & 3,545 \\
\hline 14-story & 2,026 \\
\hline Total & 11,685 \\
\hline
\end{tabular}




\subsection{Efficiency Assessment}

The estimated cost-effective efficiency resource and corresponding level of investment required to obtain the resource is presented in this chapter. Section 3.1 describes the measures considered for application in Kyiv, as well as those not considered applicable to this project. The technical and economic analysis approaches employed to estimate the efficiency resource are described in Section 3.2. The building sector efficiency resource is discussed in Sections 3.3, 3.4, and 3.5.

The efficiency resource and investment levels are developed with attention to the institutional buildings sector. The efficiency resource and investment levels are also estimated for the residential sector using existing information.

\subsection{Efficiency Measures}

Forty six energy conservation opportunities (ECOs) were evaluated for improving building sector energy efficiency. Of these, 20 were determined to be applicable to one or more building types and were analyzed with respect to energy efficiency potential, cost, and availability on the Ukrainian market.

A brief discussion of the ECOs evaluated follows. Measures considered applicable to Kyiv buildings within the scope of this project are presented in Section 3.1.1; measures not considered applicable are located in Section 3.1.2; and a summary of the applicable measures is located in Section 3.1.3.

\subsubsection{Efficiency Measures Considered}

The 20 efficiency measures considered applicable to buildings in Kyiv are presented by category of application: building envelope measures, air handling measures, domestic water heating measures, and heating system measures. The description of each measure includes the building type application, installation cost, and availability. Efficiency measure cost data are presented in more detail in Appendix C.

\section{Building Envelope Measures}

1. Insulate Exterior Side Walls - Insulation installed on the exterior walls of the building improves the R-value, or thermal retention, of the building shell, and therefore decreases heat loss through the walls. Depending on the method used and the material thickness, the R-value of the walls may be increased by 0.8 to $1.4 \mathrm{~m}^{2} \mathrm{~K} / \mathrm{W}$. Exterior insulation also results in increasing the temperature in zones adjacent to exterior walls by as much as 3 to $5^{\circ} \mathrm{C}$, thus indirectly reducing overheating of the building core space when building temperatures are properly adjusted and building temperature controls are available. An additional positive effect is the elimination of moisture condensation on the interior side of the external walls in cold weather. 
The insulation of exterior walls with a large window-to-wall ratio is typically labor intensive and costly. Only insulation of walls without windows or with a relatively small number of windows was considered. Practically, this means that only two sides are insulated for most buildings.

\section{Building Type Application}

- This measure was considered applicable to most building types. Exceptions include buildings constructed prior to 1958, mainly because these buildings have thick brick walls with complex external surfaces which make it very difficult and inefficient to install any external insulation. In addition, some cultural buildings are not suitable for external insulation because of changes that would occur to the external appearance.

\section{Considerations}

- Although this ECO is widely used, poor workmanship can cause the energy savings to be less than expected in many installations.

- This ECO generally has a high installation cost and is therefore not cost-effective in most applications. In particular, one study in Kyiv found exterior insulation difficult to justify economically, with payback periods ranging from 7 to 26 years (TACIS 1994). New spray-ontype foam insulation is much cheaper and has been used in some projects for this ECO; however, this method has not been widely demonstrated and is not considered here.

- Positive impact on comfort, elimination of condensation problems in coldest rooms, and elimination of health problems (due to fungus growth on wet wall surfaces) supports selection of this ECO.

- Although this ECO is passive, its effectiveness relies upon active measures to control heat input to prevent overheating.

- Heat controls require operational oversight and maintenance.

- Change in building exterior appearance must be considered.

Cost

- Material costs vary widely depending on the type of insulation used. For this project, material costs are estimated to be $\$ 10.50 / \mathrm{m}^{2}$.

- Labor time to install the measure is estimated to be 1.1 hours $/ \mathrm{m}^{2}$, with a labor cost of $\$ 14.66 / \mathrm{m}^{2}$. 


\section{Availability}

- Insulation materials are readily available domestically.

- Materials may be a source of domestic manufacture. One manufacturing operation in Kyiv has developed an external insulation product that includes fastening and facing materials; however, the product is not currently in production and may not be cost-effective.

2. Insulate Roof - The top floor ceiling in many building types is poorly insulated, which results in substantial heat loss from the top floor. Higher space heat to compensate for this often causes overheating of the building core space. Insulating the top floor ceiling from the interior side sometimes causes moisture condensation in the corners and on the upper portion of vertical walls due to thermal bridging of walls/ceiling. Roof insulation installed from the outside must be covered by a new layer of roofing material. This technology is applicable to buildings with a flat roof and single-roof-panel construction (without a ventilation space). Roofs of buildings with ventilation space (between the ceiling and the roof panels) can be insulated by applying the insulation between the ceiling and roof panel. The roof insulation increases the R-value by 2.1 to $3.0 \mathrm{~m}^{2} \mathrm{~K} / \mathrm{W}$.

\section{Building Type Application}

- This measure is applicable to all buildings with a flat roof (without attic). For this study, all institutional buildings constructed after 1958 are assumed to have a flat roof. Some buildings constructed earlier also have flat roofs; however, peaked roofs are more common. For these buildings attic insulation is considered (measure 3 described below).

\section{Considerations}

- Application of the insulation to the exterior roof surface requires installation of a water membrane.

- Insulation installed in the ventilation space between the roof and ceiling panels must be well ventilated to prevent condensation and deterioration of the insulation material.

- Ukrainian fire codes restrict the use of synthetic insulation in buildings.

- Although this measure is passive, its effectiveness relies on active measures to control heat input to prevent overheating.

\section{Costs}

- Material costs are estimated to be $\$ 23.41 / \mathrm{m}^{2}$. 
- Labor time to install the measure is estimated to be 0.34 hours $/ \mathrm{m}^{2}$ with a labor cost of $\$ 4.54 / \mathrm{m}^{2}$.

\section{Availability}

- $\quad$ Roof insulation and roofing materials are readily available.

- Foreign-made insulation and roofing materials are available from local outlets of foreign suppliers.

3. Insulate Attic - Insulating the attic is a widely used method of reducing heat losses in buildings that have an attic space. The insulation may be installed in many different ways (e.g., blown into the attic, laid on top of the ceiling, or poured in as a foam/liquid). Fiberglass blankets or boards or Styrofoam boards are most commonly used. Depending on the method used, the R-value can be increased by as much as $3.5 \mathrm{~m}^{2} \mathrm{~K} / \mathrm{W}$.

\section{Building Type Application}

- This ECO is applicable to all buildings with a pitched roof and an attic space. All buildings constructed prior to 1958 are assumed to have an attic space suitable for installing the insulation; however, the ECO may be more cost-effective in some building types than others. Information indicates that buildings constructed after 1958 typically do not have a pitched roof, and attic insulation is not applicable to these buildings.

\section{Considerations}

- Insulation in attics accessible as storage space must be protected in walkways and in areas used as storage or for any other purposes.

- The cost of protection material and its installation must be considered.

- Ukrainian fire codes restrict the use of synthetic insulation in buildings.

Costs

- Material costs are estimated to be $\$ 6.45 / \mathrm{m}^{2}$.

- Labor time to install the measure is estimated to be 0.37 hours $/ \mathrm{m}^{2}$, with a labor cost of $\$ 4.93 / \mathrm{m}^{2}$.

\section{Availability}

- Attic insulation materials are readily available in all forms (hard boards, spray, fiberglass) from local sources. 
4. Insulate Floor Above Basement - Insulating the floor above a cold basement, crawl space, or concrete slab improves the floor R-value as well as the comfort of occupants, which typically results in a lower thermostat setting. Many floor covering materials with good thermal insulation are available. For floors with an air cavity, blown-in cellulose-based insulation is also available.

\section{Building Type Application}

- Floor insulation is applicable to all buildings considered in the study.

\section{Considerations}

- Insulation installed on the floor must be designed to sustain required traffic or must be protected by walk-on materials. Many flooring materials having the required insulation characteristics can be used.

- Ukrainian fire codes restrict the use of synthetic insulation in buildings.

- Floor insulation increases the comfort level for occupants by lowering the room's vertical air temperature stratification.

- Although this measure is passive, its effectiveness relies on active measures to control heat input to prevent overheating.

- Balancing the heating system (radiator control) in the space with insulated floors may be necessary.

- Basement below the insulated floor will be colder, and in some instances it may be necessary to heat the basement to prevent frost damage to plumbing.

- Buildings with a basement may also be insulated from the bottom (basement ceiling).

\section{Costs}

- Material costs are estimated to be $\$ 6 / \mathrm{m}^{2}$.

- Labor time to install the measure is estimated to be 0.12 hours $/ \mathrm{m}^{2}$, with a labor cost of $\$ 1.60 / \mathrm{m}^{2}$.

\section{Availability}

- Limited types of floor insulation materials and basement ceiling insulation materials are available from domestic manufacturers. Decorative floor materials are available from local outlets of foreign suppliers. 
5. Weatherstrip Windows and Doors - Sealing cracks around windows and doors is a simple way to reduce infiltration to occupied and unoccupied spaces and thus reduce the energy required to heat ambient air entering the heated space and reduce the heat losses to unheated spaces. Windows, especially in older buildings, fit poorly, resulting in significant levels of unnecessary infiltration. To be functional, seals have to be properly installed and maintained.

\section{Building Type Application}

- Weatherstripping of windows and doors is applicable to all buildings in which the windows were not recently replaced with new tight-construction, high-performance windows. It is assumed that such upgrades have been done in only a small number of buildings in the city of Kyiv.

\section{Considerations}

- Weatherstripping improves comfort levels in the space by eliminating drafts close to windows.

- Some spaces indirectly rely on fresh air supply by uncontrolled infiltration through the windows. Proper sealing of window gaps may cause lower indoor air quality. Spaces with high requirements for fresh air must be provided with forced ventilation with heat recovery.

- In buildings that suffer from periodic or chronic under-heating, building occupants may have previously adopted some type of weatherstripping or sealing measures to reduce infiltration. Commonly found measures include the use of foam-type material in areas of poor window sealing, and taping window frames closed during winter months when ventilation requirements are small. In many cases, these measures appear to be quite effective; however, in the absence of under-heating, maintenance of these measures may be limited. In addition, as with most measures, weatherstripping will be effective only if active measures are taken to control space temperatures.

- Seals have to be inspected and properly maintained. The life of a typical seal is approximately 5 years; then it has to be replaced.

\section{Costs}

- Material costs are estimated to be $\$ 0.9 / \mathrm{m}$.

- Labor time to install the measure is estimated to be 0.1 hours $/ \mathrm{m}$, with a labor cost of $\$ 1.05 / \mathrm{m}$. 


\section{Availability}

- Good quality window seals currently must be imported or purchased from local outlets of foreign manufacturers, but could be a source of domestic manufacture. Good quality seal materials are crucial to attaining savings.

6. Install Storm Windows and Weatherstripping - The fenestration area of buildings in Ukraine can be a significant fraction of the building envelope area. The U-value, or rate of heat loss, of the windows is 2.7 to 4.2 times greater than for the walls. Consequently, heat losses through windows are significant. Installation of a third pane on existing windows provides improved R-value for the fenestration area and reduces heat losses through the glass. The U-value of a window with a third glass (storm window) is typically 1.9 to $2.1 \mathrm{~W} / \mathrm{m}^{2} \mathrm{~K}$, whereas the common two-pane window has a $\mathrm{U}$-value of 2.6 to $2.8 \mathrm{~W} / \mathrm{m}^{2} \mathrm{~K}$. It is also assumed that new storm windows will provide a tighter fit resulting in lower infiltration. Installation of weatherstripping on existing windows is assumed to be done at the same time.

\section{Building Type Application}

- This measure is assumed to be applicable to all buildings.

\section{Considerations}

- The storm window is installed in its own light frame attached to the exterior side of the existing window frame (typically wood frame). The storm window frame can easily be used as an insect screen during the summer.

- On some windows designed to open to the outside, the third glass may be installed on the external side of the openable window frame.

- A storm window will reduce uncontrolled infiltration, and spaces relying on such sources of fresh air may need to be ventilated via controlled ventilation (with heat recovery).

\section{Costs}

- Material costs are estimated to be $\$ 60$ per window.

- Labor time to install the measure is estimated to be 5 hours per window, with a labor cost of $\$ 66.67$ per window. 


\section{Availability}

- Storm windows may be manufactured by local window/door manufacturers or purchased from local outlets of foreign suppliers.

- This product may be a source of local manufacture.

7. Install High-Performance Glass and Weatherstripping - Depending on the ratio between the external wall area and the fenestration area, up to $30 \%$ of the heat loss by the building envelope is through the glass. Existing windows have regular potassium-based glass with thickness in the range of 2.5 to $3 \mathrm{~mm}$. Such windows have U-values of approximately 2.7 to $3.07 \mathrm{~W} / \mathrm{m}^{2} \mathrm{~K}$. It is typically not economical to replace the entire window including the fixed frame. Instead, only the glass or window wings are replaced. Window glass available on the market today is highly heat reflective and has greater thermal resistance resulting in lower U-values in the range of 1.5 to $1.8 \mathrm{~W} / \mathrm{m}^{2} \mathrm{~K}$.

Installation of weatherstripping on existing windows is assumed to be done at the same time.

\section{Building Type Application}

- This measure is assumed to be applicable only to cultural buildings.

\section{Considerations}

- When the frame of the window glass is structurally acceptable, only the glass pane is replaced; however, sometimes, especially in very old windows, the window must be retrofitted by replacing the entire movable part.

- High-performance glass is highly reflective and provides a thermal shield during the summer time, especially in windows exposed to direct sunshine. Should air conditioning be used in the space, energy savings during the cooling season are significant.

- It is usually sufficient to replace only one (external) pane in a double-glassed window.

\section{Costs}

- The material costs for this measure are estimated at $\$ 24.50 / \mathrm{m}^{2}$.

- Labor time to install this measure is estimated at 1.4 hours $/ \mathrm{m}^{2}$, with a labor cost of $\$ 18.66 / \mathrm{m}^{2}$.

\section{Availability}

- High-performance glass is available from local outlets of foreign manufacturers and suppliers. 
8. Install Third Window Pane - One of the commonly used methods of increasing the thermal resistance of windows is to install a third pane into the existing window frame. This is accomplished by modifying the existing window frame holding the glass pane and inserting an additional highperformance pane. The most appropriate way is to install the new high-performance glass to the outside. Practically, it is easier to install it between the existing panes. Sometime, a UV-resistant plastic foil with thickness of $0.04 \mathrm{~mm}$ is installed between the frames and sufficiently stretched to avoid light/view distortion. However, the life of plastic foil is substantially shorter (3-5 years) and overall life cycle costs may be greater.

Installation of weatherstripping on existing windows is assumed to be done at the same time.

\section{Building Type Application}

- This measure is assumed for all building categories, except where the appearance of the window is critical (historical buildings).

\section{Considerations}

- It may not be feasible to install a third pane in windows with poor frames or in windows that have complex shapes.

- It is necessary to ensure that the third pane is removable for window cleaning.

- Assembly must be airtight to prevent dust and moisture entering the space between the panes.

\section{Costs}

- The material costs for this measure are estimated at $\$ 13.00 / \mathrm{m}^{2}$.

- Labor time to install this measure is estimated at 1.33 hours $/ \mathrm{m}^{2}$, with a labor cost of $\$ 17.69 / \mathrm{m}^{2}$.

\section{Availability}

- High-performance glass is available from local outlets of foreign manufacturers and suppliers.

- Window foil is available from local suppliers.

9. Install Heat Reflectors Behind Each Radiator - Heat reflectors deflect the radiant portion of the heat otherwise absorbed by the wall (in most cases an exterior wall) into the heated space. The wall temperature behind the radiator is lowered and the R-value of the part of the wall covered by the reflector is increased, thus reducing the heat losses. This is in many cases a "do-it-yourself" inexpensive measure. 


\section{Building Type Application}

- All buildings are heated by hot water (or steam) radiators, and this measure is applicable to all buildings.

\section{Considerations}

- Some radiator types in Kyiv may be installed too close to the wall and may require some additional work during the installation of the reflecting material. Removal of the radiator or its disconnection from pipes was not considered to be necessary. Such cases are assumed to be minimal.

- Reflectors improve thermal comfort in the room, sometimes resulting in a lower temperature setting of the thermostat (where available).

- Reflecting material with thermal insulation was assumed for the application.

- Self-adhesive materials can be used in easy-to-access places; adhesive tape should be used for places with difficult access behind radiators.

Costs

- Material costs are estimated to be $\$ 5.16$ per radiator.

- Labor time to install the measure is estimated to be 0.37 hours, with a labor cost of $\$ 3.90$ per radiator.

Availability

- This material will have to be imported or purchased from local outlets of foreign manufacturers.

\section{Air Handling Measures}

10. Install Ventilation Heat Recovery - Buildings designed to hold gatherings or large crowds require substantial fresh air supply. Hot air ventilation is typically installed only in buildings constructed after 1958. In older buildings the fresh air is delivered via opened windows, doors, or with assistance of exhaust fans. When fresh air is not delivered, the space can become uncomfortable within less than 30 minutes, depending on space size and number of people occupying the space. Such ventilation causes uncontrolled infiltration and thus substantial heat loss. Installation of an air make-up unit with a heat recovery system allows controlled ventilation during heavy load in the wintertime and, if air conditioning $(\mathrm{A} / \mathrm{C})$ is available, also during the summer. Existing total heat recovery systems achieve up to $80 \%$ efficiency. 


\section{Building Type Application}

- This measure applies to cultural buildings only.

\section{Considerations}

- Economy of the heat recovery installation is strongly dependent on the total number of operating hours and typically is applied to systems operating 24 hours a day.

- Air heat recovery can only be used when it is technically possible to install supply and exhaust air ducts close to each other.

- Application of heat recovery in air handling systems with cooling is typically economical due to year-round savings.

Cost

- Material costs are estimated to be $\$ 2.20 / \mathrm{m}^{3} /$ hour.

- Labor time to install the measure is estimated to be 0.04 hours $/ \mathrm{m}^{3} /$ hour, with a labor cost of $\$ 0.41 / \mathrm{m}^{3} /$ hour.

Availability

- Good quality heat recovery heat exchangers with efficiency of more than $75 \%$ are available only from several foreign suppliers.

11. Install Ceiling Fans - Halls accommodating large numbers of people are typically designed with excessively high ceilings to provide sufficient air supply. High open spaces cause room temperatures to stratify. As a result, the temperature difference between the floor and the ceiling may be as high as $10^{\circ} \mathrm{C}$, which results in discomfort and space overheating mainly during low and medium occupancy load. De-stratification of temperatures in high ceiling spaces is accomplished by application of large-diameter, slow-speed ceiling fans. The use of ceiling fans eliminates the air temperature stratification and reduces temperature losses caused by overheating. In the cooling mode, ceiling fans produce a slight air draft and delay the use of $\mathrm{A} / \mathrm{C}$ during low cooling demand periods.

\section{Building Type Application}

- This measure applies to cultural buildings only. 


\section{Considerations}

- In some buildings, such as those with chandeliers or decorative art on the ceiling, the installation of ceiling fans may not be desirable.

- In some spaces with interior decorative walls, it may be difficult to install required electrical wiring.

\section{Cost}

- Material costs are estimated to be $\$ 163$ per fan.

- Labor time to install the measure is estimated to be 3.0 hours per fan, with a labor cost of $\$ 40.00$ per fan.

\section{Availability}

- Certain types of ceiling fans are available locally. Decorative fans are available from foreign manufacturers and may have to be imported.

\section{Domestic Water Heating Measures}

Domestic water heating (DWH) systems in institutional buildings utilize mostly shell-and-tube instantaneous heat exchangers located either in the substations or directly in the buildings. Except for some small number of newer substations, DWH systems are insufficient, inoperative, or completely lack temperature controls. Pipes and heat exchangers are generally poorly insulated or not insulated at all. DWH heat exchangers are instantaneous, through-flow types without a hot water storage tank and, as such, are designed for maximum flow. During off-peak periods, domestic water is overheated and heating water is returned back to the return pipe at much higher temperature, typically mixing with the space heating return water. Because the heating water flow is constant, this occurs permanently and increases heat loses in the return pipe. And, because the heat supply is not metered, credit for higher return temperature cannot be taken by the user.

Heat exchangers located in the substations require separate DWH piping between the building and the substation, resulting in additional losses. In addition, Ukrainian law requires that heat metering for space heating and domestic hot water be carried out via a common meter (Cabinet of Ministers of Ukraine 1995). This is not possible in systems with hot water heat exchangers located in substations, which represent approximately $80 \%$ of the institutional building stock. In such cases, it is necessary to disconnect the existing DWH connections and install the DWH heat exchanger in each building. 
12. Install Hot Water Heat Exchanger - The equipment required for the DWH system upgrade is composed of a heat exchanger, necessary piping and plumbing components, and a thermostatic control.

Energy savings by this measure are accomplished by introducing the ability to control the required domestic water temperature by preventing unnecessary losses in the DWH pipes; by eliminating the unnecessary return of hot heating water back to the return line; by insulating the internal pipes; and, in some installations, by eliminating losses in the external pipes (between the substation and the building).

\section{Building Type Application}

- This measure is considered for all building types, but is assumed to apply to only $80 \%$ of buildings, or that fraction which currently operates on a four-pipe system. The measure is probably not appropriate for buildings with low hot water demands such as hospital administration and cultural buildings. For simplicity, it is applied across all buildings.

\section{Considerations}

- Utilization of compact, package-type pre-assembled DWH systems is highly recommended, because they reduce the number of field-installation-related problems and are more reliable.

- Installation of water treatment, such as filters and softeners is desirable, especially in hospitals and schools. This will also increase the life of the system.

- This measure is considered necessary to comply with Ukrainian regulations.

Costs

- Material costs associated with retrofit of a domestic water heating system are a function of the installed water heater capacity and range from $\$ 11$ to $\$ 25$ per $\mathrm{kW}$ of installed capacity, with smaller systems bearing larger per unit costs. ${ }^{(a)}$

- Labor time to install the measure is estimated to be 50 hours for every $100 \mathrm{~kW}$ of installed capacity. In monetary terms the labor cost represents an average cost of $\$ 7.62$ per $\mathrm{kW}$ of installed capacity.

(a) Costs are estimated from the cost per unit capacity for heat system retrofits and estimated hot water demand. This method may underestimate costs for systems with low demand, for which this measure is probably inappropriate. 
- Periodic inspection and O\&M is necessary, and its cost should be included in the operational budget of the building owner/occupant.

\section{Availability}

- Domestic water heating systems and components are available from local sources and from several foreign companies having representation (sales offices) in Ukraine.

13. Install Tank-Type Storage Water Heating System - The equipment required for the DWH system upgrade is composed of a heat exchanger, necessary piping and plumbing components, thermostatic control, and an appropriately sized domestic water storage tank. The use of a properly insulated storage tank will enhance temperature control (prevent overheating) and will also enhance the availability of hot water to occupants.

Energy savings by this measure are accomplished by introducing the ability to control the required domestic water temperature by preventing unnecessary losses in the DWH pipes; by eliminating the unnecessary return of hot heating water back to the return line; by insulating the internal pipes; and, in some installations, by eliminating losses in the external pipes (between the substation and the building). Enhanced by a simple timer, the control system is capable of lowering the domestic water temperature in the tank during unoccupied periods.

\section{Building Type Application}

- This measure is considered for all buildings with considerable domestic hot water consumption, such as hospitals and schools. It was not considered for administration and cultural buildings, in which the volume of water consumption and consequent energy savings would not justify the required investment.

\section{Considerations}

- Installation of the storage tank will require availability of floorspace.

- Water storage tank cleaning should be done periodically (at least every 5th year).

- Utilization of compact, package-type pre-assembled DWH systems is highly recommended, because they reduce the number of field-installation-related problems and are more reliable.

- Installation of water treatment, such as filters and softeners is desirable, especially in hospitals and schools. This will also increase the life of the system.

- This measure is usually considered as a substantial capital improvement of the building and bears a relatively high cost. 
Costs

- Material costs associated with retrofit of a domestic water heating system are a function of the installed water heater capacity and range from $\$ 24$ to $\$ 32$ per $\mathrm{kW}$ of installed capacity, smaller systems bearing larger per unit costs.

- Labor time to install the measure is estimated to be 62 hours for every $100 \mathrm{~kW}$ of installed capacity. In monetary terms the labor cost represents an average cost of $\$ 9.45$ per $\mathrm{kW}$ of installed capacity.

- Periodic inspection and O\&M is necessary and its cost should be included in the operational budget of the building owner/occupant.

\section{Availability}

- Domestic water heating systems and components are available from local sources and also from several foreign companies having representation (sales offices) in Ukraine.

14. Install Low-Flow Showerheads - Low-flow showerheads available on the market can reduce the required water flow through the shower by 40 to $50 \%$ without sacrificing user comfort. These showerheads create the same "massaging" effect as high-flow models. Showerheads are easy to install and do not require plumbing changes.

\section{Building Type Application}

- Showerhead installation is assumed in hospitals having in-patient facilities. Polyclinics, schools, kindergartens, and offices are assumed to have insufficient hot water use in shower facilities to substantially influence the hot water consumption.

\section{Considerations}

- Installation of showerheads requires that the existing pipe connections be in reasonable condition.

- Savings from low-flow showerheads are dependent on reducing average flow rates of showers. The effectiveness of this ECO is often overestimated because of overestimates of existing showerhead flow rates.

\section{Costs}

- Material costs are estimated to be $\$ 7.69$ per showerhead. 
- Labor time to install the measure is estimated to be 0.25 hours, with a labor cost of $\$ 2.64$ per showerhead.

Availability

- Showerheads are locally available from outlets of foreign suppliers, and could be a source of domestic manufacture.

15. Install Aerators in Faucets - Aerators reduce the flow of water in bathrooms and utility room faucets for bathing, dish washing, etc. Installing aerators is simple and inexpensive and can be done by the occupant or as a maintenance procedure. The water consumption can be reduced by up to 30 to $50 \%$ of the faucet flow for a "running water" usage.

\section{Building Type Application}

- This measure is assumed to be applicable in hospitals, schools, and residential buildings. In other building types water usage is not considered large enough to result in significant energy savings.

\section{Considerations}

- Aerators are effective only when a "running water" usage is assumed. For faucets used to fill containers or tubs, aerators should not be used as they do not reduce energy use and increase the filling time in such cases. Also, some faucets may not be amenable to adding an aerator.

Costs

- Material costs are estimated to be $\$ 3$ per aerator.

- Labor time to install the measure is estimated to be 0.15 hours, with a labor cost of $\$ 1.59$ per aerator.

\section{Availability}

- This material is available from local sources. Some good quality models can also be obtained from local outlets of foreign suppliers and could be a source of domestic manufacture.

16. Install Hot Water Meters - Metering does not itself directly impact hot water use. Instead, it provides building occupants with an incentive to reduce hot water consumption and thus leads to reductions in hot water use. In institutional buildings, heat consumption for hot water would be measured at a single point of heat supply because heat costs are paid at the building level. For residential buildings, unlike heat metering, which is difficult to implement because of the one-pipe 
heating systems, hot water metering would be relatively straight forward by installing meters at the single point of supply to each apartment. Studies have shown that hot water metering can have a dramatic impact on hot water use. Not only are hot water costs a significant portion of energy costs for a typical family in Kyiv (more than \$9 per month according to IEA [1996]), hot-water-related energy use for residential customers is also a large component of total heat consumption in Kyiv.

\section{Building Type Application}

- This measure is applicable in residential buildings.

\section{Considerations}

- Metering imposes an additional burden of reading meters and billing. While these costs are expected to be passed on to the consumers, no attempt is made to quantify them here.

Costs

- Meter costs are estimated to be $\$ 95$ per meter.

- Labor time to install the measure is estimated to be 3 hours, with a labor cost of $\$ 40.00$ per meter.

\section{Availability}

- This material is available from local sources.

17. Insulate Hot Water Pipes in Unheated Spaces - Hot water pipes are generally insulated from the point of heating to the bottom of riser shafts, but not in the unheated shafts themselves (Ekono Energy 1996). In addition, old insulation may be insufficient, damaged, or otherwise not functional. Additional new insulation and/or repair of damaged parts of insulation lowers the hot water heat losses. Insulation in heated spaces is not considered economical, since the heat is "utilized" for space heating during the heating season.

\section{Building Type Application}

- All buildings are considered for this measure.

\section{Considerations}

- If existing pipe insulation contains asbestos fibers, the disturbance of the old insulation may create hazardous conditions and require additional measures to control and dispose of the asbestos. Asbestos is not known to be used for building insulation in Ukraine, however. 
- Good insulation decreases heat loss, which helps maintain the water temperature and reduces the recirculation pump capacity.

Costs

- Material costs are estimated to be $\$ 3.30 / \mathrm{m}$.

- Labor time to install the measure is estimated to be 0.2 hours $/ \mathrm{m}$ with a labor cost of $\$ 2.72 / \mathrm{m}$.

\section{Availability}

- Insulation materials based on mineral wool, closed cell foams, or fiberglass are readily available.

\section{Heating System Measures}

An important characteristic of heating systems found in most institutional (and residential) buildings in Ukraine is the single-pipe design, either with or without bypasses on the radiators. Without costly plumbing changes, this design does not allow zoning or control of the heating by a single zone valve for a building section. Heat metering for individual apartments in residential buildings is also difficult for the same reason. Multiple zone valves on each segment and multiple heat allocation devices would have to be used to meter the occupants' heat consumption.

Except for a small number of large buildings with more than 10 stories and some other important buildings, virtually all buildings in the city of Kyiv supplied by the district heating system utilize hydroelevators (venturi nozzles) for circulation of heating water inside the buildings. Buildings greater than 10 stories use a heat exchanger and circulation pump system. In a hydroelevator system, the temperature of the circulating water in the building heating system is reduced in the hydroelevator by mixing with return water. Such building heating systems directly circulate the district heating water and require (and assume) constant pressure in the district heating system pipes. Control of hydroelevator systems is very difficult; however, most of the systems were designed without controls, and the mixing ratio is driven only by the system pressure. At high-supply water temperatures, buildings will be overheated, and during low-supply temperature (which is currently the case) the relatively low-supply water temperature $\left(65\right.$ to $75^{\circ} \mathrm{C}$ ) is uncontrollably mixed with the return water, which reduces the water temperature entering the building system to almost unusable temperature levels of 40 to $45^{\circ} \mathrm{C}$.

Hydroelevator systems are quite outdated and are very inefficient. Without the ability to control building temperature, virtually no energy efficiency improvements could be effective (produce savings) without implementing a building heating control system upgrade. Based on available options, it is apparent that the building control system upgrade will require the installation of substations with waterto-water heat exchangers, and all necessary plumbing such as pipes, control and shutoff valves, liquid filters, circulating pumps, etc. In other words, to be able to improve energy efficiency of buildings, the hydroelevator system in each building must be replaced by a heat-exchanger-based substation. It is 
important to understand that even weatherization of a building envelope (e.g., by insulating the walls) will not produce savings without control of heat input to the space. Lack of such controls will result in space overheating, which leads to the use of windows to control temperatures.

The substation controller retrofit includes the substation with outdoor temperature reset control, equalizing (balancing) valves for the heat system branches throughout the building, and a control system utilizing occupied/unoccupied period setback when applicable.

The energy conservation effort must, in general, include two parts: the party responsible for energy bills must 1) be able to control the energy consumption and 2) must have an incentive to actually save energy. Installing temperature controls alone would likely not produce sufficient and sustainable energy savings as the occupants would not be rewarded for efforts to save energy. Therefore, metering energy consumption is very important, and energy meters must be installed for each user and are assumed to be part of every energy conservation measure considered in this study. Some Eastern European countries, such as the Czech and Slovak Republics, mandated metering by legislative order supported by financial incentives for metered consumption (leading to temporarily better rates).

Ukraine's building code requires all new buildings be equipped with a heat metering device (Cabinet of Ministers of Ukraine 1995). In addition, the Decree ratified a program for installing heat and water meters in existing residential buildings within the period of 1996 to 2000 . The implementation process is coordinated by the State Committee on Housing and Communal Services, and regional state administrations are responsible for the implementation.

The main objective of the metering program is to minimize demand on energy resources by reducing heat and water consumption. For the existing building stock, in the first stage, building-level metering is to be introduced in high-rise (5-story and more) buildings and then in low-rise buildings. In the second stage, apartment-level metering will be introduced.

Installation of meters is to be financed from the special-purpose funds created by regional administrations. The program is oriented mainly to domestically manufactured meters and temperature controls. New production facilities are to be created for equipment not currently available in Ukraine.

18. Install Building Heat Meters - As described above, building heat meters are considered an integral part of the energy-efficiency retrofits in all buildings. Building heat meters, because they allow for payment based on actual service, not calculated service, provide an incentive for building occupants to minimize heat consumption. This can have a substantial impact on the operations and maintenance of energy savings measures. It also allows for the verification of energy savings.

\section{Building Type Application}

- This measure is included for all buildings. 


\section{Considerations}

- Metered service results in additional meter reading and billing requirements. Though it is assumed that these costs will be passed on to the consumer, no attempt is made to quantify them here.

Costs

- Material costs are estimated to be $\$ 2,800$ per meter.

- Labor time to install the measure is estimated to be 12 hours per meter, with a labor cost of $\$ 160$ per meter.

\section{Availability}

- High-quality meters are available from local sales outlets of foreign suppliers and from local manufacturers.

19. Retrofit Heating System - Considering the existing design and poor condition of the building heating systems, the overall retrofit of the heating substations in institutional buildings was deemed to be the most appropriate. The retrofit assumes the replacement of the existing hydroelevator-based systems with new, heat-exchanger-based substations; installation of balancing valves and proper balancing of individual loops (risers); and utilization of outdoor temperature reset controls with unoccupied setback (night, weekends). Balancing valves installed on each riser will allow more accurate distribution of heat throughout the building sections.

Energy savings by this measure are accomplished by the ability to control the required heat input to the building during the occupied and unoccupied periods, and to provide sufficient heat to difficultto-heat spaces (such as building corner rooms) without severely overheating the building core space.

\section{Building Type Application}

- This measure is considered for all buildings currently equipped with hydroelevator-type heating systems without temperature control and without proper heating system balancing. In some buildings, such as inpatient hospital facilities, unoccupied setback cannot be utilized due to permanent occupation of the space.

\section{Considerations}

- This measure does not provide for temperature control in individual zones/rooms.

- Balancing should be done periodically (at least every 5th year). 
- Utilization of compact, package type pre-assembled heat substations is recommended, because they are highly reliable and reduce the number of field-installation-related problems.

- A building-side pipe cleaning procedure prior to installation of the new substation is necessary. Failure to clean the pipes may result in severe operational problems.

- This measure is usually considered a substantial capital improvement of the building and bears a substantial cost.

- Installation of heat exchangers in a large portion of buildings on a single district heating loop may change operating conditions in other buildings on the loop that continue to use a hydroelevator system. If the system is not adjusted to account for these changes, overheating of the buildings with hydroelevators may occur. In such cases, it may be necessary to balance the district heating loop.

Costs

- Material costs associated with retrofit of substations are a function of the installed substation capacity and range from $\$ 11$ to $\$ 25$ per $\mathrm{kW}$ of installed capacity, with smaller substations bearing larger unit costs.

- Labor time to install the measure is estimated to be 50 hours for every $100 \mathrm{~kW}$ of installed capacity (including the labor time for installation of balancing valves). In monetary terms the labor cost represents an average of $\$ 7.62$ per $\mathrm{kW}$ of installed capacity.

- Substation seasonal inspection and O\&M is necessary, and its cost should be included in the operational budget of a building owner/occupant.

\section{Availability}

- Packaged substations including all components are available from several western European companies having representation (sales offices) in Ukraine. The heating system retrofit assumes that field installation of individual components will utilize a majority of domestic parts and import items not individually available domestically (controls). Riser balancing valves are available domestically or from local sales outlets of major companies.

20. Install Radiator Balancing Valves - Temperature control is assumed to be provided by the outdoor temperature reset in the substation. Balancing valves installed on each radiator will allow more accurate distribution of heat throughout the building. This measure does not allow for temperature control; however, it can be used for permanent (or long-term) reduction of heat output by individual 
radiators. Energy savings are accomplished by the ability to provide sufficient heat to difficult-to-heat spaces (such as building corner rooms) and thus the ability to reduce unnecessary heat supply to the building core space.

\section{Building Type Application}

- This measure is considered for all buildings without proper heating system balancing, mainly in combination with temperature control systems. As a stand-alone measure, it is considered for buildings with permanent occupation, such as hospitals, where unoccupied setback cannot be utilized.

\section{Considerations}

- This measure does not provide for temperature control.

- Balancing should be done periodically (at least every 5th year).

- This measure is usually combined with temperature control installation.

Costs

- Material costs are estimated to be $\$ 14.25$ per valve.

- Labor time to install the measure is estimated to be 1.0 hour for radiators not requiring a bypass and 1.5 hours for radiators requiring a bypass, for total labor costs of $\$ 13.34$ and $\$ 20.00$ per valve, respectively.

\section{Availability}

- Radiator balancing valves are available domestically or from local sales outlets of major companies.

\subsubsection{Efficiency Measures Not Considered}

A number of ECOs identified (26) were not considered for further evaluation because they did not offer an adequate level of efficiency improvement potential, they could only be addressed through a more focused data collection effort beyond the scope of this effort, they would address only a small part of the building stock, and/or they were applicable to the energy supply side. Applicable ECOs that were not considered are presented in this subsection by ECO category. 


\section{Building Envelope}

1. Revolving or Double Door in Building Vestibule. Installation of revolving doors was not considered because most of the buildings either already have a second door or the installation is impractical or costly.

2. Triple Pane Windows. This measure was not considered due to its high cost. Windows are typically replaced as part of overall reconstruction of a building where the replacement is not based on investment payback from the energy savings.

3. Storm Doors. Storm doors are not practical on high-traffic entrance doors of institutional buildings.

4. Add Internal Insulation in Walls. This measure is expensive to implement, affects the appearance of the interior, and imposes a considerable burden on the occupant. Also it may potentially cause structural damage to the wall material. If installed improperly, with air access between the wall and the insulation, it may cause condensation and fungus growth.

5. Insulate Exterior Walls of Historical Buildings and Buildings with Complex Exterior Appearance. This was rejected as unacceptable for the historic buildings and too expensive for the other building groups.

6. Insulate Building Exterior Walls Having Windows. This was considered too expensive to do in a manner that would be acceptable from an appearance standpoint. Installation of insulation on walls with many windows has proved not to be cost-effective

7. Insulate Internal Walls Between Heated and Unheated Spaces (stairways). This was not considered to provide sufficient efficiency improvement and would have required additional data collection and analysis to evaluate.

8. Insulate Basement Perimeter Above the Ground. This was not considered to provide sufficient efficiency improvement and would have required additional data collection and analysis to evaluate.

9. Repair Leaking Roofs and Gutters. Leaks in roofs and gutters cause wet roof and wall insulation to become ineffective. This was not considered to be a common measure and would have required additional data collection and analysis to evaluate. Also, such a measure is considered to be a necessary building maintenance issue. 


\section{Heating System}

1. Re-Work Building Heating System Plumbing. Re-designing and re-working the building heating system from a single, not-zoned system to allow a single control and energy consumption measurement point for each occupant (tenant of an office building, or hospital budget center) was not considered cost-effective.

2. Replace or Improve Existing Gas or Room Heaters. This was not considered to be a common measure. Room heaters are mostly being used to supplement the main heating system during heat shortages. Because room heaters are primarily electric, and because electricity use is metered, building occupants have a disincentive to use them when the heat supply is adequate.

3. Insulate Boilers and Water Heaters to Reduce Standby Losses. This measure is not applicable due to a very low fraction of local boilers and water heaters. Insulation of domestic water heater tanks in substations is considered a supply-side measure.

4. Switch Fuel. This supply-related measure was beyond the scope of this analysis.

5. Replace Circulating Pumps and Temperature and Flow Control Components with High-Performance Parts. Replacement of standard motors (pumps, blowers, etc.) by high-efficiency units does not produce sufficient monetary savings and produces a long payback period. Pumps and other motors are typically replaced for other than energy saving reasons, such as failure, need to increase capacity, etc.

6. Insulate Conduits Between Boiler or Heat Exchanger and Building. This measure is related to the supply side of the energy system and insufficient data exist to effectively evaluate it.

7. Use Heat Pumps for Space and Water Heating. High-performance heat pumps are not available locally, and foreign made heat pumps are too expensive to produce a reasonable payback period. The Ukraine climate would require a ground-source heat pump for efficient operation during the winter. Additional data collection and analysis of heat pump performance characteristics would have to be performed for local climatic conditions.

8. Use of Thermal Storage. Thermal storage is a load-shifting measure, not an energy-saving measure, and therefore was not considered.

9. Implement Nonconventional Energy Sources, Such as Solar, Geothermal, Waste Heat From Local Industry, etc. This was not considered to be a common measure and was assumed to be of an experimental nature, requiring longer-term data collection and analysis for local climatic conditions. 
10. Improve Maintenance (cleaning) of Heat Sources, Such as Local Boilers, Room Heaters, etc. This would have required additional data collection and analysis to evaluate.

11. Outdoor Temperature Reset Control System for the Substations Serving Multiple Buildings. This was considered to be a supply-side measure, which will be included in the supply-side analysis and implementation.

\section{Ventilation and Heat Recovery}

1. Install Indoor Air Quality Ventilation/Heat Recovery Units. High-efficiency heat recovery ventilation units in rooms or building sections would introduce the required quantity of fresh air. Unless the use of ventilation systems is mandated by minimum air quality standards (such as ventilation standards for surgery rooms), this measure may actually increase energy consumption.

2. Install Combustion Air Preheating for Local Heaters. This supply-related measure was beyond the scope of this analysis.

3. Install Heat Recovery Vent System in Basements. Although this measure typically produces good savings in the residential sector, it was deemed not to be economical in institutional buildings, where basements are not used for storage and do not require ventilation.

4. Install Waste Water Heat Recovery Heat Exchanger. Application of heat recovery in the waste water system requires certain hot water usage patterns and quantities. Except for a small portion of hospital buildings with inpatients facilities, this measure would not be economical and was not recommended.

\section{Domestic Water Heating}

1. Insulate Hot Water Pipes in Conditioned Space. This was not considered to be a cost-effective measure. Heat lost from the hot water pipes is utilized for space heating and, from an energy conservation view, insulation of such pipes in heated space would not produce savings. Also, most of the hot water pipes are reasonably insulated.

2. Lower Domestic Hot Water Temperatures. Domestic water temperature is maintained at $55^{\circ} \mathrm{C}$, and lowering the temperature may introduce a health hazard. Also, lowering the temperature of the water could, in some cases, cause a hot water capacity shortage. 


\subsubsection{Summary of Efficiency Measures Considered}

Table 3.1 summarizes the 20 efficiency measures considered by installed cost per unit.

Table 3.1. Efficiency Measures Considered and Installed Cost Per Unit

\begin{tabular}{||l|c|c||}
\hline \multicolumn{1}{|c|}{ Efficiency Measure } & Unit & Cost (\$)/Unit \\
\hline Building Envelope & $\mathrm{m}^{2}$ & 25.17 \\
Exterior Side Walls & $\mathrm{m}^{2}$ & 27.94 \\
Roof Insulation & $\mathrm{m}^{2}$ & 11.38 \\
Attic Insulation & $\mathrm{m}^{2}$ & 7.59 \\
Basement Floor Insulation & $\mathrm{m}$ & 1.96 \\
Weatherstripping & each & 127 \\
Storm Windows & $\mathrm{m}^{2}$ & 43.17 \\
High-performance Glass & $\mathrm{m}^{2}$ & 30.68 \\
Third Window Pane & each & 9.07 \\
Radiator Reflectors & & \\
\hline Air Handling & per fan & 203 \\
Ceiling Fans & $\mathrm{m}^{3} / \mathrm{hr}$ & 2.60 \\
Ventilation Heat Recovery & & \\
\hline Domestic Water Heating & bldg. & 2,190 \\
Hot Water Heat Exchanger (weighted average) & bldg. & 3,147 \\
Storage Water Heater & each & 10.32 \\
Low-Flow Showerheads & each & 4.58 \\
Faucet Aerators & each & 135 \\
Hot Water Meters & $\mathrm{m}$ & 6.02 \\
Insulate Pipes & & 2,960 \\
\hline Heating System & each & 9,018 \\
Building Heat Meters & bldg. & 27.58 \\
Retrofit Heating System (weighted average) & each & \\
Radiator Balancing Valves & & \\
\hline
\end{tabular}

Different combinations of measures were installed depending on the performance of the measures in each building type. These combinations are discussed further in Section 3.3. Appendix C provides additional detail on the installed cost of the measures by building type.

\subsection{Analysis Approach}

The focus of the analysis was on the institutional buildings sector, so greater attention and more detailed analysis underlies the institutional sector estimates. Two subsections (3.2.1 and 3.2.2) describe 
the technical and economic analysis methods, respectively. Differences in the analysis approach for the institutional and residential sectors are noted in these two sections.

\subsubsection{Technical Analysis Method}

The technical analysis was based on the simulation of efficiency measure performance in prototype buildings chosen to reflect the mix of buildings found in Kyiv. The prototype building designs were developed based on site visits to buildings in Kyiv. A total of 33 prototypes were developed to model the Kyiv building stock. These prototypes are described in more detail in Appendix C.

Because the prototype buildings do not necessarily match the size of the average buildings in Kyiv for which they are used, all building level estimates are scaled to the average building area, by building category. The purpose of this scaling is two-fold: to allow for the estimation of per building costs and savings for average buildings in Kyiv, and to ensure that costs per building for measures, such as heat meters, accurately reflect the requirement that one heat meter be installed in each building.

Data presented on a per-building basis are consistent with per-unit floorspace estimates and total floorspace by building type. It should be noted, however, that there is not a one-to-one correspondence of building types to building prototypes. Hence, detailed level estimates, such as cost by ECO and building type, will not correspond exactly to the full set of building types (e.g., see Tables C.4 and E.1).

The analysis methodology, by measure type, is described below.

\section{Analysis of Building Envelope Measures}

The ASEAM5 (A Simplified Energy Analysis Method, Version 5) computer program was used in this analysis to model heat losses in buildings based on procedures recommended by the American Society for Heating, Refrigeration, and Air Conditioning Engineers (ASHRAE). The program calculates the peak building energy demands and annual energy consumption based on weather conditions in a given location. This computer program utilizes a bin-type TMY (typical meteorological year) weather file created from hourly weather data collected over a long period. The output reports include effects of other factors on building heat loads, such as occupancy schedule, lighting, appliance usage, insulation, etc., which helps determine the most effective energy conservation measure for each building type.

Baseline and post-measure installation heat and hot water energy consumption were calculated for each measure and each building type, the difference being the efficiency improvement. The development of the baseline building heating loads for each institutional building type required making several assumptions. The most important assumptions were infiltration rates, internal temperatures in different locations, and occupancy and equipment schedules. These assumptions were based on recommended values, previous experience, and information gathered during the energy audit of the representative buildings for each group. 
In the modeling of each ECO, only the pertinent value describing the given ECO was changed in the model. Insulation of walls, ceilings, and floors was modeled by lowering U-values. Weatherstripping was modeled by lowering the infiltration rate. Modeling of triple-pane and storm windows was accomplished by lowering U-values.

\section{Analysis of Water Heating Measures}

Efficiency improvement calculations for low-flow showerheads and faucet aerators were based on statistical information regarding the use of hot water in Ukraine, statistical information on hot water use by purpose (dishwashing, shower, laundry, etc.), and manufacturers' performance information. Calculation of efficiency improvements obtainable by insulating the hot water pipes in unconditioned spaces is based on lowering heat losses through additional pipe insulation with improved R-value or replacement of existing insulation with high-performance materials. Because of the limited nature of this effort, exact length and sizes of pipes could not be determined, but rather were estimated for each building group based on typical plumbing designs.

\section{Analysis of Building Heating System}

All ECOs in this category provide improved energy management in the building and assume that outdoor temperature reset control is installed in each substation of the central district heating system.

Installation of temperature control devices in conjunction with installation of energy consumption metering provides building occupants/owners with an incentive to reduce energy consumption. The use of a programmable thermostat also improves the use of setback during unoccupied periods. The combination of better energy management and distribution within the building and the ability of motivated occupants to lower energy consumption results in two effects:

- Room temperature is kept at the lowest possible acceptable (comfortable) level.

- Windows are opened only to maintain acceptable indoor air quality and not for temperature control.

The computerized calculations used for the building heating system efficiency improvements were also derived from procedures recommended by ASHRAE. For each measure, the baseline and postmeasure installation heat loss were both calculated. The difference between the two heat loss values is the energy-use reduction. For each ECO analyzed, the temperatures and infiltration rates were estimated based on performance of the proposed equipment and expected occupant behavior. In general, more accurate equipment and motivated occupants will produce lower temperatures and lower infiltration rates. The temperatures were not assumed to drop below accepted comfort limits. 


\section{Analysis of Ventilation Heat Recovery Measures}

Although none of the ventilation energy-efficiency measures were considered for application, evaluation of several measures was performed. The energy saving calculations developed for the heat recovery applications were again derived from procedures recommended by ASHRAE. Inputs to the calculations include properties and mass flow of media from which the waste heat is recovered and manufacturers' performance characteristics for the heat recovery equipment.

\subsubsection{Economic Analysis Method}

This section provides a discussion of the economic analysis metrics, the economic assumptions, and the approach employed to assess the economic performance of the efficiency measures.

\section{Analysis Metrics}

The ECOs described in the previous section were analyzed using a number of economic methods or "metrics" to evaluate the attractiveness of each option. A number of economic metrics commonly used to evaluate measure performance are simple payback, present and net present value (NPV), and internal rate of return (IRR). These metrics are described below.

Simple Payback. The most basic economic analysis metric is the simple payback period, which in its simplest form is calculated by dividing the installed cost of the ECO by the value of the annual energy savings. The simple payback period is the number of years required for the savings resulting from an investment in energy efficiency to offset the cost of the investment. The lower the payback period, the more attractive the investment.

In many analysis situations, this metric is too simplistic to be of much use. ECOs with future costs may be overvalued if these costs are not accounted for. Escalating fuel prices will also undervalue an ECO. Simple payback does not enable ready comparison for measures having different useful lifetimes. This method also does not account for the time value of money and may not be readily comparable with other investments using more sophisticated measures of value. Despite the many shortcomings of this method, it is frequently used along with first cost to evaluate the attractiveness of measures.

Present and Net Present Value. A Hryvna today is worth more than a Hryvna tomorrow for two principal reasons: general price inflation and the time value of money. Based on general price inflation, the purchasing power of a Hryvna declines over time, and because the true value of money lies in what it is capable of purchasing, inflation causes its value to decline. The time value of money refers to the fact that even in the absence of general price inflation, money received sooner is preferred to money received later. 
It is this preference for consuming sooner rather than later that leads to the existence of positive rates of interest, even in the absence of price-level inflation. Individuals and firms are willing to pay a premium to obtain goods and services sooner rather than later, and the premium they are willing to pay is the "real rate of interest." The market or "nominal" rate of interest is the real rate plus the rate of inflation (this is a slight simplification). As an example, 100 Hryvna received 2 years from today is worth 82.64 Hryvna today, assuming a 10\% nominal rate of interest. Conversely, 82.64 Hryvna invested today at a $10 \%$ per annum annual nominal rate of interest yields 100 Hryvna 2 years later.

The costs and benefits of an efficiency investment occur at different periods in time, which must be accounted for in the analysis. A metric for reflecting this fact is net present value, where the present value of all the costs of an ECO is compared to the present value of all the benefits of the ECO. The difference between the two, NPV, is a measure of the cost-effectiveness of an ECO. A negative NPV means the costs of an ECO outweigh its benefits, while a positive NPV means that the benefits are greater than the costs. The higher the NPV, the better. The formula for calculating the NPV is:

$$
N P V=\sum_{i=1}^{N} \frac{R_{t}}{(1+d)^{t}}-C
$$

where: $\mathbf{t}=$ year

$\mathrm{R}=$ annual return

$\mathrm{d}=$ discount rate

$\mathrm{C}=$ capital outlay

Internal Rate of Return. The IRR is the interest rate that equates the present value of the expected future cash flows or receipts to the initial capital outlay. The formula for calculating the IRR is:

$\mathrm{IRR}=\mathrm{r}$ such that:

$$
\sum_{t+1}^{N} \frac{R_{t}}{(1+r)^{t}}-C=0
$$

where: $\mathbf{t}=$ year

$\mathrm{R}=$ annual return

$\mathrm{r}=$ interest rate

$\mathrm{C}=$ capital outlay

The difference between the NPV and IRR is the discount rate (d) and interest rate (r). In the case of IRR, the formula is solved for the interest rate ( $r$ ) where the benefits minus the costs equals zero. The IRR is often used to screen and rank alternative investments--in general, the higher the IRR, the better. In the case of this analysis, an IRR of $20 \%$ or greater is deemed acceptable before accounting for risks, and the minimum acceptable IRR after risks is the discount rate of $10 \%$. 
In this analysis the IRR is computed only for those ECOs where a conventional cash flow stream exists and where the NPV is positive. Other cases may lead to multiple solutions or no solution. Conventional cash flow is the net cash flow stream, which begins with a disbursement of funds followed by a stream of savings.

Economic Assumptions. Two types of economic analysis methods typically used are nominal and real. The main difference between the two is the presence or absence of inflation, respectively. In a nominal analysis, the value of energy savings in 1997 is expressed in 1997 Hryvna, the value of energy savings in 1998 is expressed in 1998 Hryvna, and so on. The nominal value of the energy savings continues to increase because of inflation and the general level of prices. A real analysis expresses all money values in constant terms by removing the effects of inflation. In the case of this analysis, all values are expressed in 1996 currency values.

The implication of using a real analysis is the need to calculate a real discount rate to reflect the time value of money, which is the "real" interest rate after the effects of inflation have been removed. For the purposes of this analysis, a simplification is used whereby the discount rate is calculated as the nominal interest rate minus the expected rate of inflation.

Basic economic assumptions are provided below.

- nominal discount rate $-16 \%$

- inflation rate $-6 \%$

- real discount rate $-10 \%$

- analysis period - 15 years.

\subsection{Efficiency Potential Assessment}

This section provides the energy and economic assessment of the 20 energy efficiency measures (described in Section 3.1.1) considered for the analysis. The method employed to assess the efficiency potential for the institutional sector consisted of three steps:

1. Screen the individual measures by simple payback; measures having a simple payback of less than 5 years were retained for additional analysis.

2. Combine the measures to identify interactive effects to avoid double counting the efficiency potential and to deselect measures that reduced the payback of selected bundles for individual building types.

3. Evaluate the measure bundles and applicable individual measures for each building type to estimate efficiency potential. 
The residential sector efficiency potential was based on a combination of previous assessments conducted in the Czech Republic (PNNL 1996), the Slovak Republic (PNL 1995), and in Russia (World Bank 1996). Residential sector prototypes constructed for an analysis in the Czech Republic were simulated using Kyiv weather data. The quantities of material for the residential building types were drawn from an analysis of residential sector efficiency potential in Russia. Cost data were specific to Ukraine and consistent with cost data used for the institutional sector assessment.

\subsubsection{Institutional Sector Efficiency Potential}

The following group of four space-heating measures having an interactive effect were selected for application:

- windows and door weatherstripping

- reflectors behind radiators

- ceiling fans

- substation-level controls.

Depending on building type, a subset of these items was selected based upon their combined performance.

The following three measures, which did not exhibit interactive effects, were also selected for application depending on their performance:

- hot water heat exchangers

- low-flow showerheads

- aerators on faucets.

In all cases building heat meters are included.

Table 3.2 shows the cost-effective institutional sector efficiency potential by building type. Additional detail is contained in Appendix D. 
Table 3.2. Institutional Sector Efficiency Potential

\begin{tabular}{||l|c|c|c|c||}
\hline \multicolumn{1}{|c|}{ Building Type } & $\begin{array}{c}\text { Baseline } \\
\text { Energy Use } \\
\text { (thousand Gcal) }\end{array}$ & $\begin{array}{c}\text { Efficiency } \\
\text { Potential } \\
\text { (thousand Gcal) }\end{array}$ & $\begin{array}{c}\text { Efficiency } \\
\text { Improvement } \\
\text { (\%) }\end{array}$ & $\begin{array}{c}\text { IRR } \\
\text { (\%) }\end{array}$ \\
\hline Hospitals & 157 & 40 & 25.8 & 27.8 \\
\hline Polyclinics & 59 & 16 & 27.2 & 24.4 \\
\hline Administration & 16 & 4 & 26.2 & 16.4 \\
\hline Kindergartens & 329 & 86 & 26.2 & 31.7 \\
\hline Schools & 470 & 129 & 27.4 & 29.1 \\
\hline Higher Education & 240 & 64 & 26.5 & 31.6 \\
\hline Hostels & 154 & 34 & 22.0 & 25.4 \\
\hline Theaters & 10 & 3 & 28.7 & 26.8 \\
\hline Art Galleries/Museums & 12 & 2 & 19.6 & 12.9 \\
\hline Total & 1,446 & 378 & 26.2 & 29.2 \\
\hline
\end{tabular}

\subsubsection{Residential Sector}

The assessment of building efficiency potential for the residential sector was based on previous analyses conducted for the Czech Republic (PNNL 1996) and for Russia (World Bank 1996), and was modified to account for differences in the size mix of the housing stock and differences in the thermal performance of residential buildings in Kyiv. Retrofit equipment cost data were taken primarily from the Russia study with modifications made in some cases based on data from the Czech study or from information developed specifically for the institutional buildings assessment in Kyiv. The following measures were selected for application:

- reflectors behind each radiator

- low-flow showerheads

- faucet aerators

- hot water flow meter in each apartment

- building-level heat meters

- substation-level temperature controllers. 
The efficiency improvement attributed to this package of measures is presented in Table 3.3.

Table 3.3. Residential Sector Efficiency Potential

\begin{tabular}{|c|c|c|c|c|}
\hline Building Type & $\begin{array}{l}\text { Baseline Energy Use } \\
\text { (thousand Gcal/year) }\end{array}$ & $\begin{array}{l}\text { Efficiency Potential } \\
\text { (thousand Gcal/year) }\end{array}$ & $\begin{array}{c}\text { Percentage } \\
\text { of Baseline } \\
(\%)\end{array}$ & $\begin{array}{c}\text { Internal } \\
\text { Rate of } \\
\text { Return } \\
(\%)\end{array}$ \\
\hline 2-story & 2,569 & 451 & 17.6 & 23.4 \\
\hline 5-story & 3,545 & 873 & 24.6 & 26.4 \\
\hline 9-story & 3,545 & 1,070 & 30.2 & 35.7 \\
\hline 14-story & 2,026 & 645 & 31.9 & 41.6 \\
\hline Total & 11,685 & 3,039 & 26.0 & 32.4 \\
\hline
\end{tabular}

\subsection{Sensitivity Analysis}

The sensitivity of the economic analysis to any particular input variable can be assessed by holding all other exogenous variables constant while the variable of interest is changed. In this fashion, the value of any particular variable at which the investment becomes unattractive (i.e., the IRR becomes less than $10 \%$ ) can be determined. This value is referred to as the switching value.

The switching analysis was carried out with respect to two variables: energy savings and efficiency measure installed costs. The switching values, expressed as the percentage of the energy savings below the estimated value, or as the percentage of installed costs above the estimated value, for which IRR becomes less than 10\%, are presented in Tables 3.4 and 3.5 for the institutional and residential building sectors.

Table 3.4. Internal Rate of Return Switching Value for Energy Savings and Installed Costs - Institutional Buildings

\begin{tabular}{||l|c|c||}
\hline \multicolumn{1}{|c|}{ Type } & Energy Savings (\%) & Installed Costs (\%) \\
\hline Hospitals & 40 & 240 \\
\hline Polyclinics & 45 & 220 \\
\hline Hospital Admin. & 70 & 160 \\
\hline Kindergartens & 35 & 280 \\
\hline Schools & 40 & 260 \\
\hline Higher Education & 35 & 280 \\
\hline Hostel!s & 45 & 220 \\
\hline Theaters & 45 & 240 \\
\hline Art Galleries/Museums & $\mathbf{8 0}$ & 120 \\
\hline
\end{tabular}


Table 3.5. Internal Rate of Return Switching Value for Energy Savings and Installed Costs - Residential Buildings

\begin{tabular}{||l|c|c|}
\hline \multicolumn{1}{|c|}{ Type } & Energy Savings (\%) & Installed Costs (\%) \\
\hline 2-story & 50 & 200 \\
\hline 5 -story & 45 & 220 \\
\hline 9-story & 30 & 300 \\
\hline 14-story & 25 & 360 \\
\hline
\end{tabular}

In the case of hospitals, the energy savings would have to fall to $40 \%$ of the estimated value for the IRR to drop below $10 \%$ (i.e., the energy savings would have to be $10.3 \%$ instead of $25.8 \%$ of baseline energy use), or the installed cost would have to increase by $240 \%$. The institutional building types most sensitive to realized efficiency improvements or installed costs of efficiency measures are cultural buildings and hospital administration buildings. In the residential sector, the sensitivity to efficiency improved and the installed cost of the measures decreases as the building height increases.

\subsection{Investment Requirements}

This section discusses investment requirements for efficiency resources described in Section 3.3.

Investment levels are expressed both in terms of investment per building and investment per square meter of floorspace. The per-square-meter estimates are multiplied by the building stock estimates to provide an overall sector investment requirement. These values should be taken as an upper bound, as they are based on the assumption of $100 \%$ penetration of the efficiency measure packages into the building stock. In reality, not all existing buildings would be susceptible to retrofit.

The investment requirements for the institutional and residential building sectors are presented in Tables 3.6 and 3.7. Efficiency measure cost estimates are presented in Section 3.1. Other assumptions used in developing the investment requirements are presented in detail in Appendix E. 
Table 3.6. Investment Requirements for the Institutional Buildings Sector

\begin{tabular}{||l|c|c|c||}
\hline \multirow{2}{*}{\multicolumn{1}{|c|}{ Building Type }} & \multicolumn{3}{c|}{ Investment Requirements (\$) } \\
\cline { 2 - 4 } & Per Building & ${\text { Per } \mathbf{~ m}^{2}}^{\text {Total }}$ \\
\hline Hospitals & 21,719 & 5.45 & $3,475,019$ \\
\hline Polyclinics & 14,143 & 5.29 & $1,555,709$ \\
\hline Administration & 8,309 & 6.21 & 573,290 \\
\hline Kindergartens & 11,771 & 5.38 & $7,062,886$ \\
\hline Schools & 24,987 & 3.47 & $9,719,980$ \\
\hline Higher Education & 27,703 & 3.92 & $4,820,270$ \\
\hline Hostels & 23,994 & 4.37 & $3,191,160$ \\
\hline Theaters & 21,295 & 5.32 & 255,545 \\
\hline Art Galleries/Museums & 12,809 & 6.08 & 397,093 \\
\hline Total & 18,505 & 4.31 & $31,050,952$ \\
\hline
\end{tabular}

Table 3.7. Investment Requirements for the Residential Building Sector

\begin{tabular}{||l|c|c|c||}
\hline & \multicolumn{3}{|c||}{ Investment Requirements (\$) } \\
\hline \multicolumn{1}{|c|}{ Building Type } & Per Building & Per $\mathbf{~ m}^{2}$ & Total (millions \$) \\
\hline 2-story & 6,044 & 13.49 & 64.9 \\
\hline 5-story & 32,626 & 4.08 & 68.7 \\
\hline 9-story & 36,844 & 6.64 & 111.8 \\
\hline 14-story & 35,102 & 4.08 & 39.2 \\
\hline Total or Average & 31,939 & 5.92 & 284.6 \\
\hline
\end{tabular}

In the institutional buildings sector, the per square meter costs range from a low of $\$ 3.47$ for primary/secondary schools to a high of about $\$ 6.08$ for houses of culture. The single largest category for investment potential is schools at $\$ 9.7$ million, followed by kindergartens at $\$ 7.1$ million. The potential investment level for residential buildings is nearly $\$ 300$ million compared to $\$ 31.1$ million for the institutional buildings considered in this analysis. 


\subsection{Impacts Assessment}

The buildings efficiency improvement program will have potential additional impacts, primarily in two categories: economic and environmental. These include impacts on employment, energy security, air pollutant emissions levels, worker health and safety during building renovation activities, and indoor air quality as a result of building renovations. In addition to the environmental aspects mentioned above, World Bank policies prohibit investment in sites with contaminated ground soil. In this chapter these issues are addressed with respect to the current situation in Kyiv. Existing environmental regulations pertaining to Kyiv, as well as World Bank operational directives, are reviewed.

\subsection{Economic Impacts}

The potential economic impacts are substantial for buildings efficiency programs in Kyiv and Ukraine. The estimated economic and employment impacts are presented in Table 4.1.

An efficiency program would have direct and positive employment impacts for retrofit installation work. This analysis assumes the ratio of Ukrainian to Western labor ranges from 5:1 to 8:1, depending on the efficiency measure. While it is not clear to what extent energy retrofit services exist in Kyiv, such capabilities are likely to develop. The resulting employment impacts are estimated at 64 full-time equivalents for the second through fifth years of the project. It is expected that domestic suppliers and manufacturers of equipment will also develop, but associated employment is not estimated.

The reduction in energy expenditures translates directly into reductions of state and municipal expenditures. Budgetary expenditures are projected to decrease by $\$ 9$ million per year in the last year of the project. This is estimated to result in a redirection of $\$ 5.8$ million in annual expenditures for fuel imports.

Although a residential sector program was not examined in detail, the burden of excessive fuel consumption is also felt by residential consumers. The International Energy Agency (IEA) estimates that a typical urban family of four pays as much as one-third of wage earnings for the energy bill (IEA 1996). Reductions in energy consumption that are translated into reductions in energy-related expenditures would have a substantial positive impact on disposable income. It is estimated that residential sector energy bills could be reduced by as much as $25 \%$. 
Table 4.1. Secondary Impacts

\begin{tabular}{|c|c|c|c|c|c|c|}
\hline & 1998 & 1999 & 2000 & 2001 & 2002 & Annual \\
\hline \multicolumn{7}{|l|}{ Budget Reductions } \\
\hline Municipal Dept. of Health (\$) & 266,411 & 543,478 & 831,521 & $1,130,869$ & $1,441,858$ & $1,441,858$ \\
\hline Municipal Dept. of Education (\$) & 945,421 & $1,928,658$ & $2,950,847$ & $4,013,152$ & $5,116,769$ & $5,116,769$ \\
\hline Ministry of Education (\$) & 429,093 & 875,349 & $1,339,284$ & $1,821,427$ & $2,322,319$ & $2,322,319$ \\
\hline Municipal Dept. of Culture (\$) & 23,314 & 47,560 & 72,768 & 98,964 & 126,179 & 126,179 \\
\hline Total (\$) & $1,664,238$ & $3,395,046$ & $5,194,420$ & $7,064,412$ & $9,007,125$ & $9,007,125$ \\
\hline \multicolumn{7}{|l|}{ Emissions Reduction (tonnes) ${ }^{(\mathbf{a})}$} \\
\hline $\mathrm{NO}_{\mathrm{x}}$ & 66 & 133 & 199 & 266 & $\overline{332}$ & 332 \\
\hline $\mathrm{SO}_{\mathrm{x}}$ & 46 & 93 & 139 & 185 & 232 & 232 \\
\hline $\mathrm{CO}_{2}$ & 17,085 & 34,171 & 51,256 & 68,342 & 85,427 & 85,427 \\
\hline \multicolumn{7}{|l|}{ Domestic Employment (FTEs) ${ }^{(b)}$} \\
\hline Direct (measure installation) & 3 & 63 & 63 & 63 & 63 & \\
\hline Indirect (materials manufacture) & * & * & * & * & * & * \\
\hline \multicolumn{7}{|l|}{ Fuel Import Reductions ${ }^{(c)}$} \\
\hline Natural Gas (thousand $\mathrm{m}^{3}$ ) & 11,452 & 22,904 & 34,357 & 45,809 & 57,261 & 57,261 \\
\hline Mazut (tonnes) & 16,118 & 32,236 & 48,354 & 64,472 & 80,590 & 80,590 \\
\hline Natural Gas (\$) & 950,531 & $1,901,062$ & $2,851,593$ & $3,802,123$ & $4,752,654$ & $4,752,654$ \\
\hline Mazut (\$) & 218,744 & 437,489 & 656,233 & 874,978 & $1,093,722$ & $1,093,722$ \\
\hline Total Fuel (\$) & $1,169,275$ & $2,338,551$ & $3,507,826$ & $4,677,101$ & $5,846,376$ & $5,846,376$ \\
\hline \multicolumn{7}{|c|}{$\begin{array}{l}\text { (a) } \mathrm{NO}_{\mathrm{x}} \text { and } \mathrm{SO}_{\mathrm{x}} \text { emission factors from Ekono Energy (1996). } \mathrm{CO}_{2} \text { emission factors from } \mathrm{DOE}(1995) \text {. } \\
\text { (b) Full-time equivalents. } \\
\text { (c) Fuel import reductions estimated from energy savings using estimated transmission } / \text { distribution losses of } 20 \% \text {, and average boiler } \\
\text { efficiency of } 88 \% \text {. Natural gas savings converted from } \mathrm{Gcal} \text { to cubic meters using } 7,975 \mathrm{kcal} / \mathrm{m}^{3} \text { (Kievenergo data) (JTC 1996), and } \\
\text { mazut savings converted from Gcal to tonnes using } 7,000 \mathrm{kcal} / \mathrm{kg} \text {. Estimated price of natural gas, } \$ 83 / \text { thousand } \mathrm{m}^{3} \text {. Estimated price } \\
\text { of mazut, } \$ 95 / \text { tonne. } \\
\text { Domestic manufacture of equipment and materials is expected, but an estimate of the types and quantities of materials and associated } \\
\text { employment impacts has not been made. }\end{array}$} \\
\hline
\end{tabular}




\subsection{Environmental Impacts}

Assessment of the net environmental impacts associated with the potential investment program, particularly emissions impacts, requires an adequate characterization of an existing or baseline situation. As with the efficiency assessment baseline, this is somewhat problematic for the city of Kyiv. Currently, a capacity shortfall exists for district heating in some parts of the city. In addition, economic circumstances have led to the refusal of service by some building owners and/or occupants, depressing energy consumption at district heating plants to below-normal levels. As a result, current pollutant emissions are also below normal levels.

The actual environmental impact of the potential investment program at the building level is also highly dependent on the level of service received by any particular building. In buildings with adequate heating or overheating, an appropriately selected set of efficiency measures will result in reduced energy use, and hence reduced emissions. In buildings where heating service is inadequate, efficiency measures may improve the comfort level in the building, but not reduce energy use. While assessing impacts based on the existing (heat supply conditions in 1995) situation may accurately reflect actual short-term changes in emissions, the assessment will not capture the full expected impacts when service levels return to normal, which may be a more appropriate measure of environmental impacts.

Further complications to estimating environmental impacts also arise as a result of under utilization of district heating services, which in some cases is caused by electric space heaters, rather than natural gas, being used to provide supplemental heating. While the emissions impacts of this additional electricity use may or may not be local to Kyiv, they are in fact real impacts, and depending on the technology used to generate this additional electricity, may be much more dramatic than impacts due to changes in natural gas consumption at district heating plants. The complexity of this issue, however, is beyond the scope of the current effort to evaluate impacts associated with changes in electricity-related emissions.

Finally, emissions reductions related to energy savings depend on the performance of the heat production and distribution system, which are the subjects of a related improvement program. Direct emissions impacts as a result of these programs are estimated elsewhere (JTC 1996; Ekono Energy 1996). Explicit changes in average emissions factors as a result of these programs will not be estimated here. Instead, generic emission factors for boilers in Ukraine will be used, in conjunction with performance estimates of the existing heat production and distribution system. This method is transparent and provides a reasonably accurate assessment of emissions impacts associated with the potential investment program.

This assessment is driven both by World Bank and Ukrainian requirements for environmental assessments related to building efficiency improvement programs. The project requires a category "B" Environmental Mitigation Plan (EMP) as defined in the Bank's Operational Directive on Environmental Assessment, O.D. 4.01 (World Bank 1991). The assessment has also been performed in accordance with 
the requirements of the Ukrainian Ministry of Environmental Protection and Nuclear Safety, 1991 Law of Ukraine "On Protection of Natural Environment" (Law of Ukraine 1991) and 1992 Law "On Protection of Ambient Air" (Law of Ukraine 1992). Specific regulations are discussed by topic area below.

\subsubsection{Emissions Impacts}

Ukrainian law regulates both total emissions and stack concentrations from gas and mazut-fired boilers. Emissions limits exist for nitrogen and sulfur oxides and particulate. The emission limits are presented in Table 4.2 .

Table 4.2. Boiler Plant Permissible Air Pollutant Emission Levels

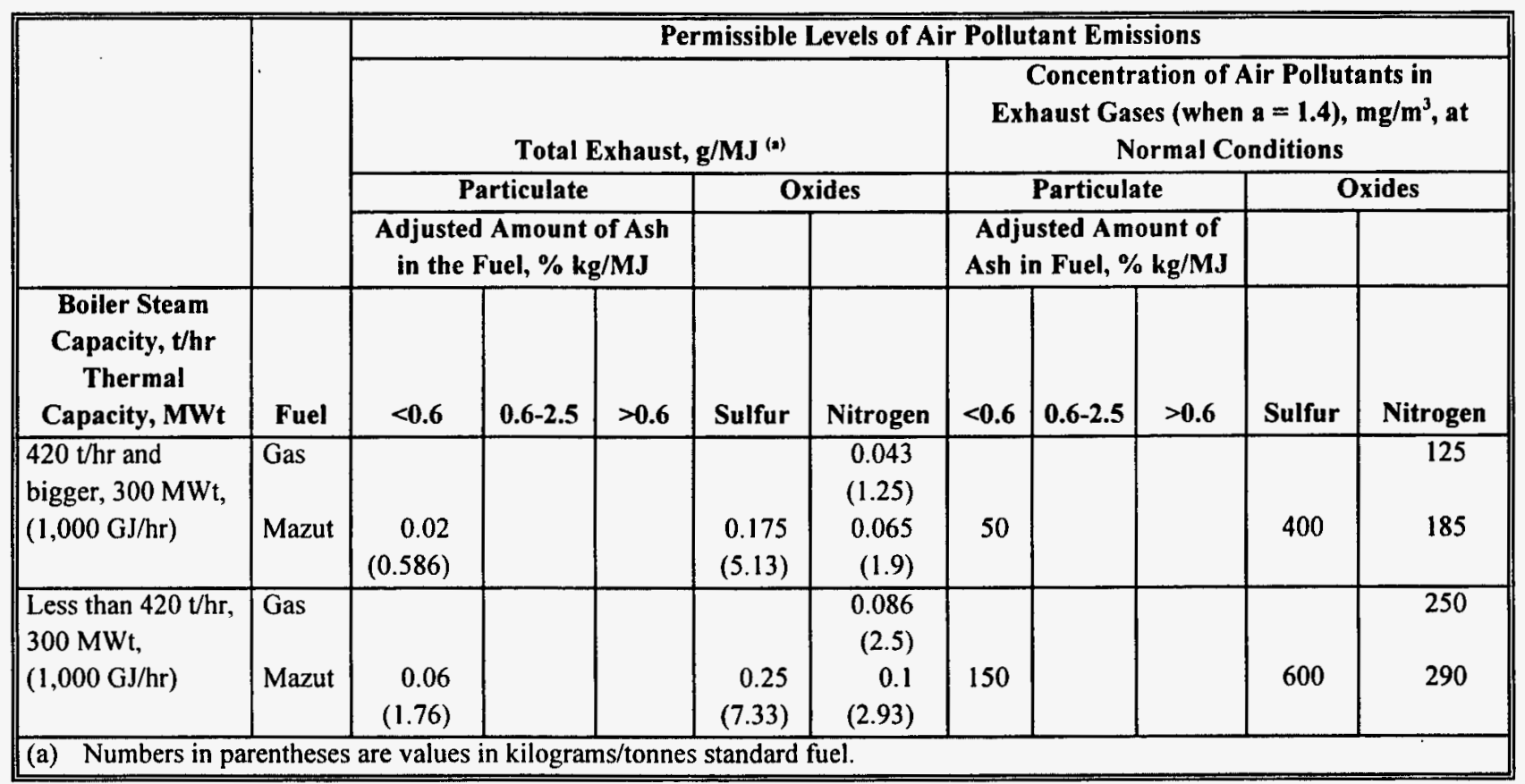

Ukrainian law (Ministry of Environmental Protection and Nuclear Safety) also regulates maximum permissible concentrations of selected air pollutants for short-term and 24-hour average concentrations. The full list of regulated pollutants includes more than 800 items, of which the most important for this project are $\mathrm{NO}_{\mathrm{x}}, \mathrm{SO}_{2}, \mathrm{CO}_{2}$, and particulate. The maximum permissible concentrations of these pollutants are presented in Table 4.3. 
Table 4.3. Maximum Permissible Concentration of Air Pollutants

\begin{tabular}{|l|c|c||}
\hline \multicolumn{1}{|c|}{ Pollutant } & $\begin{array}{c}\text { Maximum Short-Term } \\
\text { Concentration (ppm) }\end{array}$ & $\begin{array}{c}\text { Average Concentration } \\
\text { per 24 Hours }\end{array}$ \\
\hline Nitrogen Dioxide & 0.085 & 0.04 \\
\hline Nitrogen Monoxide & 0.6 & 0.06 \\
\hline Sulfur Dioxide & 0.5 & 0.05 \\
\hline $\begin{array}{l}\text { Residential Oil Ash (recalculated to } \\
\text { vanadium penoxide) }\end{array}$ & -- & 0.02 \\
\hline $\begin{array}{l}\text { Nonorganic Particulates (silicon dioxide } \\
\text { content above 70\%) }\end{array}$ & 0.15 & 0.05 \\
\hline $\begin{array}{l}\text { Nonorganic Particulates (silicon dioxide } \\
\text { content ranging from 20 to 70\%) }\end{array}$ & 0.3 & 0.1 \\
\hline $\begin{array}{l}\text { Nonorganic Particulates (silicon dioxide } \\
\text { content below 20\%) }\end{array}$ & 0.5 & 0.15 \\
\hline Note: ppm is parts per million. & \\
\hline
\end{tabular}

The potential investment program is expected to reduce heat demand in buildings, and hence energy consumption and emissions. The magnitude of the emissions reduction is a function of the heat demand reduction, the net heat production and distribution efficiency, and the emissions rates of the district heating boilers. As discussed above, precisely estimating the actual emissions reduction is difficult. However, a reasonable approximation can be made using estimated average emission factors and system performance. The assumptions used in this analysis are presented in Table 4.4.

Table 4.4. Emissions Estimate Assumptions

\begin{tabular}{|l|c|c|c|}
\hline & Natural Gas & Mazut & Total or Average \\
\hline Fuel Share & $\mathbf{8 5 \%}$ & $15 \%$ & $\mathbf{1 0 0 \%}$ \\
\hline Emission Factors (g/MJ) & & & \\
$\mathrm{NO}_{\mathbf{x}}$ & 0.21 & 0.21 & 0.21 \\
$\mathrm{SO}_{\mathrm{x}}$ & - & 0.975 & 0.146 \\
$\mathrm{CO}_{2}$ & 50.3 & 74.7 & 54.0 \\
\hline Boiler Efficiency & $\mathbf{8 8 \%}$ & $\mathbf{8 8 \%}$ & $\mathbf{8 8 \%}$ \\
\hline Transmission Efficiency & $\mathbf{8 0 \%}$ & $\mathbf{8 0 \%}$ & $\mathbf{8 0 \%}$ \\
\hline Heat Use Reduction (Gcal) & 321,501 & 56,735 & 378,236 \\
\hline Fuel Use Reduction(Gcal) & 456,677 & $\mathbf{8 0 , 5 9 0}$ & 537,267 \\
\hline Fuel Use Reduction (MJ) & 1,912 & 337 & 2,249 \\
\hline
\end{tabular}

Total emissions reductions by year as a result of the project are presented in Table 4.1. It is projected that after the year 2002, $\mathrm{NO}_{\mathrm{x}}$ emissions would be reduced by 332 tons, $\mathrm{SO}_{\mathrm{x}}$ emissions would be reduced by 232 tons, and $\mathrm{CO}_{2}$ emissions would be reduced by 85,427 tons annually. 


\subsubsection{Health and Safety}

Both the World Bank and Ukraine have health and safety guidelines for construction activities. Of primary concern is the potential for exposure of workers and occupants to asbestos, which is sometimes used in building materials such as insulation. Exposure to airborne asbestos particles poses a known health risk. In Ukraine, asbestos is used primarily to produce asbestocement, which may be used as a material for different types of pipes and ducts, and for roofing tiles. Asbestocement air ducts may be used in ventilation exhaust systems. However, Ukrainian law (State Committee of Ukraine on Affairs of Urban Development and Architecture 1996, SNiP No. 2.04.05-91) prohibits the use of asbestocement air ducts in input ventilation systems. It has been determined that asbestos is not commonly used as an insulating material. The potential investment program does not contain components related to the ventilation system. Hence, the potential to encounter asbestos in renovation projects is negligible; however, it is recommended that the presence of asbestos and its potential disturbance be addressed in the audit of individual buildings.

An additional health issue that may be worthy of further consideration relates to the use of industrial waste materials in concrete used to manufacture prefabricated panels for high-rise apartment construction. Since the early 1960s, these panels were manufactured at industrial facilities along the Dnieper River. In some cases industrial residues from the Donets Basin were used as aggregate in these panels (TACIS 1994). The use of such residues is now prohibited due to the potential for high heavy metals content in the waste. However, little publicly available information has been located on the health hazards associated with the use of these panels in existing buildings.

Positive health impacts can be expected due to improved temperature control in buildings. The improved environment may reduce the number of occupant sick days and improve productivity; however, it would be extremely difficult to quantify such impacts, and no attempt to do so is made here.

\subsubsection{Indoor Air Quality}

Ukrainian sanitary norms regulate maximum permissible concentrations of harmful substances in ambient (outdoor) air. Under regulations of the Ministry of Health, maximum concentrations for indoor air of residential and institutional buildings must not exceed established maximum permissible concentrations for ambient air. To comply with these regulations, Ukrainian law (State Committee of Ukraine on Affairs of Urban Development and Architecture 1996, SNiP 2.04.05-91) requires that the building ventilation system be designed appropriately, and that the heating system design must account for heat losses due to the warming of ventilation air. These heat losses are normally calculated on the basis of one air change per hour, though some buildings may be designed for greater air change rates. The World Bank requires a minimum ventilation rate of 0.5 air changes per hour. 
Actual existing ventilation rates in Ukraine are difficult to quantify. In institutional buildings, ventilation systems are often inoperable. Because of high infiltration rates, however, indoor air quality is generally not a problem. Because some efficiency measures are expected to reduce infiltration, it will be necessary to ensure that adequate ventilation is maintained.

The potential for insufficient ventilation will be addressed for individual buildings at the time of the building audit to determine applicable efficiency measures. In addition, the monitoring and verification activities should include a component to monitor air quality in selected buildings.

\subsubsection{Soil Contamination}

The potential investment program is not expected to have a significant impact on soil contamination. None of the materials expected to be used in the program are, or contain, contaminants. World Bank directives also prohibit investment in buildings with soil contamination.

Existing soil contamination may be of concern in Kyiv due to the location of past or present industrial activities near residential and commercial areas. In addition, Kyiv is located in an area affected by the 1986 Chornobyl nuclear power plant explosion, which spewed radioactive materials into the atmosphere. This contamination is no longer considered to pose a hazard, but it is recommended that the potential for disturbance of contaminated soil be addressed during the audit of individual buildings.

\subsubsection{Ozone Depleting Substances}

In compliance with the Montreal Protocol ${ }^{(a)}$ (signed by Ukraine on February 18, 1988, and ratified by the Ukrainian Parliament on September 20,1988), the Cabinet of Ministers of Ukraine issued decree \#1274 (Cabinet of Ministers of Ukraine 1996) approving a program for stopping the production and use of ozone depleting substances (ODS) in Ukraine. While ODS regulated by the Montreal Protocol are not manufactured in Ukraine, they are used in almost every sector of the economy.

Ukraine will receive financial assistance, partly financed by a Global Environmental Facility (GEF) grant of $\$ 26.5$ million, to implement projects on the conversion of ODS-using enterprises. The grant is conditioned on the implementation of licensing procedures for the import of ODS and ODS-containing equipment and materials, including foam insulation manufactured with chlorofluorocarbon (CFC) foaming agents such as HCFC-11. The total number of licenses will gradually be reduced as required by the London amendments to the Montreal Protocol.

(a) The 1997 Montreal Protocol on Substances that Deplete the Ozone Layer, as adjusted and amended by meetings in London in June 1990, in Copenhagen in November 1992, and in Vienna in December 1995; sponsored by the Ozone Secretariat, United Nations Environmental Program. 
The World Bank also restricts the use of ODS in particular foam insulations manufactured with CFCs or their derivatives. To comply with these regulations, all tender documents for this project will stipulate that foam insulation materials shall not be manufactured using CFCs. 


\subsection{Conclusions}

The government of Ukraine, through the State Committee of Energy Conservation (State Committee), is considering the implementation of energy efficiency measures in state and municipal institutional buildings in the city of Kyiv. The State Committee entered into an agreement with the U.S. Department of Energy to assess the efficiency potential of the institutional buildings sector in Kyiv. Results of this assessment would support a loan by the World Bank for implementing a buildings efficiency improvement program in Kyiv.

This report documents the assessment of the institutional buildings sector efficiency resource conducted by PNNL and its subcontractors, Tysak Engineering and the Agency for Rational Energy Use and Ecology (ARENO-ECO). The assessment consists of three primary tasks: evaluation of the institutional sector building stock in Kyiv, estimation of heat energy consumption in this building stock, and assessment of the cost-effective energy efficiency potential through retrofits to the buildings.

In conducting this assessment, because of limitations in quality and availability of existing data, uncertainty arose regarding the size, distribution, and energy consumption of the institutional sector building stock. This assessment focused on reducing the uncertainties associated with size and distribution data by directly surveying the owning institutions. The uncertainty associated with the baseline energy consumption could not be addressed as directly due to time and budget limitations. In place of direct measurement of energy use, information from the literature and professional experience were drawn upon to produce baseline estimates. The energy consumption information generated in this manner is therefore considered conservative.

Of the 1,678 buildings included in the survey, education buildings make up the largest category with 1,296 buildings and a total of 6 million square meters of floorspace. A total of 989 of these buildings are under the jurisdiction of the Municipal Department of Education, the remainder being under the jurisdiction of the Ministry of Education. The Municipal Department of Health is estimated to own 339 buildings having about 1 million square meters of floorspace. Forty three cultural buildings were also included in the survey with a total of 131 thousand square meters of floorspace. Total floorspace for the institutional sector included in the survey is 7.2 million square meters. By comparison, residential buildings include about 49 million square meters of floorspace.

Of energy supplied to the buildings sector in the form of hot water for space heating and domestic hot water purposes, the share by sector is estimated as follows: residential sector $45 \%$, industrial sector $34 \%$, institutional sector $11 \%$, and commercial sector about $10 \%$. Although the literature review and professional experience indicate these estimates to be reasonable, uncertainty is high for these estimates. Of the institutional buildings included in this assessment, the educational category was estimated to represent about $84 \%$ of the total energy consumption. 
Building types were analyzed by size and age subcategories to determine the cost-effective energy efficiency potential. Measures to improve energy efficiency were selected and applied to each subcategory to reduce space heating and domestic hot water energy use. Measures were selected based on the economic criterion of a 5-year or less simple payback. The measures include insulation (exterior, roof, attic, and pipe), weatherstripping, storm windows, radiator reflectors, controls (building radiator level), low-flow showerheads, and faucet aerators. After measures were selected, the performance of the measure package was evaluated based on simple payback, IRR, and NPV.

The estimated averages for efficiency potential range from $20 \%$ of baseline energy use for art galleries and museums to $29 \%$ for theaters. For education buildings, cultural buildings, and hospital administration buildings, the bulk of the efficiency potential is achieved through the building heat substation retrofit, which enhances temperature control and allows for setback of temperatures during unoccupied periods. For inpatient hospital buildings, the efficiency potential due to enhanced building controls is reduced because of the 24-hour occupancy schedule; however, high hot water use levels result in additional efficiency potential from the hot water heat exchanger retrofit (see Table 3.2).

The investment levels associated with efficiency improvements range from $\$ 3.47$ per square meter for schools to $\$ 6.08$ per square meter for hospital administration buildings, or an average investment of $\$ 4.31$ per square meter. These investment costs are primarily related to building size. The cost per unit capacity for building controls and hot water heat exchanger retrofits are higher for smaller units, and hence are higher for smaller buildings. In addition, heat meter costs are the same regardless of building, and hence cost more per unit floorspace for small buildings. The per square meter investment levels lead to a total investment of $\$ 31.1$ million.

The performance of the efficiency measure package varies as a function of building size, age, and function. In general IRR is lower for small and older buildings. By function, IRR is lowest for hospital administration buildings (16\%) and art galleries/museums (13\%), and highest for kindergartens and higher education buildings (32\%). The weighted average IRR is $29 \%$ (see Table D.4).

The sensitivity of the economic assessment with respect to efficiency measure performance and installed costs was also examined. The estimated values for efficiency measure performance and installed costs were either raised or lowered until the IRR fell to $10 \%$, the minimum value for which the net present value is positive. For the value of the IRR to fall below $10 \%$, at a heat price of $\$ 22 / \mathrm{Gcal}$, the efficiency improvement would have to decrease between $35 \%$ and $80 \%$ of the estimated value. For example, the efficiency improvement of kindergartens would have to fall from $26 \%$ to $9.1 \%$ for the IRR to fall to $10 \%$. The cost of materials would have to more than double for the IRR to fall below $10 \%$ in all but hospital administration buildings and art galleries/museums, for which the cost of materials would have to escalate by $20 \%$ to $60 \%$ (see Table 3.4 ).

As a result of energy efficiency improvements, a reduction of $\$ 1.7$ million in energy bills is estimated in the first year, increasing to over $\$ 9$ million annually when the installation of efficiency measures is completed in the fifth year of the program. The reduction in energy costs translates to 
additional funding available for redirection to other uses in the agencies or reductions in the state and municipal budgets. The reduced consumption of energy also translates to a decrease in the outflow of currency to purchase fuels. In addition to energy use reductions, emissions are expected to be reduced as follows: 332 metric tons of $\mathrm{NO}_{x}, 232$ metric tons of $\mathrm{SO}_{\mathrm{x}}$, and 85,427 metric tons of $\mathrm{CO}_{2}$ annually (see Table 4.1). None of the measures considered are expected to have significant health impacts or other negative environmental impacts. 


\subsection{References}

Cabinet of Ministers of Ukraine. 1995. On Program for Staged Equipping of Residential Building Stock with the Instruments for Metering and Regulation of Water and Heat Consumption in 1996-2000, Decree \#947 of November 27, 1995, Cabinet of Ministers of Ukraine, Kyiv, Ukraine.

Cabinet of Ministers of Ukraine. 1996. On Program for Stopping the Production and Use of OzoneDepleting Substances in Ukraine, Decree \#1274 of October 17, 1996, Cabinet of Ministers of Ukraine, Kyiv, Ukraine.

Ekono Energy. 1996. Feasibility Study for Heat Supply and Energy Efficiency Project Kiev. Ekono Energy, Espoo, Finland.

International Energy Agency (IEA). 1996. Energy Policies of Ukraine: 1996 Survey, Organization for Economic Cooperation and Development. International Energy Agency, Paris, France.

Joseph Technology Corporation (JTC). 1996. Ukraine Kiev District Heating Project. Joseph Technology Corporation, Woodcliff Lake, New Jersey.

Law of Ukraine. 1991. On Protection of Natural Environment, Decree \#1268-12 of June 26, 1991, Parliament of Ukraine, Kyiv, Ukraine. With changes introduced by the Laws \#3180-12 of May 5, 1993, and \#81/96-BP of March 6, 1996, Parliament of Ukraine, Kyiv, Ukraine.

Law of Ukraine. 1992. On Protection of Ambient Air, Decree \#2708-12 of October 16, 1992, Parliament of Ukraine, Kyiv, Ukraine. With changes introduced by the Law \#75/95-BP of February 28, 1995, Parliament of Ukraine, Kyiv, Ukraine.

Pacific Northwest National Laboratory (PNNL). 1995. An Assessment of the Building Sector Efficiency Resource for the Town of Handlova. PNNL-10847. Pacific Northwest National Laboratory, Global Studies Program, Richland, Washington.

Pacific Northwest National Laboratory (PNNL). 1996. Assessment of the Buildings Sector Efficiency Resource for the City of Plzen, Czech Republic. PNNL-10898. Pacific Northwest National Laboratory, Richland, Washington.

State Committee of Ukraine on Affairs of Urban Development and Architecture. 1996. SNiP 2.04.05-91*U, Heating, Ventilation and Air Conditioning, Order \#117 of June 27, 1996, State Committee of Ukraine on Affairs of Urban Development and Architecture, Kyiv, Ukraine. 
TACIS. 1994. Study of the Potential for Developing Actions to Improve the Overall Energy Efficiency in the Building Sector in Ukraine. Commission of European Communities by Sogelberg Ingeniere, and TechInvest, Lisbon, Portugal.

Ukrenergoprom. 1995. Draft Plan of the Kiev District Heating Development in the Period 2005 and Potentially until 2010. Ukrenergoprom, Kyiv, Ukraine.

United States Department of Energy (DOE). 1995. Emissions of Greenhouse Gases in the United States: 1987-1994, DOE/EIA-0573(87-94), U.S. Department of Energy, Energy Information Administration, Washington, D.C.

World Bank. 1991. Operational Directive 4.01: Environmental Assessment, The World Bank Operational Manual, World Bank, Washington, D.C.

World Bank. 1996. Staff Appraisal Report, Russian Federation, Enterprise Housing Divestiture Project, Report No. 15112-RU, World Bank, Washington, D.C. 


\section{Appendix A}

Institutional Building Stock Survey and Data Collection 


\section{Appendix A}

\section{Institutional Building Stock Survey and Data Collection}

\section{A.1 General Description}

Kyiv, the capital of Ukraine, is situated on the banks of the Dnieper River and has a population of about 2.8 million. The city is divided into 14 districts and covers an area of about 80,000 hectares ( 200,000 acres). Overall the city contains about 50,000 buildings including residential, industrial, commercial, and public (institutional) buildings. There is a large industrial area along the Dnieper River, and a newly developed area, with primarily residential buildings, on the outskirts of the left (East) bank. Institutional buildings are spread throughout the city, but the majority are located on the right (West) bank in the older parts of the city.

Institutional buildings are a diverse category that includes buildings with various social functions, such as:

- healthcare (hospitals, polyclinics, medical research institutes, etc.)

- primary and secondary education (kindergartens, schools, boarding schools, children's centers, grammar schools, lyceums, etc.)

- professional and higher education (professional colleges, institutes, universities, academies, student hostels, etc.)

- social and cultural institutions (museums, theaters, concert halls, libraries, sport complexes, etc.)

- administration and office buildings (ministries, committees, city and district administrations, various municipal organizations, research and design institutes, etc.).

The goal of the project was to consider only those buildings with state or municipal (city and district) ownership. Until quite recently, the state was the nominal owner of almost all real-estate property. State and municipal institutions acted as actual owners who were responsible for accounting procedures and maintenance of buildings. In this capacity there are such major institutions as ministries, state committees, ministry-level organizations (e.g., National Agency for Reconstruction and Development, State Property Fund, etc.), and the city and district administrations. Ministries and state committees, 
apart from their own buildings, may have in their subordination research, design, and educational institutes, research and development bureaus, etc. Although formally subordinated, these institutions act as separate legal entities with full rights of property disposal (except selling the property).

As a result of insufficient financing from the state and municipal budgets, these institutions are usually forced to rent their buildings to government or commercial organizations and to charge the tenants with the operation and maintenance expenses. The current ownership situation is further complicated because of ongoing processes of privatization and transformation of ownership: stateowned buildings are being transferred to municipal property, and public buildings are being sold to private owners. As a result, the institutional buildings stock is undergoing rapid changes and cannot be regarded as fixed.

\section{A.1.1 Targeted Buildings}

Because the purpose of this study is to provide an assessment of the institutional buildings sector efficiency potential and investment level for a potential World Bank loan, the focus was on institutional buildings with large populations administered by a single owner. It is more likely that such owners will consider a loan and that the loan and its repayment will be administered more easily. Also, the administrative process of issuing the loan (due diligence) is much simpler and less expensive for larger borrowers. In addition, the willingness of large owners to provide data and to cooperate during the survey phase was a positive sign of their interest in obtaining the potential loan.

The existing ownership structure was analyzed, and the owners with large building populations were selected. Preference was given to those buildings where ownership relations were simplest and building stock could be considered as sufficiently stable (i.e., buildings are not rented to various tenants and the privatization process did not complicate the situation). In this regard, the obvious categories to consider were healthcare and education. Preschool and secondary education buildings (kindergartens, schools, boarding schools, youth centers, etc.) are owned by the city. The majority of higher and professional education buildings are subordinated to the Ministry of Education, and some other ministries have their own educational establishments. Healthcare institutions (hospitals, polyclinics, etc.) are owned by the city and the Ministry of Health. There is a much smaller number of healthcare buildings with other owners: Cabinet of Ministers, Ministry of Internal Affairs, Ministry of Transport, etc. There are very few of these buildings and information on them was much more difficult to obtain. Thus, they were not included in the detailed assessment.

An additional argument in favor of evaluating healthcare and education buildings was their substantial energy-saving potential due to their occupancy schedule. In addition, there are important social aspects of improving the overall conditions and level of comfort in educational and medical institutions. Also, in these categories many buildings were constructed according to standard designs, which makes it possible to replicate approaches to energy conservation opportunities and will reduce required implementation costs. Institutional buildings in other categories were not built according to the same standard designs and would require an individual approach. 
Another category with a large number of buildings is research and design institutes. Here the largest owner is the Ukrainian National Academy of Sciences. It has dozens of institutes in its structure, although each of them is regarded as a separate legal identity. The situation here is quite complicated, as the Academy is now in the process of restructuring, and the privatization process is under way. As a result, the current ownership structure is changing, and the prospects for these buildings are not yet clear. Other institutes are formally subordinated either to ministries or other state structures, or to the city. These also have separate legal identities and, under conditions of insufficient financing, are usually forced to rent their office space to various commercial structures or state organizations.

Tables A.1 and A.2 present summary information on the number of buildings and floorspace for 9 categories of buildings: hospitals, polyclinics, and hospital administration buildings; kindergartens, secondary schools, higher education buildings, and student hostels; and theaters and art galleries/ museums. Data for healthcare facilities primarily include information for buildings owned and operated by the Municipal Department of Health. Data on healthcare institutions with other owners (Cabinet of Ministers, Ministry of Defense, Ministry of Internal Affairs and the National Safety Service) are not available. Healthcare units not located in separate buildings were not assessed for efficiency potential, as well as those where the efficiency potential is relatively small and implementation of energy conservation opportunities does not make sense (pathologies, laundries, garages, warehouses, etc.).

\section{A.1.2 Building Categorization}

Information in Tables A.1 and A.2 is segregated by vintage and size (number of stories). The time periods used in the analysis are prior to 1958,1958 to 1980 , and after 1980; gradation by size is small (1 to 2 stories), medium ( 3 to 4 stories), and large (greater than 4 stories).

Prior to 1958, Russian building codes (abbreviated SNiP) did not exist. Construction practices were based on methods described in special literature and reference books. These methods were based on traditional practices for constructing buildings with thick brick walls, which provided satisfactory heat insulation levels. For these buildings, it is difficult to make an accurate estimate of thermal resistance values for the building envelope. However, available reference information allows indirect estimation of these values based on so-called "specific heat characteristics" of different buildings, which were used before 1957 for approximate calculation of heat losses.

In 1957 some SNiP chapters appeared, including standards regulating the level of thermal insulation for building envelopes. Under theses norms, which were valid until 1994, thermal resistance of building envelope elements (apart from windows) was determined by the maximum allowed by the norms as a function of the difference between the temperature of indoor air and internal surface of the building envelope. For example, for external walls this difference varied between 6 and $7^{\circ} \mathrm{C}$ for different types of public buildings. Practically all buildings were designed and constructed to minimize their cost, so the building envelope had the minimum possible thickness. 
Table A.1. Number of Buildings by Vintage and Size

\begin{tabular}{|c|c|c|c|c|c|c|c|c|c|c|}
\hline \multirow{3}{*}{$\begin{array}{l}\text { Institutional Building } \\
\text { Owner and Category }\end{array}$} & \multicolumn{10}{|c|}{ Number of Buildings by Vintage and Size } \\
\hline & \multicolumn{3}{|c|}{ Pre-1958 } & \multicolumn{3}{|c|}{$1958-1980$} & \multicolumn{3}{|c|}{ Post-1980 } & \multirow{2}{*}{$\begin{array}{c}\text { Total Number } \\
\text { of Buildings }\end{array}$} \\
\hline & $<3$ Stories & 3-4 Stories & $>4$ Stories & $<3$ Stories & 3-4 Stories & $>4$ Stories & $<3$ Stories & 3-4 Stories & $>4$ Stories & \\
\hline \multicolumn{11}{|l|}{ Municipal Dept. of Health } \\
\hline Hospitals & 41 & 26 & 5 & 12 & 22 & 30 & 3 & 2 & 19 & 160 \\
\hline Polyclinics & 25 & 8 & 1 & 10 & 22 & 3 & 4 & 14 & 23 & 110 \\
\hline Administration & 34 & 2 & 1 & 13 & 5 & 4 & 3 & 3 & 4 & 69 \\
\hline Subtotal & 100 & 36 & 7 & 35 & 49 & 37 & 10 & 19 & 46 & 339 \\
\hline \multicolumn{11}{|l|}{ Municipal Dept. of Ed. } \\
\hline Kindergartens & 43 & 1 & 0 & 375 & 0 & 0 & 153 & 28 & 0 & 600 \\
\hline Schools & 7 & 95 & 0 & 11 & 185 & 0 & 7 & 84 & 0 & 389 \\
\hline Subtotal & 50 & 96 & 0 & 386 & 185 & 0 & 160 & 112 & 0 & 989 \\
\hline \multirow{2}{*}{\multicolumn{11}{|c|}{ Ministry of Education }} \\
\hline & & & & & & & & & & \\
\hline Education Buildings & 4 & 32 & 5 & 9 & 43 & 48 & 4 & 7 & 22 & 174 \\
\hline Hostels & 2 & 6 & 7 & 2 & 5 & 97 & 0 & 0 & 14 & 133 \\
\hline Subtotal & 6 & 38 & 12 & 11 & 48 & 145 & 4 & 7 & 36 & 307 \\
\hline \multicolumn{11}{|l|}{ Municipal Dept. of Culture } \\
\hline Theaters & 0 & 8 & 1 & 2 & $\overline{0}$ & 0 & 0 & $\overline{0}$ & 1 & 12 \\
\hline Art Galleries/Museums & 17 & 8 & 1 & 0 & 0 & 1 & 3 & 1 & 0 & 31 \\
\hline Subtotal & 17 & 16 & 2 & 2 & 0 & 1 & 3 & 1 & 1 & 43 \\
\hline Total & & & & & & & & & & 1,678 \\
\hline
\end{tabular}




\begin{tabular}{|c|c|c|c|c|c|c|c|c|c|c|}
\hline II $19^{6} Z I Z^{6} L$ & & & & & & & & & & ן1810I \\
\hline I0t'EI I & $0 Z t^{\circ} \mathcal{E}$ & $006^{6} \mathrm{Z}$ & $58 \varsigma^{6} \varepsilon$ & $000^{6} 0 z$ & 0 & $\varepsilon S t^{6} \varepsilon$ & $080^{6} 8$ & $629^{6} \mathrm{ES}$ & $\pitchfork \varepsilon \varepsilon^{\prime} 8 I$ & [E]01qnS \\
\hline $8 \mathcal{H} E^{\prime} S 9$ & 0 & $006^{6} z$ & $\varsigma 8 \mathcal{S}^{6} \varepsilon$ & $000^{\circ} 0 Z$ & 0 & 0 & $08 \varepsilon^{\prime} \varsigma$ & $6 S I^{\prime} S I$ & $\downarrow \mathcal{E} \mathcal{E}^{6} 8 \mathrm{I}$ & 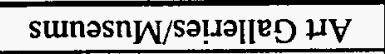 \\
\hline \multirow[t]{2}{*}{$\varepsilon t 0^{\prime} 8 t$} & $0 Z \nabla^{\circ} \varepsilon$ & 0 & 0 & 0 & 0 & $E S D^{6} \varepsilon$ & $00 L^{\prime} Z$ & $0 \angle t^{6} 8 \varepsilon$ & 0 & S.әІвәЧ.L \\
\hline & & & & & & & & & & 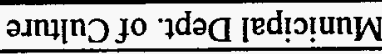 \\
\hline & & & & & & & & & & \\
\hline $6 L E^{\prime} 6 S 6^{6} I$ & SZI'IEE & $6 S S^{6} I S$ & $799^{6}$ I I & $E 6 I^{\prime} 0 L 6$ & $\mathcal{E} \mathcal{E} \mathcal{E}^{\prime} \subseteq L Z$ & $S 08^{6} E Z$ & $677^{6} 85$ & $188^{\prime} 60 z$ & $0 \angle \varepsilon^{6} L Z$ & jetolqns \\
\hline$\nabla\left[9^{\circ} 0 \mathcal{E} L\right.$ & $059^{6} 08$ & & & $68 L 66 E S$ & $68 I^{\prime} 6 \varepsilon$ & $078^{\circ} \varepsilon$ & $\varsigma Z \varsigma^{6} I \mathcal{E}$ & $668^{\prime} 9 z$ & $Z Z L^{\prime} 8$ & slə]sOH \\
\hline \multirow[t]{3}{*}{$S 9 L^{\prime} 8 Z Z^{6} I$} & $s \angle t^{\prime} 0 S Z$ & $6 S S^{6} I S$ & $699^{6}$ II & $t 0 t^{\circ} 0 \varepsilon t$ & tDI'9EZ & $\$ 96^{6} 6 I$ & $\downarrow z 6^{6} 9 z$ & $286^{\prime} \mathrm{C} 8 \mathrm{I}$ & $879^{\prime} 81$ & sôu!p!!ng uo!̣eonpg \\
\hline & & & & & & & & & & uo!̣eonpa jo Kns!̣u!W \\
\hline & & & & & & & & & & \\
\hline $76 \varsigma^{\prime} 9 I^{\prime} t$ & 0 & $I Z L^{6} 668$ & $\angle 06^{6} I S t$ & 0 & ISZ6It'I & SIZ'ZSL & 0 & I $t 8^{\circ} \mathrm{ZES}$ & $659^{\circ} 09$ & [ejolqns \\
\hline $89 z^{6} t 08^{6} z$ & 0 & SIt'L08 & $\angle 86^{6} 6 \mathrm{I}$ & 0 & $I S Z^{6} 6 I^{6} \mathrm{I}$ & $60 t^{6} 6 I$ & 0 & tIt'IES & $26 L^{6} 2 I$ & șooy's \\
\hline \multirow[t]{2}{*}{$9 Z E^{\prime} Z I \varepsilon^{6} I$} & 0 & $90 \varepsilon^{6} 86$ & $026^{6} I \varepsilon t$ & 0 & 0 & $908^{6} Z \varepsilon L$ & 0 & LZ†'I & $\angle 98^{\circ} \angle t$ & 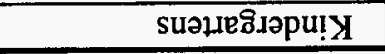 \\
\hline & & & & & & & & & & 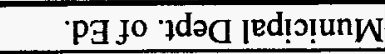 \\
\hline & & & & & & & & & & \\
\hline$\angle \varepsilon Z^{6} \varepsilon Z 0^{\circ} I$ & $98 I^{\prime} S L E$ & $98 \varsigma^{6} 0 L$ & ES96 SI & z9z'0zz & S66'0ZI & $10 \varepsilon^{6} 8 Z$ & $268^{\prime} 6 \mathrm{I}$ & $\angle \mathcal{E} L ' 0 L$ & \$8ऽ'I0I & [e]olqns \\
\hline$s \triangleright Z^{6} 26$ & $218^{6} \nabla z$ & $19 Z^{6} 9$ & $0 z t^{6} Z$ & $220^{\circ} 91$ & $S \mathcal{E} L^{\prime} 8$ & $681^{6} 6$ & $00 I^{\prime} \varepsilon$ & $\angle 8 t^{\circ} \mathrm{Z}$ & $6 I I^{6} 6 I$ & uǫ̣eдs!u!up \\
\hline$\angle 98^{6} \varepsilon 62$ & 9SL'EEI & 29t'IS & $9 \angle 8^{\circ} \mathrm{Z}$ & $\angle S L^{\prime} Z I$ & $988^{\circ} 0 S$ & SIL'9 & $00 \varepsilon^{6} I$ & $S L L 66$ & $0 \nabla \varepsilon^{6} \triangleright \tau$ & 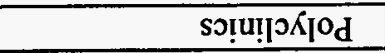 \\
\hline \multirow[t]{2}{*}{$S Z I^{\prime} \angle E 9$} & $819^{6} 912$ & $\varepsilon 98^{6}$ ZI & $\angle S E^{6} O I$ & $\varepsilon 87^{6} 161$ & $\nabla \angle \varepsilon^{6} 19$ & $\angle \mathcal{E} \nabla^{6} Z I$ & $26 b^{6} \varsigma I$ & $S \angle t^{6} 8 S$ & $920^{6} 85$ & s|el!dsoH \\
\hline & & & & & & & & & & ч)|еән jo ‘dəa jed!̣!unW \\
\hline \multirow{2}{*}{$\begin{array}{l}\text { sฮిu!pI!ng Jo } \\
\text { əoeds.I0o[! }\end{array}$} & sa!jutS t< & Sə!̣נ01S t- $\varepsilon$ & sə!̣01S \& & sə̣.10+S $b<$ & so!̣.107S t $-\varepsilon$ & Sə!̣01S \& $>$ & so!̣otS b< & sว!I.JO+S t-E & Sว!̣.101S \& & \multirow{3}{*}{ 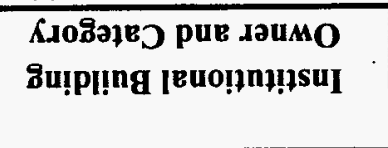 } \\
\hline & & $086 \mathrm{I}-750 \mathrm{~d}$ & & & $086 I-896 I$ & & & $896 I^{-\partial I d}$ & & \\
\hline \multicolumn{10}{|c|}{ 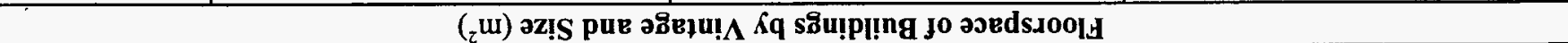 } & \\
\hline
\end{tabular}

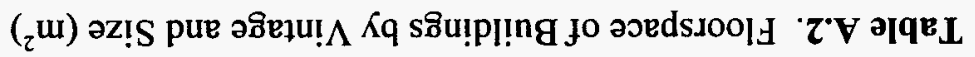


After the 1970s energy crisis in the West, former norms and standards were supplemented by instructions to compare the thickness of thermal insulation for selected building envelopes against the economically justified value, but the suggested method of calculation was not used in practice because of its over-complexity. As a result, in 1980 standard adjustment factors to norms on thermal resistance values were introduced. They were required to be taken into account as a minimum addition in calculations of economically justified heat insulation thickness. It is these adjustment factors (between 1.1 and 2.0) that appeared in construction designs beginning in 1980, and their official introduction is the reason for some improvement of heat insulating properties in building envelopes.

Beginning in 1994, new guidelines appeared in Ukraine for the calculation of thermal resistance of building envelopes, with requirements for thermal insulation 2 to 2.5 times higher than previously required. But decreased volume of construction in recent years, and financial problems in the introduction of new norms, led to the situation where by the end of 1996, the new norms had not yet substantially influenced heat consumption in existing buildings.

In addition to factors connected with the age of buildings, their thermal characteristics are influenced by the number of floors (stories). All institutional building types considered in this analysis have been divided into groups characterized by the number of stories. The breakdown by stories was carried out according to principles that make a basis for normative tables of energy-use intensity values, where these values are similar for different groups of buildings.

\section{A.1.3 Data Collection Methodology}

To accelerate the process of project preparation, data collection activities were focused primarily on the owners who will probably retain the authority over the structures subordinated to them, and who could issue executive orders to provide the data (city/district administrations, Municipal Department of Health, Municipal Department of Education, Ministry of Education, Municipal Department of Culture). Energy savings potential for corresponding building categories (healthcare, education, cultural) appeared to be the most promising.

Obtaining the information from the owners directly was preferred to "anonymous" data collection, because the project is the basis for a potential loan to the owner. Also, obtaining data from the central city registry of buildings (Bureau of Technical Information) would have taken much time and effort and could not produce a comprehensive picture. The registry keeps technical data on each individual building whose owner contacted the registry sometime in the past. Information is not computerized and is identified only by the address of each building. The current owner and purpose of the building is not in the registry and must be determined by contacting each owner directly. Also, information on the building stock is not complete, because not all buildings have been included in the registry.

The State Committee for Energy Conservation coordinated data collection activities and made initial contacts that were necessary for successful implementation of the work. The State Committee on Energy Conservation organized a meeting with representatives of important structures: the Ministry of Health, 
City Department of Education, Department of Health, Department of Finance, and the State Committee on Urban Development and Architecture. The objectives of the project were presented and cooperation in collecting necessary basic data was requested. Subsequent meetings were held within these organizations with representatives of subordinate district structures, and a questionnaire was explained and distributed among the participants.

Responses were obtained from Municipal Departments of Education who provided detailed data on pre-school and secondary education buildings (kindergartens, secondary schools, boarding schools, grammar schools, lyceums, youth clubs, etc.). The summary data are included in Tables A.1 and A.2.

In addition, a letter from the State Committee on Energy Conservation was forwarded to the Deputy Chairman of City State Administration. As mentioned above, there is not a central registry that could provide basic data on buildings in the form required for the project, so the city authorities gave instructions to a subordinate organization to provide help in collecting necessary data. This organization, Kievzhilspetsekspluatatsia, is responsible for servicing residential and nonresidential buildings in the city of Kyiv. It worked with district administrations to provide the required data on buildings. This work and the analysis of obtained data have shown that the process of privatization and renting the buildings is quickly changing the structure of ownership and financing. Pure municipal budget financing of office/ administration buildings is used only for buildings of city/district administrations (that is, 15 buildings) and a small number of other municipally owned buildings. The same is true for the ministries and other state structures. Pure budget financing is applicable almost exclusively to buildings where the headquarters of ministries, committees, etc. are located.

The information provided by district administrations is not always complete and must be supplemented by estimates and additional data. For example, some healthcare institutions, although owned and operated by the city, were not included in the submitted data. Information on healthcare buildings was obtained with the help of the Ministry of Health. There is a construction design institute that was formerly owned by the Ministry, but now has been transformed into the joint-stock company Medinvestproject. The Ministry recommended this company help in providing the required information. On a contract basis, Medinvestproject has prepared basic data on healthcare building stock and some additional information, such as indoor temperatures, for different buildings.

Another letter from the State Committee on Energy Conservation was forwarded to the Ministry of Education to request help in collecting data on their buildings (there are 19 institutions of higher education, such as universities, academies, and institutes; and 41 technical colleges). The Ministry prepared letters to subordinate institutions that provided the data.

Other state structures are too numerous to allow the collection of necessary information within the timeframe of the project. (There are 54 ministries and state committees, National Academy of Sciences, etc.). Moreover, many of their subordinate organizations, such as research and design institutes, have already become independent stock companies, and others are now in the process of making this change. 


\section{Appendix B}

\section{Baseline Energy Consumption}




\section{Appendix B}

\section{Baseline Energy Consumption}

This appendix presents the estimated baseline district heat energy consumption for each of the building types. Baseline energy consumption is estimated as the product of building floorspace and specific energy consumption per unit floorspace. The sources of floorspace data and specific energy consumption data are described in each subsection.

The baseline energy consumption estimates are referenced to a base year of 1995 . The baseline estimates are premised on the delivery of design heat levels to all buildings (i.e., to maintain design temperatures of $18^{\circ} \mathrm{C}$ ). In reality, in 1995 these design conditions were often not met due to adverse economic circumstances, which led to fuel supply constraints, and a capacity shortfall in the district heating system. Because this situation is expected to be temporary, the baseline estimates reflect normal service delivery. Sector level estimates are presented below.

\section{B.1 Institutional Buildings Sector}

Institutional building stock estimates and data collection are described in Appendix A. Because of difficulties in collecting data on the institutional buildings sector, these estimates are not comprehensive. Building stock estimates used in this analysis are also not comprehensive, but instead represent that fraction of the institutional buildings stock for which a large volume of buildings was subordinated to a single budget organization, and for which detailed building characteristic data were available. This stock was considered the most suitable for effective implementation of a buildings energy efficiency program.

Specific energy consumption estimates for the building types included in the assessment were derived from design data and other estimates. Design energy use in buildings can be divided into three components: space heating, water heating, and ventilation. Specific energy consumption estimates for space heating were derived from design data and were verified using simulation modeling of prototype buildings with Kyiv weather data. Because water heating energy use in institutional buildings is a function of factors such as occupancy, it was estimated generically on the basis of building function as a percentage of space heating energy use. Space and water heating energy intensity estimates are presented by building type in Table B.1.

Specific energy use for ventilation was not estimated. Mechanical ventilation is seldom used in Kyiv, and no ventilation energy conservation measures were considered, so no energy efficiency improvements are expected from ventilation changes. 
Table B.1. Specific Energy Intensity by Vintage Size (space heat and hot water)

\begin{tabular}{|c|c|c|c|c|c|c|c|c|c|c|}
\hline \multirow[b]{3}{*}{$\begin{array}{l}\text { Institutional Building } \\
\text { Owner and Category }\end{array}$} & \multicolumn{9}{|c|}{ Specific Energy Intensity by Vintage Size (Gcal/m $\left.{ }^{2}\right)$} & \multirow{3}{*}{$\begin{array}{l}\text { Percentage } \\
\text { of Energy } \\
\text { Use for } \\
\text { Space Heat }\end{array}$} \\
\hline & \multicolumn{3}{|c|}{ Pre-1958 } & \multicolumn{3}{|c|}{ 1958-1980 } & \multicolumn{3}{|c|}{ Post-1980 } & \\
\hline & $<3$ Stories & 3-4 Stories & $>4$ Stories & $<3$ Stories & 3-4 Stories & $>4$ Stories & $<3$ Stories & 3-4 Stories & $>4$ Stories & \\
\hline \multicolumn{11}{|l|}{ Municipal Dept. of Health } \\
\hline Hospitals & 0.20 & 0.17 & 0.17 & 0.30 & 0.30 & 0.28 & 0.30 & 0.23 & 0.23 & 60 \\
\hline Polyclinics & 0.16 & 0.16 & 0.16 & 0.24 & 0.24 & 0.20 & 0.24 & 0.20 & 0.19 & 75 \\
\hline Administration & $\overline{0.14}$ & 0.14 & 0.14 & 0.24 & 0.19 & 0.19 & 0.24 & 0.19 & 0.16 & 90 \\
\hline \multicolumn{11}{|l|}{ Municipal Dept. of Ed. } \\
\hline Kindergartens & 0.15 & 0.15 & & 0.27 & & & 0.23 & 0.23 & & 80 \\
\hline Schools & $\overline{0.12}$ & $\overline{0.12}$ & & 0.19 & 0.19 & & 0.16 & 0.16 & & 80 \\
\hline & & & & & & & & & & \\
\hline \multicolumn{11}{|l|}{ Ministry of Education } \\
\hline Education Buildings & 0.15 & 0.15 & 0.15 & 0.27 & 0.27 & 0.19 & 0.23 & 0.23 & $\overline{0.16}$ & 80 \\
\hline Hostels & 0.21 & 0.21 & 0.21 & 0.21 & 0.21 & 0.21 & & & 0.21 & 72 \\
\hline & & & & & & & & & & \\
\hline \multicolumn{11}{|l|}{ Municipal Dept. of Culture } \\
\hline Theaters & & 0.20 & 0.20 & 0.31 & & & & & 0.23 & 95 \\
\hline Art Galleries/Museums & 0.16 & 0.16 & 0.16 & & & 0.23 & 0.23 & 0.23 & & 95 \\
\hline
\end{tabular}


Baseline energy consumption can be estimated by building category by multiplying the specific energy intensity estimates in Table B.1 by the floorspace of each building category from Table A.2. Baseline energy consumption estimates are presented in Table B.2.

\section{B.2 Residential Building Sector}

Though the residential sector was not the primary focus of this study, a richer body of information exists with which to characterize the sector. Not only does this information complement the analysis of institutional buildings, but it also provides some basis for assessing the relative accuracy with which design estimates of building energy consumption conform with other estimates.

Estimates of floorspace for the residential building sector are found in a variety of references. Total residential floorspace estimates over the past 16 years are presented in Table B.3.

According to TACIS (1994), the vast majority of public buildings in Kyiv are connected to the district heating network. Hence, the residential stock supplied by district heating in 1995 is estimated at 48.1 million square meters. The residential building stock can also be broken out roughly by size as follows: 1 to 4 stories $-8.3 \%$; 5 to 9 stories $-67.9 \%$; 10 or more stories - $23.8 \%$ (Ekono 1996).

There are several sources of specific energy consumption estimates (energy use per unit floorspace); however, there appears to be little measured data. In addition, much of the available information on energy use in residential buildings is presented in terms of energy demand, not annual energy use. Some of the available estimates are discussed below.

Specific energy consumption estimates for residential buildings can be derived from design peak demands (SNiP 2.04.07-86) for existing buildings using estimates of the number of equivalent hours at full load. Design data, in watts per square meter, for standard efficiency buildings built prior to 1985 are presented in Table B.4 for outdoor design temperatures of $-20^{\circ} \mathrm{C}$ and $-25^{\circ} \mathrm{C}$, as well as interpolated values for $-22^{\circ} \mathrm{C}$, the design condition for Kyiv. ${ }^{(\mathrm{a})}$ The latter values are then converted to annual specific energy consumption using an assumed full load equivalent operating hours (FLEOH) of 2143. This value is derived from Kievenergo's method for estimating annual energy use for heating from demand values. Annual heat energy use is estimated from the equation:

$$
\mathrm{Qa}=\frac{24 \text { hours } / \text { day } * \mathrm{Qd} * \text { HDD }}{\Delta \mathrm{T}}
$$

(a) SNiP 2.04.07-86 also has standards for efficient buildings built prior to 1985 and for buildings built after 1985. Both of these building categories have lower energy consumption; however, the standard values used here are felt to more accurately represent the aging building stock. 
Table B.2. Baseline Annual Energy Consumption (space heat and hot water)

\begin{tabular}{|c|c|c|c|c|c|c|c|c|c|c|}
\hline \multirow[b]{3}{*}{$\begin{array}{l}\text { Institutional Building } \\
\text { Owner and Category }\end{array}$} & \multicolumn{10}{|c|}{ Baseline Energy Consumption of Buildings by Vintage and Size (Gcal) } \\
\hline & \multicolumn{3}{|c|}{ Pre-1958 } & \multicolumn{3}{|c|}{ 1958-1980 } & \multicolumn{3}{|c|}{ Post-1980 } & \multirow{2}{*}{\begin{tabular}{|c|} 
Energy \\
Consumption \\
(Gcal)
\end{tabular}} \\
\hline & $<3$ Stories & 3-4 Stories & $>4$ Stories & $<3$ Stories & 3-4 Stories & $>4$ Stories & $<3$ Stories & 3-4 Stories & $>4$ Stories & \\
\hline \multicolumn{11}{|l|}{ Municipal Dept. of Health } \\
\hline Hospitals & 11,783 & 9,778 & 2,591 & 3,763 & 18,572 & 53,368 & 3,134 & 3,022 & 50,886 & 156,896 \\
\hline Polyclinics & 3,954 & 1,588 & 211 & 1,626 & 12,318 & 2,601 & 696 & 10,491 & 25,136 & 58,621 \\
\hline Administration & 2,602 & 337 & 420 & 2,220 & 1,623 & 2,977 & 585 & 1,163 & 3,886 & 15,811 \\
\hline Subtotal & 18,338 & 11,703 & 3,221 & 7,608 & 32,513 & 58,945 & 4,415 & 14,676 & 79,908 & 231,328 \\
\hline \multirow{2}{*}{\multicolumn{11}{|c|}{ Municipal Dept. of Ed. }} \\
\hline & & & & & & & & & & \\
\hline Kindergartens & 7,290 & 217 & 0 & 199,132 & 0 & 0 & 99,313 & 22,604 & 0 & 328,556 \\
\hline Schools & 1,566 & 65,062 & 0 & 3,651 & 267,000 & 0 & 3,223 & 129,230 & 0 & 469,732 \\
\hline Subtotal & 8,856 & 65,279 & 0 & 202,783 & 267,000 & 0 & 102,536 & 151,833 & 0 & 798,287 \\
\hline & & & & & & & & & & \\
\hline \multicolumn{10}{|l|}{ Ministry of Education } & \\
\hline Education Buildings & 2,840 & 27,867 & 4,100 & 5,425 & 64,170 & 80,971 & 2,682 & 11,855 & 40,390 & 240,299 \\
\hline Hostels & 1,837 & 5,665 & 6,639 & 809 & 8,253 & 113,672 & 0 & 0 & 16,984 & 153,857 \\
\hline Subtotal & 4,677 & 33,532 & 10,739 & 6,234 & 72,422 & 194,643 & 2,682 & 11,855 & 57,373 & 394,157 \\
\hline \multicolumn{11}{|l|}{ Municipal Dept: of Culture } \\
\hline Theaters & 0 & 7,694 & 540 & 1,054 & 0 & 0 & 0 & 0 & 792 & 10,080 \\
\hline Art Galleries/Museums & 2,895 & 2,394 & 849 & 0 & 0 & 4,632 & 830 & 672 & 0 & 12,271 \\
\hline Subtotal & 2,895 & 10,088 & 1,389 & 1,054 & 0 & 4,632 & 830 & 672 & 792 & 22,351 \\
\hline & & & & & & & & & & \\
\hline Total & & $\cdot$ & & & & & & & & $1,446,123$ \\
\hline
\end{tabular}


Table B.3. Residential Buildings and Floorspace ${ }^{(a)}$

\begin{tabular}{|c|c|c|c|}
\hline Year & $\begin{array}{c}\text { Number of } \\
\text { Dwellings }\end{array}$ & Average Area $\left.\mathbf{( m}^{\mathbf{2}}\right)$ & $\begin{array}{c}\text { Floorspace } \\
\left(\text { million } \mathbf{~ m}^{\mathbf{2}}\right)\end{array}$ \\
\hline 1980 & 620,400 & 53.4 & 33.1 \\
\hline 1985 & 701,300 & 54.4 & 38.1 \\
\hline 1990 & $\mathbf{8 0 7 , 3 0 0}$ & 54.0 & 43.6 \\
\hline 1991 & (b) & (b) & 44.5 \\
\hline 1992 & (b) & (b) & 45.5 \\
\hline 1993 & (b) & (b) & 46.3 \\
\hline 1994 & (b) & (b) & 47.2 \\
\hline 1995 & (b) & (b) & 48.1 \\
\hline 1996 & $\mathbf{8 8 9 , 4 0 0}$ & 55.1 & 49.0 \\
\hline
\end{tabular}

(a) Estimates for 1980-1990 are from TACIS (1994). Total floorspace estimates from 19911996 are from Ekono Energy (1996). Number of dwellings in 1996 is from JTC (1996).

Average area in 1996 is estimated from the total floorspace and number of dwellings, and is consistent with the trend toward larger apartments.

(b) No data available.

Table B.4. Design Heat Demand and Annual Energy Use Estimate Assuming 2,143 Equivalent Hours at Full Load

\begin{tabular}{|c|c|c|c|c|c|}
\hline & \multicolumn{3}{|c|}{$\begin{array}{c}\text { Specific Energy Demand }\left(\mathrm{W} / \mathrm{m}^{2}\right) \\
\text { by Design Temperature }\end{array}$} & \multirow{2}{*}{$\begin{array}{c}\begin{array}{c}\text { Annual } \\
\text { Energy Use }\end{array} \\
\left(\mathrm{kWh} / \mathrm{m}^{2}\right)\end{array}$} & \multirow{2}{*}{$\begin{array}{c}\begin{array}{c}\text { Annual } \\
\text { Energy Use }\end{array} \\
\left(\text { Gcal } / \mathbf{m}^{2}\right)\end{array}$} \\
\hline Stories & $-20^{\circ} \mathrm{C}$ & $-22^{\circ} \mathrm{C}$ & $-25^{\circ} \mathrm{C}$ & & \\
\hline $1-2$ & 205 & 208 & 213 & 446 & .38 \\
\hline $3-4$ & 117 & 121 & 126 & 259 & .22 \\
\hline$\geq 5$ & 79 & 82 & 86 & 176 & .15 \\
\hline
\end{tabular}

where Qa is annual heat consumption in Gcal, Qd is design heat load in Gcal/hr, HDD is the number of heating degree days per year, and $\Delta \mathrm{T}$ is the difference between the design indoor temperature $\left(18^{\circ} \mathrm{C}\right)$ and the design outdoor temperature $\left(-22^{\circ} \mathrm{C}\right)$. HDD is calculated as the difference between the design indoor temperature $\left(18^{\circ} \mathrm{C}\right)$ and the average outdoor temperature during the heating season $\left(-1.1^{\circ} \mathrm{C}\right)$ times the length of the heating season (187 days), or $3572 \mathrm{HDD}$. The value of FLEOH can be derived from this equation as:

$$
\mathrm{FLEOH}=\frac{24 \text { hours } / \text { day } * \mathrm{HDD}}{\Delta \mathrm{T}}=\frac{24 * 3,572}{40}=2,143 \text { hours/year }
$$


Based on these design data, it is clear that specific energy use is highly dependent on the number of building stories. Average specific energy use can be estimated by weighting the estimates in Table B.4 by the size distribution data cited above. The resulting estimate for average annual specific energy use is $0.17 \mathrm{Gcal} / \mathrm{m}^{2}$.

Several estimates of average specific energy consumption are found in the literature. One study cites design annual specific energy consumption in Kyiv at $155 \mathrm{kwh} / \mathrm{m}^{2}\left(0.13 \mathrm{Gcal} / \mathrm{m}^{2}\right)$ (based on net area), and estimates actual consumption at $250 \mathrm{kwh} / \mathrm{m}^{2}\left(0.22 \mathrm{Gcal} / \mathrm{m}^{2}\right)$, or about $60 \%$ higher than the design values (IEA 1996). This value may include heat use for hot water.

In another study, specific energy intensity estimates for Kyiv were derived from a combination of measurement and modeling approaches (TACIS 1994). The simulation model used in this assessment was calibrated using 4 months of metered data on two high-rise apartment buildings. Based on this work, the specific energy intensity for heating over the entire season was estimated to range from 0.11 to $0.28 \mathrm{Mwh} / \mathrm{m}^{2}\left(0.09\right.$ to $\left.0.24 \mathrm{Gcal} / \mathrm{m}^{2}\right)$.

More recently, residential specific energy consumption was estimated for buildings supplied by Kievenergo based on annual fuel use, assumptions about the efficiency of the heat transmission and distribution network ( $20 \%$ losses), and the fraction of Kyiv residential floorspace served by Kievenergo (56\%) (Ekono Energy 1996). These estimates are given in terms of energy use per unit volume. Using the energy use and floorspace data, these values can be recalculated on a per-unit floorspace basis, yielding an estimate of actual average consumption in 1995 of $191 \mathrm{kwh} / \mathrm{m}^{2}\left(0.16 \mathrm{Gcal} / \mathrm{m}^{2}\right)$. Because of fuel and capacity constraints in 1995 , this fuel consumption is estimated to be far below actual consumption had there been no such constraints. In this case, specific energy use is estimated at $260 \mathrm{kwh} / \mathrm{m}^{2}$ $\left(0.22 \mathrm{Gcal} / \mathrm{m}^{2}\right)$, or about $36 \%$ higher than actual heat consumption in 1995 .

These results are based on estimates that $56 \%$ of Kievenergo heat is supplied to residential customers. Kievenergo data found in Joseph Technology Corporation (JTC 1996) suggest that the supply to residential buildings in 1995 was significantly higher, or about $69 \%$ (the sum of residential and construction cooperative housing) of the total. These data are presented in Table B.5. It is not clear what the source of this discrepancy is; however, if the higher value is used, the resulting estimates of specific heat consumption would be $0.23 \mathrm{Gcal} / \mathrm{m}^{2}$ in 1995 with energy supply constraints, and about $0.30 \mathrm{Gcal} / \mathrm{m}^{2}$ without energy supply constraints. 
Table B.5. Kievenergo 1995 Actual District Heat Supply (JTC 1996)

\begin{tabular}{|l|c|c|}
\hline \multicolumn{1}{|c|}{ Type of Customer } & $\begin{array}{c}\text { Heat Supply } \\
(\mathbf{1 0 0 0} \mathbf{~ G c a l )}\end{array}$ & $\begin{array}{c}\text { Percentage of Total } \\
\text { Heat Supply }\end{array}$ \\
\hline Industrial & 4,188 & 31.1 \\
\hline Communal Housing & 13 & 0.1 \\
\hline Residential Housing & 7,669 & 57.0 \\
\hline Construction Coop. Housing & 1,560 & 11.6 \\
\hline Green Houses & 22 & 0.2 \\
\hline Garage Construction Coop. & 14 & 0.1 \\
\hline Wholesale Customers and Dist. & -- & -- \\
\hline Total & 13,454 & 100 \\
\hline $\begin{array}{l}\text { (a) Total heat supply is not exactly equal to the sum of the components in the } \\
\text { reference. The estimates given here are as cited in Joseph Technology Corporation } \\
\text { (JTC 1996). }\end{array}$ & \\
\hline
\end{tabular}

The Ekono Energy (1996) estimates include heat use for hot water. Because of the lack of hot water metering in Kyiv, there are few data on hot water consumption in residential buildings. Estimates of hot water consumption range from about $70 \%$ of the design consumption of 105 liters/person/day (Ekono Energy 1996), to more than 300 liters/person/day (IEA 1996). Direct estimates of heat energy use for hot water can be made from Kievenergo data found in Joseph Technology Corporation (JTC 1996). In this report, Kievenergo estimates of thermal energy supply for 1996 are given by quarter. Assuming that third quarter (July to September) thermal energy supply is almost exclusively for hot water, the consumption of heat for hot water can be estimated for the entire year. Based on these data, hot water heat consumption is estimated at $0.06 \mathrm{Gcal} / \mathrm{m}^{2}$, compared to space heat energy.use of $0.16 \mathrm{Gcal} / \mathrm{m}^{2}$, or total heat energy use of $0.22 \mathrm{Gcal} / \mathrm{m}^{2}$. Hence, hot water energy use amounts to $28 \%$ of total energy consumption.

Based on the above data, residential specific energy consumption for normal heat supply conditions is estimated based on design heat loads for space heating, or a floorspace weighted average value of $0.17 \mathrm{Gcal} / \mathrm{m}^{2}$. Heat energy consumption for hot water is estimated as $28 \%$ of the total heat consumption, or $0.07 \mathrm{Gcal} / \mathrm{m}^{2}$, for a total heat consumption of $0.24 \mathrm{Gcal} / \mathrm{m}^{2}$. These appear to be conservative estimates for total actual heat consumption in periods of normal heat supply.

Baseline energy consumption is estimated as the product of specific energy consumption and estimated floorspace for each of the building types. The estimated annual residential energy consumption is presented in Table B.6 for each of the four building types. 
Table B.6. Residential Building Baseline Energy Consumption Estimates

\begin{tabular}{|c|c|c|}
\hline Building Type & $\begin{array}{l}\text { Floorspace } \\
\left(\text { million } \mathbf{m}^{2}\right)\end{array}$ & $\begin{array}{l}\text { Annual Energy Use } \\
\text { (thousand Gcal) }\end{array}$ \\
\hline 2-story & 4.8 & 2,569 \\
\hline 5-story & 16.8 & 3,545 \\
\hline 9-story & 16.8 & 3,545 \\
\hline 14-story & 9.6 & 2,026 \\
\hline Total & 48.1 & 11,685 \\
\hline
\end{tabular}




\section{Appendix C}

\section{Efficiency Measure Cost Data}




\section{Appendix C}

\section{Efficiency Measure Cost Data}

This appendix provides the estimated quantity of materials and installed costs of the efficiency measures, by building type, for the prototypes used for the institutional and residential buildings sectors. Material costs and quantities are also presented for average buildings for the institutional sector. ${ }^{\text {(a) }}$ The quantities of material for the institutional buildings were estimated based on analysis of specific buildings in Kyiv, or based on design calculations. Per unit labor requirements were based on professional judgment and were drawn from analysis conducted for the Enterprise Housing Divestiture Project (EHDP) Staff Appraisal Report (SAR) conducted for the World Bank in Russia (World Bank 1996). The quantities of material, equipment, and labor for the residential sector are also drawn primarily from the EHDP SAR. Cost estimates were derived from a variety of sources, including direct quotes from both foreign and domestic equipment suppliers, as well as from other building efficiency assessments in Eastern Europe (PNNL 1995, 1996; World Bank 1996). The ratio of Ukrainian labor to foreign labor to install the measures ranges from 5:1 to 8:1 depending on the measure. Ukrainian labor rates are estimated at $\$ 5.00$ per hour, foreign labor rates at $\$ 55.00$ per hour.

\section{C.1 Institutional Buildings Sector}

The institutional buildings sector is modeled using nine categories of buildings: hospitals, polyclinics, and hospital administration buildings; kindergartens, schools, higher education buildings and student hostels; and theaters and art galleries/museums. Within these broad categories, the building prototypes are further subdivided by age and size (in this case number of stories). The age classes used are buildings built before 1958, those built from 1958 to 1980, and those built after 1980. These age classes roughly delineate architectural practices that impact thermal performance, and are described further in Appendix A. The size classes were chosen to match the existing building stock and include 1 to 2 story buildings, 3 to 4 story buildings, and buildings greater than 4 stories, except for student hostels, which were modeled using residential prototypes ( 5 and 9 stories).

Not all building categories include examples of each of the building subcategories. For example, there are no kindergartens or schools greater than 4 stories. Also, some building categories have very little floorspace in a particular subcategory, hence these subcategories were not included as a prototype. In total, 33 prototypes are used to model the institutional buildings sector. These are presented in Table C.1.

(a) For a discussion of the conversion from prototype to average buildings, see Section 3.2.1. 
Table C.1. Institutional Building Sector Prototypes

\begin{tabular}{|c|c|c|}
\hline Building Type & Building Subtypes & $\begin{array}{c}\text { Number } \\
\text { Prototypes }\end{array}$ \\
\hline \multirow[t]{3}{*}{ Hospitals } & 1 to 2 stories before 1958 & 1 \\
\hline & 2 to 4 stories, $1958-1980$ and after 1980 & 2 \\
\hline & $>4$ stories, $1958-1980$ and after 1980 & 2 \\
\hline \multirow[t]{3}{*}{ Polyclinics } & 1 to 2 stories before 1958 & 1 \\
\hline & 3 to 4 stories, $1958-1980$ and after 1980 & 2 \\
\hline & $>4$ stories after 1980 & 1 \\
\hline \multirow[t]{2}{*}{ Hospital Administration } & 1 to 2 stories before 1958 and $1958-1980$ & 2 \\
\hline & $>4$ stories, $1958-1980$ and after 1980 & 2 \\
\hline Kindergartens & 1 to 2 stories, all age groups & 3 \\
\hline Schools & 3 to 4 stories, all age groups & 3 \\
\hline \multirow[t]{2}{*}{ Higher Education } & 3 to 4 stories, all age groups & 3 \\
\hline & $>4$ stories, $1958-1980$ and after 1980 & 2 \\
\hline Hostels & 5 stories and 9 stories & 2 \\
\hline \multirow[t]{3}{*}{ Theaters } & 1 to 2 stories, $1958-1980$ & 1 \\
\hline & 3 to 4 stories, before 1958 & 1 \\
\hline & $>4$ stories, after 1980 & 1 \\
\hline \multirow[t]{3}{*}{ Art Galleries/Museums } & 1 to 2 stories, before 1958 and after 1980 & 2 \\
\hline & 3 to 4 stories, before 1958 & 1 \\
\hline & $>4$ stories, after 1980 & 1 \\
\hline Total & & 33 \\
\hline
\end{tabular}

Table C. 2 provides the estimated installed cost of the 20 measures considered applicable to institutional buildings in Kyiv. The costs are developed to show the quantity of labor, cost of labor, and the installed cost of the measure. Table C.3 illustrates the penetration of each efficiency measure in the general building categories. Not all retrofit options apply to each building prototype. For example, ceiling fans are only applicable in buildings with high ceilings, such as cultural buildings. In addition, many retrofit measures are not found to be cost-effective in some or all building types. Within building categories the number of cost-effective efficiency measures also varies by building vintage and size, though this variation is small compared to the differences between building categories.

Table C. 4 presents the total material requirements and total installed costs for each of the efficiency measures and each of the 33 institutional building prototypes, as well as the total costs for each building. In Table C.5, these values are presented per average building for the Kyiv building stock. The total per building costs in Table C.5 match the per building investment requirements in Appendix E, Table E.1. 
Table C.2. Measure Cost Data

\begin{tabular}{|c|c|c|c|c|c|c|c|c|}
\hline \multirow{3}{*}{$\begin{array}{l}\text { Measure } \\
\text { Category/Description }\end{array}$} & \multicolumn{2}{|c|}{ Equipment } & \multicolumn{5}{|c|}{ Labor } & \multirow{3}{*}{$\begin{array}{l}\text { Total Cost } \\
\text { Per Unit } \\
\text { Installed (\$) }\end{array}$} \\
\hline & \multirow[b]{2}{*}{ Unit } & \multirow{2}{*}{\begin{tabular}{|c|} 
Per Unit \\
Cost $(\$)$
\end{tabular}} & \multicolumn{2}{|c|}{ Hours/Unit } & \multirow{2}{*}{\begin{tabular}{|c|} 
Ratio \\
Dom./For.
\end{tabular}} & \multicolumn{2}{|c|}{ Cost/Unit (\$) ${ }^{(a)}$} & \\
\hline & & & Domestic & Foreign & & Domestic & Foreign & \\
\hline \multicolumn{9}{|l|}{ Envelope } \\
\hline Exterior Side Walls & $\mathrm{m}^{2}$ & 10.50 & 0.92 & 0.18 & 5 & 4.58 & 10.08 & 25.17 \\
\hline Roof Insulation & $\mathrm{m}^{2}$ & 23.41 & 0.28 & 0.06 & 5 & 1.42 & 3.12 & 27.94 \\
\hline Attic Insulation & $\mathrm{m}^{2}$ & 6.45 & 0.31 & 0.06 & 5 & 1.54 & 3.39 & 11.38 \\
\hline Basement Floor Insulation & $\overline{m^{2}}$ & 6.00 & 0.10 & 0.02 & 5 & 0.50 & 1.10 & 7.59 \\
\hline Weatherstrip Windows and Doors & $\mathrm{m}$ & 0.90 & 0.09 & 0.01 & 8 & 0.44 & 0.61 & 1.96 \\
\hline Storm Windows and Weatherstripping & each & 60.00 & 4.17 & 0.83 & 5 & 20.83 & 45.83 & 127 \\
\hline High Perf. Glass and Weatherstripping & $\mathrm{m}^{2}$ & 24.50 & 1.17 & 0.23 & 5 & 5.83 & 12.83 & 43.17 \\
\hline Third Window Pane & $\mathrm{m}^{2}$ & 13.00 & 1.11 & 0.22 & 5 & 5.53 & 12.16 & 30.68 \\
\hline Radiator Heat Reflectors & each & 5.16 & 0.33 & 0.04 & 8 & 1.64 & 2.26 & 9.07 \\
\hline \multicolumn{9}{|l|}{ Air Handling } \\
\hline Ceiling Fans & per fan & 163 & 2.50 & 0.50 & 5 & 12.50 & 27.50 & 203 \\
\hline Ventilation Heat Recovery & $\mathrm{m}^{3} / \mathrm{hr}$ & 2.20 & 0.03 & 0.01 & 5 & 0.13 & 0.28 & 2.60 \\
\hline \multicolumn{9}{|l|}{ Domestic Water Heating } \\
\hline Hot Water Heat Exchanger (weighted average) & bldg. & 1,748 & 27.62 & 5.52 & 5 & 138 & 304 & 2,190 \\
\hline Storage Water Heater & bldg. & 2,480 & 41.67 & 8.33 & 5 & 208 & 458 & 3,147 \\
\hline Low-Flow Showerheads & each & 7.69 & 0.22 & 0.03 & 8 & 1.11 & 1.53 & 10.32 \\
\hline Faucet Aerators & each & 3.00 & 0.13 & 0.02 & 8 & 0.67 & 0.92 & 4.58 \\
\hline Apartment-Level Meters & each & 95 & 2.50 & 0.50 & 5 & 12.50 & 27.50 & 135 \\
\hline Insulate Pipes & $\mathrm{m}$ & 3.30 & 0.17 & 0.03 & 5 & 0.85 & 1.87 & 6.02 \\
\hline \multicolumn{9}{|l|}{ Heating System } \\
\hline Building-Level Meters & each & 2,800 & 10.00 & 2.00 & $\overline{5}$ & 50 & 110 & 2,960 \\
\hline Retrofit Heating System (weighted average) & bldg. & 7,198 & 114 & 22.75 & 5 & 569 & 1,251 & 9,018 \\
\hline Radiator Balancing Valves & each & 14.25 & 0.83 & 0.17 & 5 & 4.17 & 9.17 & 27.58 \\
\hline
\end{tabular}


Table C.3. Penetration of Efficiency Measures by Building Type

\begin{tabular}{|c|c|c|c|c|c|c|c|c|c|}
\hline \multirow{2}{*}{$\begin{array}{l}\text { Institutional } \\
\text { Building Owner } \\
\text { and Category }\end{array}$} & \multirow{2}{*}{\begin{tabular}{|l|} 
Envelope \\
Radiator \\
Reflector \\
\end{tabular}} & \multirow{2}{*}{\begin{tabular}{|c|} 
Weatherstrip \\
$\begin{array}{c}\text { Windows } \\
\text { Doors }\end{array}$ \\
\end{tabular}} & \multirow{2}{*}{$\begin{array}{c}\text { Air Handling } \\
\text { Ceiling } \\
\text { Fans }\end{array}$} & \multicolumn{3}{|c|}{ Domestic Water Heating } & \multicolumn{3}{|c|}{ Heating System } \\
\hline & & & & $\begin{array}{c}\text { Low-Flow } \\
\text { Shower }\end{array}$ & $\begin{array}{c}\text { Faucet Flow } \\
\text { Restrictors }\end{array}$ & $\begin{array}{l}\text { Heat } \\
\text { Exch. }\end{array}$ & $\begin{array}{c}\text { Building } \\
\text { Meters }\end{array}$ & $\begin{array}{c}\text { Riser Bal. } \\
\text { Valves }\end{array}$ & $\begin{array}{l}\text { System } \\
\text { Retrofit }\end{array}$ \\
\hline \multicolumn{10}{|l|}{ Municipal Dept. of Health } \\
\hline Hospitals & $x$ & $x$ & & $x$ & $x$ & $x$ & $x$ & $\mathrm{x}$ & $x$ \\
\hline Polyclinics & $x$ & $x$ & & & $\mathbf{x}$ & $\mathrm{x}$ & $x$ & $x$ & $\mathbf{x}$ \\
\hline Administration & $x$ & $\bar{x}$ & & & & $x$ & $x$ & $\mathrm{x}$ & $\mathbf{x}$ \\
\hline \multicolumn{9}{|l|}{ Municipal Dept. of Ed. } & \\
\hline Kindergartens & $\mathrm{x}$ & $\bar{x}$ & & & $\mathbf{x}$ & $\mathrm{x}$ & $\bar{x}$ & $\bar{x}$ & $\mathbf{x}$ \\
\hline Schools & $\mathrm{x}$ & $\mathrm{x}$ & & & $\mathbf{x}$ & $\mathrm{x}$ & $\mathbf{x}$ & $\mathbf{x}$ & $\mathbf{x}$ \\
\hline \multirow{2}{*}{\multicolumn{10}{|c|}{ Ministry of Education }} \\
\hline & & & & & & & & & \\
\hline Education Buildings & $\mathrm{x}$ & $\mathbf{x}$ & & $\mathbf{x}$ & $\mathrm{x}$ & $\mathrm{x}$ & $\mathbf{x}$ & $\mathbf{x}$ & $\mathbf{x}$ \\
\hline Hostels & $x$ & $\mathrm{x}$ & & $\mathbf{x}$ & $\mathrm{x}$ & $x$ & $x$ & $\mathbf{x}$ & $x$ \\
\hline \multicolumn{10}{|l|}{ Municipal Dept. of Culture } \\
\hline Theaters & & $\mathrm{x}$ & $\mathrm{x}$ & & & $\mathrm{x}$ & $\mathbf{x}$ & $\mathbf{x}$ & $\bar{x}$ \\
\hline Art Galleries/Museums & & $\mathrm{x}$ & $\mathrm{x}$ & & & $\mathrm{x}$ & $\mathbf{x}$ & $\mathbf{x}$ & $\bar{x}$ \\
\hline
\end{tabular}


Table C.4. Institutional Prototype Building Material Requirements and Costs

\begin{tabular}{|c|c|c|c|c|c|c|c|c|c|c|c|c|c|c|c|c|c|}
\hline \multirow{2}{*}{$\begin{array}{c}\text { Institutional Building } \\
\text { Prototype }\end{array}$} & \multicolumn{2}{|c|}{$\begin{array}{l}\text { Radiator } \\
\text { Reflector }\end{array}$} & \multicolumn{2}{|c|}{$\begin{array}{l}\text { Weather- } \\
\text { stripping }\end{array}$} & \multicolumn{2}{|c|}{$\begin{array}{c}\text { Ceiling } \\
\text { Fans }\end{array}$} & \multicolumn{2}{|c|}{$\begin{array}{l}\text { Heating } \\
\text { Syst. Ret. }\end{array}$} & \multicolumn{2}{|c|}{$\begin{array}{c}\text { Shower- } \\
\text { heads }\end{array}$} & \multicolumn{2}{|c|}{ Aerators } & \multicolumn{2}{|c|}{$\begin{array}{c}\text { Heat } \\
\text { Meters }\end{array}$} & \multicolumn{2}{|c|}{$\begin{array}{c}\text { DHW } \\
\text { Heat Ex. }\end{array}$} & \multirow{2}{*}{$\begin{array}{l}\text { Total } \\
\text { Cost (\$) }\end{array}$} \\
\hline & Each & Cost (\$) & Meters & Cost (\$) & Each & Cost (\$) & BIdg(a) & Cost (\$) & Each & Cost (S & Each & Cost (S) & Each & Cost (\$) & Each(a) & Cost (\$) & \\
\hline Small Hospital, before 1957 & 97 & 879 & 731 & 1,430 & 0 & 0 & 0.94 & 8,457 & 16 & 165 & 22 & 99 & 2 & 5,005 & 2.06 & 4,510 & 16,035 \\
\hline Medium Hospital, before 1957 & 194 & 1,759 & 1,463 & 2,860 & 0 & 0 & 1.42 & 12,842 & 32 & 330 & 43 & 199 & 2 & 5,939 & 3.13 & 6,849 & 23,928 \\
\hline Medium Hospital, 1958 to 1980 & 194 & 1,759 & 1,463 & 2,860 & 0 & 0 & 1.42 & 12,842 & 32 & 330 & 43 & 199 & 2 & 6,229 & 3.13 & 6,849 & 24,218 \\
\hline Large Hospital, 1958 to 1980 & 291 & 2,638 & 2,194 & 4,290 & 0 & 0 & 1.67 & 15,034 & 48 & 496 & 65 & 298 & 1 & 3,330 & 3.66 & 8,018 & 26,087 \\
\hline Large Hospital, after 1980 & 291 & 2,638 & 2,194 & 4,290 & 0 & 0 & 1.67 & 15,034 & 48 & 496 & 65 & 298 & 1 & 1,945 & 3.66 & 8,018 & 24,702 \\
\hline Small Polyclinic, before 1957 & 97 & 879 & 731 & 1,430 & 0 & 0 & 0.93 & 8,404 & 16 & 0 & 22 & 99 & 2 & 6,800 & 1.02 & 2,241 & 17,612 \\
\hline Medium Polyclinic, 1958 to 1980 & 194 & 1,759 & 1,463 & 2,860 & 0 & 0 & 1.29 & 11,652 & 32 & 0 & 43 & 199 & 3 & 8,435 & 1.42 & 3,107 & 24,904 \\
\hline Medium Polyclinic, after 1980 & 194 & 1,759 & 1,463 & 2,860 & 0 & 0 & 1.29 & 11,652 & 32 & 0 & 43 & 199 & 1 & 3,751 & 1.42 & 3,107 & 20,220 \\
\hline Large Polyclinic, after 1980 & 291 & 2,638 & 2,194 & 4,290 & 0 & 0 & 1.84 & 16,632 & 48 & 0 & 65 & 298 & 1 & 3,655 & 2.03 & 4,435 & 27,513 \\
\hline Small Hosp. Admin., before 1957 & 97 & 879 & 731 & 1,430 & 0 & 0 & 0.93 & 8,404 & 16 & 0 & 22 & 0 & 4 & 10,565 & 0.34 & 747 & 21,278 \\
\hline Small Hosp.Admin., 1958 to 1980 & 97 & 879 & 731 & 1,430 & 0 & 0 & 0.93 & 8,404 & 16 & 0 & 22 & 0 & 3 & 9,762 & 0.34 & 747 & 20,475 \\
\hline Large Hosp. Admin., 1958 to 1980 & 291 & 2,638 & 2,194 & 4,290 & 0 & 0 & 1.84 & 16,632 & 48 & 0 & 65 & 0 & 3 & 8,223 & 0.68 & 1,478 & 31,784 \\
\hline Large Hosp. Admin., after 1980 & 291 & 2,638 & 2,194 & 4,290 & 0 & 0 & 1.84 & 16,632 & 48 & 0 & 65 & 0 & 1 & 3,427 & 0.68 & 1,478 & 26,987 \\
\hline Kindergartens, before 1957 & 140 & 1,269 & 2,056 & 4,021 & 0 & 0 & 1.51 & 13,578 & 10 & 0 & 25 & 115 & 5 & 14,230 & 1.24 & 2,716 & 33,213 \\
\hline Kindergartens, 1958 to 1980 & 140 & 1,269 & 2,056 & 4,021 & 0 & 0 & 1.51 & 13,578 & 10 & 0 & 25 & 115 & 3 & 8,158 & 1.24 & 2,716 & 27,141 \\
\hline Kindergartens, after 1980 & 140 & 1,269 & 2,056 & 4,021 & 0 & 0 & 1.51 & 13,578 & 10 & 0 & 25 & 115 & 2 & 5,442 & 1.24 & 2,716 & 24,425 \\
\hline Schools, before 1957 & 280 & 2,538 & 4,113 & 8,043 & 0 & 요 & 2.04 & 18,422 & 20 & 0 & 50 & 229 & 2 & 5,977 & 1.68 & 3,684 & 35,210 \\
\hline Schools, 1958 to 1980 & 280 & 2,538 & 4,113 & 8,043 & 0 & 0 & 2.04 & 18,422 & 20 & 0 & 50 & 229 & 1 & 4,344 & 1.68 & 3,684 & 33,577 \\
\hline Schools, after 1980 & 280 & 2,538 & 4,113 & 8,043 & 0 & 0 & 2.04 & 18,422 & 20 & 0 & 50 & 229 & 1 & 3,533 & 1.68 & 3,684 & 32,766 \\
\hline Med. Higher Ed., before 1958 & 140 & 1,269 & 2,056 & 4,021 & 0 & 0 & 1.51 & 13,578 & 20 & 0 & 25 & 115 & 1 & 2,860 & 1.24 & 2,716 & 21,843 \\
\hline Med. Higher Ed., 1958 to 1980 & 140 & 1,269 & 2,056 & 4,021 & 0 & 0 & 1.51 & 13,578 & 10 & 0 & 25 & 115 & 1 & 3,237 & 1.24 & 2,716 & 22,220 \\
\hline Med. Higher Ed., after 1980 & 140 & 1,269 & 2,056 & 4,021 & 0 & 0 & 1.51 & 13,578 & 10 & 0 & 25 & 115 & 1 & 2,774 & 1.24 & 2,716 & 21,756 \\
\hline Large Higher Ed., 1958 to 1980 & 280 & 2,538 & 4,113 & 8,043 & 0 & 0 & 2.07 & 18,653 & 20 & 0 & 50 & 229 & 1 & 3,556 & 1.70 & 3,731 & 33,020 \\
\hline Large Higher Ed., after 1980 & 280 & 2,538 & 4,113 & 8,043 & 0 & 0 & 2.07 & 18,653 & 20 & 0 & 50 & 229 & 1 & 2,801 & 1.70 & 3,731 & 32,265 \\
\hline Medium Hostels & 300 & 2,720 & 0 & 0 & 0 & 0 & 1.37 & 12,388 & 90 & 929 & 180 & 825 & 1 & 2,744 & 1.76 & 3,854 & 23,460 \\
\hline Large Hostels & 405 & 3,672 & 0 & 0 & 0 & 0 & 1.42 & 12,768 & 108 & 1,115 & 216 & 990 & 1 & 3,244 & 1.81 & 3,972 & 25,760 \\
\hline Small Theaters & 0 & 0 & 1,554 & \begin{tabular}{l|}
3,039 \\
\end{tabular} & 14 & 2,842 & 1.60 & 14,405 & 0 & 0 & 0 & 0 & 3 & 7,821 & 0.28 & 607 & 28,108 \\
\hline Medium Theaters & 0 & 0 & 1,554 & 3,039 & 14 & 2,842 & 1.60 & 14,405 & 0 & 0 & 0 & 0 & 1 & 2,952 & 0.28 & 607 & 23,238 \\
\hline Large Theaters & 0 & 0 & 1,554 & 3,039 & 14 & 2,842 & 1.60 & 14,405 & 0 & 0 & 0 & 0 & 1 & 3,948 & 0.28 & 607 & 24,235 \\
\hline Small Art Galleries/Museums, before 1958 & 0 & 0 & 2,196 & 4,294 & 15 & 3,045 & 1.66 & 14,977 & 0 & 0 & 0 & 0 & 5 & 13,482 & 0.29 & 631 & 35,798 \\
\hline Small Art Galleries/Museums, after 1980 & 0 & 0 & 2,196 & 4,294 & 15 & 3,045 & 1.66 & 14,977 & 0 & 0 & 0 & 0 & 3 & 8,968 & 0.29 & 631 & 31,285 \\
\hline Medium Art Galleries/Museums & 0 & 0 & 2,196 & 4,294 & 15 & 3,045 & 1.66 & 14,977 & 0 & 0 & 0 & 0 & 2 & 6,371 & 0.29 & 631 & 28,688 \\
\hline Large Art Galleries/Museums & 0 & .0 & 2,196 & 4,294 & 15 & 3,045 & 1.66 & 14,977 & 0 & 0 & $\overline{0}$ & 0 & $\overline{2}$ & 727 & 0.29 & 631 & 23,044 \\
\hline
\end{tabular}


Table C.5. Average Institutional Building Requirements and Costs

\begin{tabular}{|c|c|c|c|c|c|c|c|c|c|c|c|c|c|c|c|c|c|}
\hline \multirow[b]{2}{*}{ Institutional Building Type } & \multirow{2}{*}{\multicolumn{2}{|c|}{\begin{tabular}{|c|c|} 
Radiator \\
Reflectors \\
Each
\end{tabular}}} & \multicolumn{2}{|c|}{$\begin{array}{l}\text { Weather- } \\
\text { stripping }\end{array}$} & \multicolumn{2}{|c|}{$\begin{array}{c}\text { Ceiling } \\
\text { Fans }\end{array}$} & \multicolumn{2}{|c|}{$\begin{array}{l}\text { Heating } \\
\text { Syst. Ret. }\end{array}$} & \multirow{2}{*}{\multicolumn{2}{|c|}{\begin{tabular}{|c|}
$\begin{array}{c}\text { Shower- } \\
\text { heads }\end{array}$ \\
Each Cost (S
\end{tabular}}} & \multirow{2}{*}{\multicolumn{2}{|c|}{  }} & \multirow{2}{*}{\multicolumn{2}{|c|}{$\begin{array}{c}\begin{array}{c}\text { Heat } \\
\text { Meters }\end{array} \\
\text { Each } \mid \text { Cost (\$ }\end{array}$}} & \multirow{2}{*}{\multicolumn{2}{|c|}{$\begin{array}{c}\text { DHW } \\
\text { Heat Ex. }\end{array}$}} & \multirow{2}{*}{$\frac{\text { Total }}{\text { Cost (\$) }}$} \\
\hline & & & Meters & Cost (S) & Each & Cost (S) & Bldg & Cost (\$) & & & & & & & & & \\
\hline Small Hospital, before 1957 & 57 & 520 & 432 & 846 & 0 & & 0.55 & 5,001 & 9 & 98 & 13 & 59 & 1.00 & 2960 & 122 & 2,667 & 12,151 \\
\hline Medium Hospital, before 1957 & 91 & 826 & 687 & 1,344 & 0 & 0 & 0.67 & 6,033 & 15 & 155 & 20 & 93 & 0.94 & 2,790 & 0.68 & 3,218 & $\frac{1,1740}{14,460}$ \\
\hline Medium Hospital, 1958 to 1980 & 113 & $\frac{0.025}{1,025}$ & 852 & 1,667 & 0 & 0 & 0.83 & 7,484 & 19 & 193 & $\frac{25}{25}$ & $\frac{93}{116}$ & \begin{tabular}{|l|}
.943 \\
1.23 \\
\end{tabular} & $\begin{array}{ll}, 3,930 \\
3030\end{array}$ & $\frac{0.00}{1.82}$ & $\frac{3,210}{3,991}$ & $\frac{14,400}{18,105}$ \\
\hline Large Hospital, 1958 to 1980 & 259 & 2,345 & 1,950 & 3,814 & 0 & 0 & 1.48 & 13,363 & 43 & 441 & 58 & 265 & 1.00 & 2,960 & 3.26 & 7,127 & 30,314 \\
\hline Large Hospital, after 1980 & 462 & 4,188 & 3 & 6,812 & 0 & 0 & 2.65 & 23,869 & 76 & 787 & 103 & 473 & \begin{tabular}{|l|}
1.04 \\
\end{tabular} & 3,088 & 5.81 & 12,730 & 51,948 \\
\hline Small Polyclinic, before 1957 & 39 & 358 & 297 & 582 & 0 & 0 & 0.38 & 3,419 & 7 & 0 & 9 & 40 & 0.93 & 2,767 & 0.42 & 912 & 8,077 \\
\hline Medium Polyclinic, 1958 to 1980 & 94 & 850 & 707 & 1,382 & 0 & 0 & 0.62 & 5,630 & 15 & 0 & 21 & 96 & \begin{tabular}{|l|l|}
1.38 \\
\end{tabular} & 4,075 & $\begin{array}{ll}0.69 \\
\end{array}$ & 1,501 & 13,534 \\
\hline Medium Polyclinic, after 1980 & 149 & 1,350 & 1,123 & 2,196 & 0 & 0 & 0.99 & 8,947 & 25 & & 33 & 152 & \begin{tabular}{|l|l|}
0.97 \\
\end{tabular} & 2,880 & 1.09 & 2,386 & 17,912 \\
\hline Large Polyclinic, after 1980 & 236 & 2,136 & 1,777 & 3,475 & 0 & 0 & 1.49 & 13,469 & 39 & 0 & 53 & 241 & 1.00 & 2,960 & 1.64 & 3,592 & 25,873 \\
\hline Small Hosp. Admin., before 1957 & 23 & 208 & 173 & 338 & 0 & 0 & 0.22 & 1,985 & 4 & 0 & 5 & 0 & \begin{tabular}{|l|l|}
0.84 \\
\end{tabular} & 2,496 & 0.08 & 176 & 5,203 \\
\hline Small Hosp.Admin., 1958 to 1980 & 29 & 260 & 216 & 422 & 0 & 0 & 0.28 & 2,482 & 5 & 0 & 6 & 0 & 0.97 & 2,884 & 0.10 & 221 & 6,269 \\
\hline Large Hosp. Admin. 1958 to 1980 & 162 & 1,471 & 1,224 & 2,393 & 0 & 0 & 1.03 & 9,277 & 27 & 0 & 36 & 0 & 1.55 & 4,587 & 0.38 & 825 & 18,553 \\
\hline Large Hosp. Admin., after 1980 & 251 & 2,279 & 1,895 & 3,706 & 0 & 0 & 1.59 & 14,367 & 41 & 0 & 56 & 0 & 1.00 & 2,960 & 0.58 & 1,277 & 24,589 \\
\hline Kindergartens, before 1957 & 29 & 262 & 425 & 831 & 0 & 0 & 0.31 & 2,806 & 2 & 0 & 5 & 24 & \begin{tabular}{|l|}
0.99 \\
\end{tabular} & 2,941 & 0.26 & 561 & 7,426 \\
\hline Kindergartens, 1958 to 1980 & 51 & 460 & 746 & 1,459 & 0 & 0 & 0.55 & 4,926 & 4 & 0 & 9 & 42 & 1.00 & 2,960 & 0.45 & 985 & 10,833 \\
\hline Kindergantens, after 1980 & 73 & 665 & 1,078 & 2,108 & 0 & of & 0.79 & 7,117 & 5 & 0 & 13 & 60 & \begin{tabular}{|l|l|}
0.96 \\
\end{tabular} & 2,852 & 0.65 & 1,423 & 14,225 \\
\hline Schools, before 1957 & 145 & 1,318 & 2,136 & 4,176 & 0 & a & 1.06 & 9,566 & 10 & & 26 & 119 & 1.05 & 3,103 & 0.87 & 1,913 & 20,196 \\
\hline Schools, 1958 to 1980 & 199 & 1,808 & 2,929 & 5,728 & 0 & 0 & 1.45 & 13,119 & 14 & & 36 & 163 & 1.05 & 3,094 & 1.20 & 2,624 & $\frac{2,265}{26,535}$ \\
\hline Schools, after 1980 & 248 & 2,248 & 3,643 & 7,123 & 0 & 0 & 1.81 & 16,315 & 18 & 0 & 44 & 203 & 1.06 & 3,129 & 1.49 & 3,263 & 32,280 \\
\hline Med. Higher Ed., before 1958 & 149 & 1,347 & 2,183 & 4,269 & 0 & 0 & 1.60 & 14,415 & 21 & $\underline{0}$ & 27 & 122 & 1.03 & 3,036 & 1.32 & 2,883 & 26,073 \\
\hline Med. Higher Ed., 1958 to 1980 & 143 & 1,294 & 2,097 & 4,100 & 0 & 0 & 1.54 & 13,844 & 10 & & 25 & 117 & 1.12 & 3,300 & 1.26 & 2,769 & 25,425 \\
\hline Med. Higher Ed., after 1980 & 191 & 1,735 & 2,812 & 5,499 & 0 & 7 & 2.06 & 18,568 & 14 & 7 & 34 & 157 & 1.28 & 3,793 & 1.70 & 3,714 & 33,467 \\
\hline Large Higher Ed., 1958 to 1980 & 233 & $\frac{1,113}{2,113}$ & 3,423 & 6,695 & 0 & 0 & 1.72 & 15,526 & 17 & 0 & 42 & 191 & \begin{tabular}{|c|}
1.00 \\
\end{tabular} & 2,960 & 1.42 & 3,105 & 30,589 \\
\hline Large Higher Ed., after 1980 & 296 & 2,683 & 4,347 & 8,500 & 0 & 0 & 2.19 & 19,714 & 21 & 0 & 53 & 242 & 1.00 & 2,960 & 1.80 & 3,943 & 38,041 \\
\hline Medium Hostels & 352 & 3,188 & 0 & 0 & 0 & 0 & & 14,522 & 106 & 1,089 & 211 & 967 & 1.09 & 3,217 & 2.06 & 4,518 & 27,502 \\
\hline Large Hostels & 370 & 3,350 & 0 & 0 & 0 & 0 & & 11,651 & 99 & 1,018 & 197 & 903 & 1.00 & 2,960 & 1.66 & 3,625 & 23,507 \\
\hline Small Theaters & 0 & 0 & 588 & 1,150 & 5 & 1,076 & 0.60 & 5,452 & 0 & & 0 & 0 & 1.00 & 2,960 & 0.10 & 230 & 10,867 \\
\hline Medium Theaters & 0 & 0 & 1,638 & 3,203 & 15 & 2,996 & 1.68 & 15,185 & 0 & 0 & 0 & 0 & 1.05 & 3,112 & 0.29 & 639 & 25,135 \\
\hline Large The & 0 & 0 & 1,165 & 2,278 & 10 & 2,131 & 1.20 & 10,799 & 0 & 4 & 0 & 0 & 1.00 & 2,960 & 0.21 & 455 & 18,623 \\
\hline lleries/Museums, before 1958 & 0 & 0 & 482 & 943 & 3 & 669 & 0.36 & 3,288 & of $12-1-1-10$ & 4 & 0 & 0 & \begin{tabular}{|c|}
1.00 \\
\end{tabular} & 2,960 & 0.06 & 138 & 7,998 \\
\hline Small Art Galleries/Museums, after 1980 & 0 & 0 & 534 & 1,045 & 4 & 741 & 0.40 & 3,644 & 0 & & 0 & 0 & 0.74 & 2,182 & 0.07 & 153 & 7,764 \\
\hline Medium Art Galleries/Museums & 0 & 0 & 847 & 1,657 & 6 & 1,175 & 0.64 & 5,778 & 0 & 0 & 0 & 0 & 0.83 & 2,458 & 0.11 & 243 & 11,310 \\
\hline Large Art Galleries/Museums & 0 & 0 & 8,941 & 17,485 & 61 & 12,398 & 6.76 & 60,983 & 0 & 4 & 0 & 0 & 8.76 & 2,960 & 1.17 & 2,568 & 96,394 \\
\hline
\end{tabular}




\section{C.2 Residential Building Sector}

Four prototype buildings were used to estimate the efficiency potential of the residential sector. The prototype building configurations and materials requirements were derived from an analysis conducted for the EHDP Staff Appraisal Report (World Bank 1996) conducted for the World Bank in Russia. Where necessary, material costs were revised to reflect typical costs in Ukraine. Energy savings estimates were developed using a simulation model. The model inputs were adopted from a study of residential sector buildings in the Czech Republic (PNNL 1996) and matched to the most similar prototypes in the Russia EHDP analysis. Finally, residential building stock information was used to develop sector-level energy savings and investment requirements. The building prototypes and floorspace are presented in Table C.6. The unit requirements and costs for each prototype building are presented in Table C.7. These costs are equivalent to costs per apartment ranging from $\$ 223$ to $\$ 755$.

Table C.6. Residential Section Building Prototypes

\begin{tabular}{||l|c|}
\hline \multicolumn{1}{|c|}{ Building Type } & Floorspace $\left(\mathbf{m i l l i o n} \mathbf{~ m}^{2}\right)$ \\
\hline 2-story, Brick Construction, with Attic & 4.81 \\
\hline 5-story, Panel Construction, with Attic & 16.84 \\
\hline 9-story, Panel Construction, No Attic & 16.84 \\
\hline 14-story, Panel Construction, No Attic & 9.62 \\
\hline Total & 48.10 \\
\hline
\end{tabular}


Table C.7. Residential Prototype Building Material Requirements and Costs

\begin{tabular}{|c|c|c|c|c|c|c|c|c|c|c|c|c|c|}
\hline \multirow[b]{2}{*}{ Prototype } & \multicolumn{2}{|c|}{ Reflectors } & \multicolumn{2}{|c|}{$\begin{array}{c}\text { Substation } \\
\text { Controls }\end{array}$} & \multicolumn{2}{|c|}{ Showerheads } & \multicolumn{2}{|c|}{ Aerators } & \multicolumn{2}{|c|}{$\begin{array}{c}\text { Building Heat } \\
\text { Meters }\end{array}$} & \multicolumn{2}{|c|}{$\begin{array}{l}\text { Apartment Hot } \\
\text { Water Meters }\end{array}$} & \multirow{2}{*}{\begin{tabular}{|c|} 
Total \\
Cost (\$)
\end{tabular}} \\
\hline & Each & Cost (\$) & Bldg. & Cost (\$) & Each & $\longdiv { \text { Cost (\$) } }$ & Each & Cost (\$) & Each & Cost (\$) & Each & Cost (\$) & \\
\hline 2 -story & 22 & 203 & 0.20 & 1,609 & 8 & 112 & 16 & 80 & 1 & 2,960 & 8 & 1,080 & 6,044 \\
\hline 5-story & 300 & 2,770 & 1.58 & 12,588 & 90 & 1,259 & 180 & 900 & 1 & 2,960 & 90 & 12,150 & 32,626 \\
\hline 9-story & 405 & 3,740 & 1.63 & 12,974 & 108 & 1,510 & 216 & 1,080 & 1 & 2,960 & 108 & 14,580 & 36,844 \\
\hline 14-story & 364 & 3,361 & 1.66 & 13,200 & 98 & 1,371 & 196 & 980 & 1 & 2,960 & 98 & 13,230 & 35,102 \\
\hline
\end{tabular}




\section{Appendix D}

Efficiency Measure Performance Analysis 


\section{Appendix D}

\section{Efficiency Measure Performance Analysis}

\section{D.1 Introduction}

The performance of 20 retrofit measures was evaluated using the estimated efficiency improvement and the estimated installed costs presented in Appendix C. This appendix contains a discussion of the economic evaluation and estimated efficiency potential for the institutional and residential sectors.

\section{D.1.1 Common Economic Values}

The measures were analyzed by three economic metrics: simple payback, net present value (NPV), and internal rate of return (IRR). These metrics and the approach to selecting the efficiency measures are discussed in Section 3.2.

Values of key economic factors underlying the analysis are

- price of district heat energy is $\$ 22 / \mathrm{Gcal}$

- real annual escalation rate of district heat energy is $2.5 \%$

- ratio of Ukrainian to foreign labor ranges from 5:1 to 8:1, depending on the efficiency measure

- hourly wage of foreign labor is $\$ 55.00$

- hourly wage of Ukrainian labor is $\$ 5.00$

- annual real discount rate is $10 \%$.

D.1 


\section{D.1.2 Technical Analysis}

The performance (efficiency improvements) of the measures were estimated for the institutional and residential sectors using A Simplified Analysis Method (ASEAM) building energy simulation program applied to the building prototypes described in Appendix C. Weather data for Kyiv were used in the simulations, with Kyiv having an estimated 3572 heating degree days. ${ }^{\text {(a) }}$

Each of the measures was evaluated separately by simple payback to develop their respective economic performance for each building prototype. The measures were then grouped to capture interactive effects with respect to efficiency improvement and reevaluated by economic metric to ensure that the minimum simple payback was achieved. Finally, the sensitivities of the measures to the cost of heat and the efficiency measure installed costs were examined using an IRR threshold of $10 \%$. An IRR of $10 \%$ is the point where the net present value of the project goes to zero.

Although the residential prototypes may not fully reflect the residential building stock in Kyiv, the simulations are felt to adequately represent the applicable measures, efficiency potential, and level of investment. Note, too, that the residential sector is not the focus of this analysis, but that it is considered for reasons of completeness. The residential sector is estimated to consume about $45 \%$ of district heat energy provided by hot water and about $68 \%$ of the buildings sector heat energy consumption.

\section{D.2 Measure Analysis}

\section{D.2.1 Institutional Sector}

Of the 20 measures considered, the following eight were determined to satisfy the cost-effectiveness criteria in one or more of the institutional building prototypes:

- window and door weatherstripping

- radiator reflectors

- substation-level heat controller

- riser balancing valves

- hot water heat exchangers

(a) Heating degree days in Ukraine are defined as the product of the length of the heating season (187 days in Kyiv) and the difference between the design indoor temperature and the outdoor average temperature $\left(18^{\circ} \mathrm{C}\right.$ and $-1.1^{\circ} \mathrm{C}$, respectively). 
- low-flow showerheads

- faucet aerators

- ceiling fans.

Building-level heat meters are included in all efficiency measure packages. Although the heat meter does not itself provide energy savings, it is felt to be critical to the performance of an energy efficiency program, and is essential for verification and operations purposes.

The economic performance for the institutional sector prototypes is shown in Tables D.1 to D.3 for the three economic criteria. Simple paybacks by prototype building range from 3.3 years for schools, to nearly 7.4 years for art galleries/museums. Simple paybacks are lowest for buildings constructed between 1958 and 1980 due to the construction practices in that period that lead to higher heat consumption. Paybacks also tend to be shorter for larger buildings, due to the lower cost per unit capacity for retrofit equipment (e.g., substation controllers) as the equipment sizes increase, and the lower costs per unit floorspace for heat meters; these effects offset the impact of decreasing energy intensity for larger buildings (Table B.1). These trends are also reflected in the IRR and NPV Tables D.2 and D.3.

The economic performance of the efficiency measures is summarized in Table D. 4 for the major institutional buildings sector categories and for the entire sector. Total institutional buildings sector performance is impacted most heavily by kindergartens and schools, which together account for more than $57 \%$ of the institutional sector floorspace included in this analysis.

The sensitivity of the IRR metric to the measure performance and material costs is shown in Tables D.5 and D.6. From these data it can be seen that the IRR is relatively sensitive to changes in measure performance and material costs for hospital administration buildings and art galleries/museums, but relatively insensitive for other building types. Material prices would have to more than double for the IRR to drop below 10\% (indicated as shaded area in data tables) for these buildings. Measure performance would have to drop to less than half its predicted value before the IRR would fall below $10 \%$. 
Table D.1. Institutional Building Sector Simple Paybacks

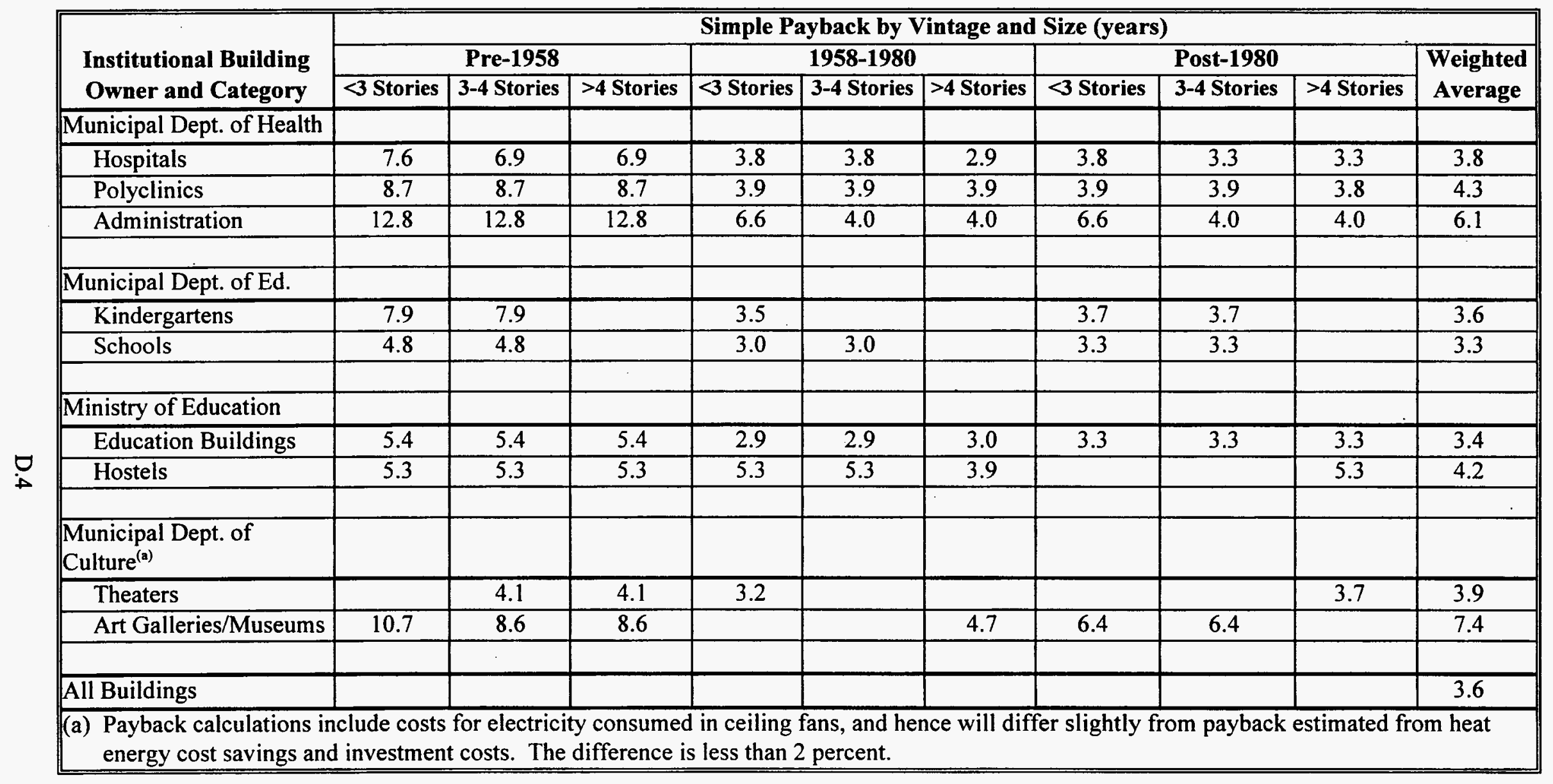


Table D.2. Institutional Building Sector Internal Rate of Return

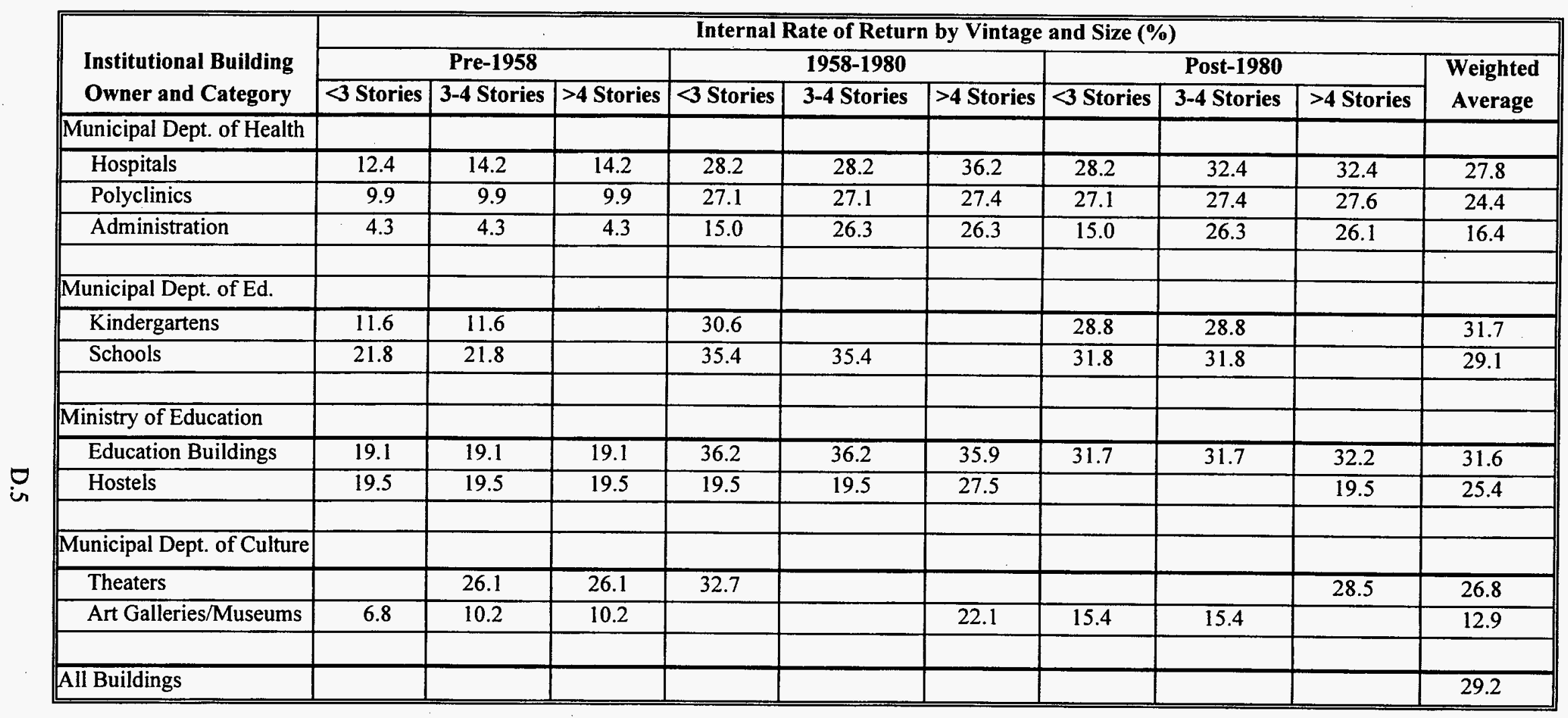


Table D.3. Institutional Building Sector Net Present Value

\begin{tabular}{|c|c|c|c|c|c|c|c|c|c|c|}
\hline \multirow{3}{*}{$\begin{array}{l}\text { Institutional Building } \\
\text { Owner and Category }\end{array}$} & \multicolumn{10}{|c|}{ Net Present Value by Vintage and Size (\$) } \\
\hline & \multicolumn{3}{|c|}{ Pre-1958 } & \multicolumn{3}{|c|}{$1958-1980$} & \multicolumn{3}{|c|}{ Post-1980 } & \multirow{2}{*}{$\begin{array}{l}\text { Floorspace } \\
\text { of Buildings }\end{array}$} \\
\hline & $<3$ Stories & 3-4 Stories & $>4$ Stories & $<3$ Stories & 3-4 Stories & $>4$ Stories & $<3$ Stories & 3-4 Stories & $>4$ Stories & \\
\hline \multicolumn{11}{|l|}{ Municipal Dept. of Health } \\
\hline Hospitals & $\overline{51,284}$ & 56,245 & 14,901 & 96,202 & 474,736 & $1,524,025$ & 80,113 & 84,313 & $1,419,859$ & $3,801,676$ \\
\hline Polyclinics & $-24,403$ & $-9,800$ & $-1,303$ & 34,464 & 261,169 & 52,921 & 14,761 & 213,484 & 498,678 & $1,039,970$ \\
\hline Administration & $-5 \overline{-5,146}$ & $-7,136$ & $-8,895$ & 29,974 & 28,316 & 51,939 & 7,894 & 20,296 & 66,241 & 133,483 \\
\hline Subtotal & $-28,265$ & 39,309 & 4,703 & 160,640 & 764,221 & $1,628,884$ & 102,767 & 318,093 & $1,984,778$ & $4,975,129$ \\
\hline & & & & & & & & & & \\
\hline \multicolumn{11}{|l|}{ Municipal Dept. of Ed. } \\
\hline Kindergartens & 25,783 & 769 & 0 & $5,971,965$ & 0 & 0 & $2,668,563$ & 607,371 & 0 & $9,274,450$ \\
\hline Schools & 29,981 & $1,245,493$ & 0 & 122,033 & $8,923,438$ & 0 & 99,084 & $3,972,941$ & 0 & $14,392,970$ \\
\hline Subtotal & 55,764 & $1,246,262$ & 0 & $6,093,997$ & $8,923,438$ & 0 & $2,767,647$ & $4,580,312$ & 0 & $23,667,420$ \\
\hline & & & & & & & & & & \\
\hline \multicolumn{11}{|l|}{ Ministry of Education } \\
\hline Education Buildings & 45,216 & 443,680 & 65,283 & 179,002 & $2,117,216$ & $2,724,355$ & 77,227 & 341,372 & $1,251,144$ & $7,244,495$ \\
\hline Hostels & 26,092 & 80,468 & 94,306 & 11,487 & 117,233 & $2,796,618$ & 0 & 0 & 241,263 & $3,367,467$ \\
\hline Subtotal & 71,308 & 524,148 & 159,590 & 190,489 & $2,234,449$ & $5,520,973$ & 77,227 & 341,372 & $1,492,407$ & $10,611,962$ \\
\hline \multicolumn{11}{|l|}{$\begin{array}{l}\text { Municipal Dept. of } \\
\text { Culture }\end{array}$} \\
\hline Theaters & 0 & 235,735 & 16,545 & 44,262 & 0 & 0 & 0 & 0 & 25,297 & 321,839 \\
\hline Art Galleries/Museums & $-22,143$ & 9,559 & 3,393 & 0 & 0 & 71,943 & 10,171 & 8,228 & 0 & 81,152 \\
\hline Subtotal & $-22,143$ & 245,294 & 19,938 & 44,262 & 0 & 71,943 & 10,171 & 8,228 & 25,297 & 402,991 \\
\hline Total & & & & & & & & & & $39,657,502$ \\
\hline
\end{tabular}


Table D.4. Institutional Buildings Sector Prototype Economic Performance by Economic Metric

\begin{tabular}{|l|c|c|c||}
\hline & \multicolumn{3}{|c|}{ Economic Metric } \\
\hline Building Type & Payback & IRR (\%) & NPV (\$) \\
\hline Hospitals & 3.8 & 27.8 & $3,801,676$ \\
\hline Polyclinics & 4.3 & 24.4 & $1,039,970$ \\
\hline Administration & 6.1 & 16.4 & 133,483 \\
\hline Kindergartens & 3.6 & 31.7 & $9,274,450$ \\
\hline Schools & 3.3 & 29.1 & $14,392,970$ \\
\hline Higher Education & 3.4 & 31.6 & $7,244,495$ \\
\hline Hostels & 4.2 & 25.4 & $3,367,467$ \\
\hline Theaters & 3.9 & 26.8 & 321,839 \\
\hline Art Galleries/Museums & 7.4 & 12.9 & 81,152 \\
\hline Total & 3.6 & 29.2 & $39,657,502$ \\
\hline
\end{tabular}


Table D.5. Sensitivity of Institutional Sector Internal Rate of Return to Efficiency Measure Performance

\begin{tabular}{|c|c|c|c|c|c|c|c|c|c|}
\hline \multirow[b]{2}{*}{$\begin{array}{l}\text { Energy Savings - } \\
\% \text { of Estimated }\end{array}$} & \multicolumn{9}{|c|}{ IRR as a Function of Energy Savings (\%) } \\
\hline & Hospital & Polyclinic & $\begin{array}{l}\text { Hospital } \\
\text { Admin. }\end{array}$ & $\begin{array}{l}\text { Kinder- } \\
\text { gartens }\end{array}$ & Schools & \begin{tabular}{|c|} 
Higher \\
Education
\end{tabular} & Hostels & Theaters & $\begin{array}{c}\text { Art Galleries } \\
\text { Museums }\end{array}$ \\
\hline 100 & 27.8 & 24.4 & 16.4 & 31.7 & 29.1 & 31.6 & 25.4 & 26.8 & 12.9 \\
\hline 95 & 26.3 & 23.1 & 15.4 & 30.1 & 27.6 & 30.0 & 24.0 & 25.4 & 12.0 \\
\hline 90 & 24.9 & 21.8 & 14.3 & 28.5 & 26.1 & 28.4 & 22.7 & 24.0 & 11.0 \\
\hline 85 & 23.4 & 20.4 & 13.3 & 26.9 & 24.6 & 26.8 & 21.3 & 22.6 & 10.1 \\
\hline 80 & 21.9 & 19.1 & 12.2 & 25.2 & 23.1 & 25.1 & 19.9 & 21.1 & 91 \\
\hline 75 & 20.4 & 17.7 & 11.1 & 23.6 & 21.5 & 23.5 & 18.5 & 19.6 & 8.0 \\
\hline 70 & 18.9 & 16.3 & 9.9 & 21.9 & 19.9 & 21.8 & 17.0 & 18.1 & 7.0 \\
\hline 65 & 17.3 & 14.8 & 8.7 & 20.1 & 18.3 & 20.1 & 15.5 & 16.6 & -5.9 \\
\hline 60 & 15.7 & 13.3 & 7.5 & 18.4 & 16.6 & 18.3 & 14.0 & 15.0 & 48 \\
\hline 55 & 14.0 & 11.8 & 62 & 16.5 & 14.9 & 16.5 & 12.4 & 13.3 & 3.6 \\
\hline 50 & 12.3 & 10.1 & 4.9 & 14.7 & 13.1 & 14.6 & 10.7 & 11.6 & 23 \\
\hline 45 & 10.5 & 8.4 & 3.4 & 12.7 & 11.2 & 12.7 & 9.0 & 9.8 & 1.0 \\
\hline 40 & 8.6 & 6.7 & 19 & 10.7 & 9.3 & 10.6 & 7.2 & 79 & -0.5 \\
\hline
\end{tabular}


Table D.6. Sensitivity of Institutional Sector Internal Rate of Return to Efficiency Measure Installed Costs

\begin{tabular}{|c|c|c|c|c|c|c|c|c|c|}
\hline \multirow{2}{*}{$\begin{array}{c}\text { Energy Savings - } \\
\text { \% of Estimated }\end{array}$} & Hospital & Polyclinic & $\begin{array}{c}\text { Hospital } \\
\text { Admin. }\end{array}$ & $\begin{array}{c}\text { Kinder- } \\
\text { gartens }\end{array}$ & Schools & $\begin{array}{c}\text { Higher } \\
\text { Education }\end{array}$ & Hostels & Theaters & $\begin{array}{c}\text { Art Galleries } \\
\text { Museums }\end{array}$ \\
\hline 100 & 27.8 & 24.4 & 16.4 & 31.7 & 29.1 & 31.6 & 25.4 & 26.8 & 12.9 \\
\hline 120 & 22.9 & 20.0 & 12.9 & 26.3 & 24.1 & 26.2 & 20.8 & 22.1 & 9.8 \\
\hline 140 & 19.3 & 16.7 & 10.2 & 22.3 & 20.4 & 22.3 & 17.4 & 18.6 & 7.3 \\
\hline 160 & 16.5 & 14.1 & 8.1 & 19.2 & 17.4 & 19.2 & 14.7 & 15.8 & 5.4 \\
\hline 180 & 14.2 & 11.9 & 6.4 & 16.7 & 15.1 & 16.7 & 12.6 & 13.6 & 3.8 \\
\hline 200 & 12.3 & 10.1 & 4.9 & 14.7 & 13.1 & 14.6 & 10.7 & 11.7 & 2.4 \\
\hline 220 & 10.6 & 8.6 & 3.6 & 12.9 & 11.4 & 12.8 & 9.2 & 10.1 & 1.2 \\
\hline 240 & 9.2 & 7.3 & 2.4 & 11.4 & 10.0 & 11.3 & 7.8 & 8.7 & 0.2 \\
\hline
\end{tabular}




\section{D.2.2 Residential Sector}

Of the 20 measures considered, the following five were determined to satisfy the cost-effectiveness criteria:

- radiator reflectors

- low-flow showerheads

- faucet aerators

- substation heat controller

- building heat meters.

The economic performance for the residential sector prototypes is shown in Table D.7 by the three economic criteria. The sensitivity of the IRR metric to fuel price and material costs is shown in Tables D.8 and D.9.

Table D.7. Residential Sector Prototype Economic Performance by Economic Metric

\begin{tabular}{||c|c|c|c|}
\hline Building Type & Payback (years) & IRR (\%) & NPV (\$) \\
\hline 2-story & 4.5 & 23.4 & 5,679 \\
\hline 5-story & 4.0 & 26.4 & 38,463 \\
\hline 9-story & 3.0 & 35.7 & 71,303 \\
\hline 14-story & 2.5 & 41.6 & 85,331 \\
\hline Average & 3.4 & 32.4 & 56,052 \\
\hline
\end{tabular}

These data show that material costs would have to increase by 1.8 times for 2-story and over 3.5 times for 14-story buildings before the IRR would drop to $10 \%$. Measure performance could be as low as $55 \%$ of the predicted value for 2 -story buildings to less than $30 \%$ of the predicted value for 14-story buildings for the IRR to fall below $10 \%$.

D. 10 
Table D.8. Sensitivity of Residential Sector Internal Rate of Return to Efficiency Measure Performance

\begin{tabular}{|c|c|c|c|c||}
\hline Energy Savings & \multicolumn{4}{|c|}{ IRR as a Function of Energy Savings } \\
\cline { 2 - 5 } \% of Estimated & 2-Story & 5-Story & 9-Story & 14-Story \\
\hline 100 & 23.4 & 26.4 & 35.7 & 41.6 \\
\hline 95 & 22.1 & 25.1 & 33.9 & 39.6 \\
\hline 90 & 20.8 & 23.7 & 32.2 & 37.5 \\
\hline 85 & 19.5 & 22.2 & 30.4 & 35.5 \\
\hline 80 & 18.2 & 20.8 & 28.6 & 33.4 \\
\hline 75 & 16.9 & 19.3 & 26.7 & 31.3 \\
\hline 70 & 15.5 & 17.9 & 24.9 & 29.2 \\
\hline 65 & 14.1 & 16.3 & 23.0 & 27.1 \\
\hline 60 & 12.6 & 14.7 & 21.1 & 24.9 \\
\hline 55 & 11.1 & 13.1 & 19.1 & 22.7 \\
\hline 50 & 9.5 & 11.4 & 17.0 & 20.4 \\
\hline 45 & 7.8 & 9.7 & 14.9 & 18.1 \\
\hline 40 & 6.1 & 7.8 & 12.8 & 15.7 \\
\hline 35 & 42 & 5.9 & 10.4 & 13.2 \\
\hline 30 & 2.2 & 3.7 & 8.0 & 10.5 \\
\hline
\end{tabular}

Table D.9. Sensitivity of Residential Sector Internal Rate of Return to Efficiency Measure Installed Costs

\begin{tabular}{|c|c|c|c|c||}
\hline \multirow{2}{*}{$\begin{array}{c}\text { Installed Costs } \\
\text { \% of Estimated }\end{array}$} & \multicolumn{5}{|c|}{ IRR as a Function of Installed Costs } \\
\cline { 2 - 5 } & 2-Story & 5-Story & 9-Story & 14-Story \\
\hline 100 & 23.4 & 26.4 & 35.7 & 41.6 \\
\hline 120 & 19.1 & 21.8 & 29.8 & 34.8 \\
\hline 140 & 15.9 & 18.3 & 25.4 & 29.8 \\
\hline 160 & 13.3 & 15.5 & 22.0 & 26.0 \\
\hline 180 & 11.3 & 13.3 & 19.3 & 23.0 \\
\hline 200 & 9.5 & 11.4 & 17.0 & 20.4 \\
\hline 220 & 8.0 & 9.8 & 15.1 & 18.3 \\
\hline 240 & 6.7 & 8.5 & 13.5 & 16.5 \\
\hline 260 & 5.5 & 7.2 & 12.1 & 14.9 \\
\hline 280 & 4.5 & 6.1 & 10.8 & 13.5 \\
\hline 300 & 3.6 & 5.2 & 9.6 & 12.3 \\
\hline 320 & 2.7 & 43 & 8.6 & 11.2 \\
\hline 340 & 2.0 & 3.5 & 7.7 & 10.1 \\
\hline
\end{tabular}




\section{D.3 Efficiency Potential}

This section provides the estimated efficiency potential for both the institutional and residential sectors. The estimated potential is calculated as the product of the building type floorspace estimates in Appendix $\mathrm{A}$ and the corresponding estimate of energy savings per unit floorspace for each of the building prototypes.

\section{D.3.1 Institutional Sector}

Estimates of institutional sector efficiency potential in Gcal per year are presented in Table D.10 by building type, vintage, and size. Table D.11 presents the estimated efficiency potential as a percentage of the baseline energy consumption (Table B.2.). Energy savings range from $19.6 \%$ of baseline to $28.7 \%$ with a floorspace weighted average of $26.2 \%$.

Annual institutional buildings sector energy cost savings can be estimated from the annual energy savings using the first year heat price of $\$ 22$. These data are presented in Table D.12 by building type, vintage, and size. The majority of savings are in the building types schools and kindergartens, which dominate the buildings included in this analysis on the basis of floorspace. Table D.13 summarizes the efficiency potential estimates by building category, and also shows the fractional contribution of each building category to the total energy savings. 
Table D.10. Energy Savings (Gcal/year)

\begin{tabular}{|c|c|c|c|c|c|c|c|c|c|c|}
\hline \multirow{3}{*}{$\begin{array}{l}\text { Institutional Building } \\
\text { Owner and Category }\end{array}$} & \multicolumn{10}{|c|}{ Efficiency Potential of Buildings by Vintage and Size (Gcal/year) } \\
\hline & \multicolumn{3}{|c|}{ Pre-1958 } & \multicolumn{3}{|c|}{ 1958-1980 } & \multicolumn{3}{|c|}{ Post-1980 } & \multirow{2}{*}{$\begin{array}{c}\text { Total Efficiency } \\
\text { Potential }\end{array}$} \\
\hline & $<3$ Stories & 3-4 Stories & $>4$ Stories & $<3$ Stories & 3-4 Stories & $>4$ Stories & $<3$ Stories & 3-4 Stories & $>4$ Stories & \\
\hline \multicolumn{11}{|l|}{ Municipal Dept. of Health } \\
\hline Hospitals & 2,923 & 2,432 & 644 & 953 & 4,702 & 13,790 & 793 & 795 & 13,393 & 40,426 \\
\hline Polyclinics & 1,024 & 411 & 55 & 446 & 3,379 & $\overline{713}$ & 191 & 2,878 & 6,876 & $\overline{15,974}$ \\
\hline Administration & 613 & 79 & 99 & $\overline{549}$ & 446 & 819 & 144 & 320 & 1,079 & 4,148 \\
\hline Subtotal & 4,560 & 2,923 & 798 & 1,947 & 8,527 & 15,322 & 1,129 & 3,993 & 21,349 & 60,548 \\
\hline \multicolumn{11}{|l|}{ Municipal Dept. of Ed. } \\
\hline$V$ indar & 1707 & 5 & $\pi$ & 51082 & & & 26258 & 5076 & & $0606 ?$ \\
\hline Nüucigartis & $1,1,4$ & J & 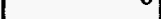 & (1) & & & $2,-20$ & ( & & 86,063 \\
\hline Schools & 428 & 17,791 & 0 & 994 & 72,677 & 0 & 898 & 36,016 & 0 & 128,805 \\
\hline Subtotal & 2,220 & 17,845 & 0 & 52,977 & 72,677 & 0 & 27,157 & 41,993 & 0 & 214,868 \\
\hline & & & & & & & & & & \\
\hline \multicolumn{11}{|l|}{ Ministry of Education } \\
\hline Education Buildings & 701 & 6,880 & 1,012 & 1,401 & 16,572 & 22,040 & 702 & 3,101 & 11,257 & 63,665 \\
\hline Hostels & 348 & 1,074 & 1,259 & 153 & 1,565 & 26,235 & 0 & $\overline{0}$ & 3,221 & 33,856 \\
\hline Subtotal & 1,049 & 7,954 & 2,271 & 1,554 & 18,137 & 48,275 & 702 & 3,101 & 14,478 & 97,521 \\
\hline \multicolumn{11}{|l|}{ Municipal Dept. of Culture } \\
\hline Theaters & 0 & 2,205 & 155 & 302 & 0 & 0 & 0 & 0 & 227 & 2,889 \\
\hline Art Galleries/Museums & 568 & 470 & 167 & $\overline{0}$ & $\mathbf{0}$ & 909 & 163 & 132 & 0 & 2,409 \\
\hline Subtotal & 568 & 2,675 & 322 & 302 & 0 & 909 & 163 & 132 & 227 & 5,299 \\
\hline Total & & & & & & & & & & 378,236 \\
\hline
\end{tabular}


Table D.11. Percentage Energy Savings

\begin{tabular}{|c|c|c|c|c|c|c|c|c|c|c|}
\hline \multirow{3}{*}{$\begin{array}{l}\text { Institutional Building } \\
\text { Owner and Category }\end{array}$} & \multicolumn{10}{|c|}{ Percentage Energy Savings of Buildings by Vintage and Size (\%) } \\
\hline & \multicolumn{3}{|c|}{ Pre-1958 } & \multicolumn{3}{|c|}{ 1958-1980 } & \multicolumn{3}{|c|}{ Post-1980 } & \multirow{2}{*}{$\begin{array}{l}\text { Weighted } \\
\text { Average }\end{array}$} \\
\hline & $<3$ Stories & 3-4 Stories & $>4$ Stories & $<3$ Stories & 3-4 Stories & $>4$ Stories & $<3$ Stories & 3-4 Stories & $>4$ Stories & \\
\hline \multicolumn{11}{|l|}{ Municipal Dept. of Health } \\
\hline Hospitals & 24.8 & 24.9 & 24.9 & 25.3 & 25.3 & 25.8 & 25.3 & 26.3 & 26.3 & 25.8 \\
\hline Polyclinics & 25.9 & 25.9 & 25.9 & 27.4 & 27.4 & 27.4 & 27.4 & 27.4 & 27.4 & 27.2 \\
\hline Administration & 23.5 & 23.5 & 23.5 & 24.7 & 27.5 & 27.5 & 24.7 & 27.5 & 27.8 & 26.2 \\
\hline \multicolumn{11}{|l|}{ Municipal Dept. of Ed. } \\
\hline Kindergartens & 24.6 & 24.6 & & 26.1 & & & 26.4 & 26.4 & & 26.2 \\
\hline Schools & 27.3 & 27.3 & & 27.2 & 27.2 & & 27.9 & 27.9 & & 27.4 \\
\hline & & & & & & & & & & \\
\hline \multicolumn{11}{|l|}{ Ministry of Education } \\
\hline Education Buildings & 24.7 & 24.7 & 24.7 & 25.8 & 25.8 & 27.2 & 26.2 & 26.2 & 27.9 & 26.5 \\
\hline Hostels & 19.0 & 19.0 & 19.0 & 19.0 & 19.0 & 23.1 & & & 19.0 & 22.0 \\
\hline & & & & & & & & & & \\
\hline \multicolumn{11}{|l|}{ Municipal Dept. of Culture } \\
\hline Theaters & & 28.7 & 28.7 & 28.7 & & & & & 28.7 & 28.7 \\
\hline Art Galleries/Museums & 19.6 & 19.6 & 19.6 & & & 19.6 & 19.6 & 19.6 & & 19.6 \\
\hline All Buildings & & & & & & & & & & 26.2 \\
\hline
\end{tabular}


Table D.12. Energy Savings (\$/year)

\begin{tabular}{|c|c|c|c|c|c|c|c|c|c|c|}
\hline \multirow[b]{3}{*}{$\begin{array}{l}\text { Institutional Building } \\
\text { Owner and Category }\end{array}$} & \multicolumn{10}{|c|}{ Value of Efficiency Potential by Building, Vintage, and Size (\$/year) } \\
\hline & \multicolumn{3}{|c|}{ Pre-1958 } & \multicolumn{3}{|c|}{ 1958-1980 } & \multicolumn{3}{|c|}{ Post-1980 } & \multirow{2}{*}{$\begin{array}{c}\text { Total } \\
\text { Efficiency } \\
\text { Potential } \\
\end{array}$} \\
\hline & $<3$ Stories & 3-4 Stories & $>4$ Stories & $<3$ Stories & 3-4 Stories & $>4$ Stories & $<3$ Stories & 3-4 Stories & $>4$ Stories & \\
\hline \multicolumn{11}{|l|}{ Municipal Dept. of Health } \\
\hline Hospitals & 65,920 & 54,839 & 14,529 & 21,486 & 106,029 & 310,969 & 17,893 & 17,934 & 302,015 & 911,613 \\
\hline Polyclinics & 23,098 & 9,276 & 1,234 & 10,055 & 76,198 & 16,086 & 4,307 & 64,893 & 155,063 & 360,211 \\
\hline Administration & 13,812 & 1,787 & 2,228 & 12,369 & 10,066 & 18,463 & 3,257 & 7,215 & 24,335 & 93,532 \\
\hline Subtotal & 102,830 & 65,903 & 17,990 & 43,910 & 192,292 & 345,518 & 25,457 & 90,042 & 481,413 & $1,365,355$ \\
\hline & & & & & & & & & & \\
\hline \multicolumn{11}{|l|}{ Municipal Dept. of Ed. } \\
\hline Kindergartens & 40,401 & 1,204 & 0 & $1,172,226$ & 0 & 0 & 592,124 & 134,769 & 0 & $1,940,725$ \\
\hline Schools & 9,657 & 401,192 & 0 & 22,412 & $1,638,873$ & 0 & 20,255 & 812,167 & 0 & $2,904,557$ \\
\hline Subtotal & 50,058 & 402,396 & 0 & $1,194,639$ & $1,638,873$ & 0 & $612,3.79$ & 946,936 & 0 & $4,845,282$ \\
\hline & & & & & & & & & & \\
\hline \multicolumn{11}{|l|}{ Ministry of Education } \\
\hline Education Buildings & 15,810 & 155,133 & 22,826 & 31,594 & 373,694 & 497,007 & 15,821 & 69,934 & 253,836 & $1,435,655$ \\
\hline Hostels & 7,855 & 24,225 & 28,391 & 3,458 & 35,294 & 591,589 & 0 & 0 & 72,633 & 763,446 \\
\hline Subtotal & 23,665 & 179,358 & 51,218 & 35,053 & 408,987 & $1,088,596$ & 15,821 & 69,934 & 326,469 & $2,199,100$ \\
\hline \multicolumn{11}{|l|}{ Municipal Dept. of Culture } \\
\hline Theaters & 0 & 49,629 & 3,439 & 6,711 & 0 & 0 & 0 & 0 & 5,068 & 64,848 \\
\hline Art Galleries/Museums & 12,707 & 10,542 & 3,734 & 0 & 0 & 20,424 & 3,566 & 2,919 & 0 & 53,892 \\
\hline Subtotal & 12,707 & 60,172 & 7,173 & 6,711 & 0 & 20,424 & 3,566 & 2,919 & 5,068 & 118,740 \\
\hline & & & & & & & & & & \\
\hline Total & & & & & & & & & & $8,528,477$ \\
\hline
\end{tabular}


Table D.13. Institutional Buildings Sector Efficiency Potential

\begin{tabular}{||l|c|c|c||}
\hline \multicolumn{1}{|c|}{ Building Type } & $\begin{array}{c}\text { Efficiency Potential } \\
\text { (thousand Gcal) }\end{array}$ & $\begin{array}{c}\text { Efficiency Potential } \\
\text { (\$/year) }\end{array}$ & $\begin{array}{c}\text { Fraction of Total } \\
\text { Savings (\%) }\end{array}$ \\
\hline Hospitals & 40 & 911,613 & 10.7 \\
\hline Polyclinics & 16 & 360,211 & 4.2 \\
\hline Administration & 4 & 93,532 & 1.1 \\
\hline Kindergartens & 86 & $1,940,725$ & 22.8 \\
\hline Schools & 129 & $2,904,557$ & 34.1 \\
\hline Higher Education & 64 & $1,435,655$ & 16.8 \\
\hline Hostels & 34 & 763,446 & 9.0 \\
\hline Theaters & 3 & 64,848 & 0.8 \\
\hline Art Galleries/Museums & 2 & 53,892 & 0.6 \\
\hline Total & 378 & $\mathbf{8 , 5 2 8 , 4 7 7}$ & 100.0 \\
\hline
\end{tabular}

\section{D.3.2 Residential Sector}

Table D.14 presents the cost-effective efficiency potential in the residential buildings sector by building prototype, both in Gcal and annual cost savings based on the first-year heat cost.

Table D.14. Residential Building Sector Efficiency Potential

\begin{tabular}{||l|c|c|c||}
\hline Building Type & $\begin{array}{c}\text { Efficiency Potential } \\
\text { (thousand Gcal/year) }\end{array}$ & $\begin{array}{c}\text { Efficiency Potential } \\
\text { (million \$/year) }\end{array}$ & $\begin{array}{c}\text { Fraction of Efficiency } \\
\text { Potential (\%) }\end{array}$ \\
\hline 2-story & 451 & 11.3 & 14.8 \\
\hline 5-story & $\mathbf{8 7 3}$ & 21.8 & 28.7 \\
\hline 9-story & 1,070 & 26.8 & 35.2 \\
\hline 14-story & 645 & 16.1 & 21.2 \\
\hline Total & 3,039 & 76.0 & 100.0 \\
\hline
\end{tabular}

D.16 


\section{Appendix E}

Investment Requirements 


\section{Appendix E}

\section{Investment Requirements}

\section{E.1 Introduction}

The investment requirements for the retrofit measure packages are estimated from the installed costs presented in Appendix $\mathrm{C}$ and the floorspace estimates described in Appendix A. This appendix contains a discussion of the estimated investment requirements for both the institutional and residential sectors.

\section{E.1.1 Institutional Sector}

The total investment requirements estimated for the prototype buildings for the institutional sector are shown in Table E.1 by building category, vintage, and size. Using the prototype building floorspace data, these values can be converted to estimates of investment requirements per square meter of floorspace. These estimates are presented by building category, vintage, and size in Table E.2. Finally, per-square-meter investment levels are used in conjunction with floorspace estimates from Appendix A (Table A.1) to estimate total institutional sector investment requirements. These data are presented in Table E. 3 along with the total investment requirements by building category, and the total investment requirements for the institutional buildings sector.

Institutional buildings sector investment requirements are driven by the substation controller retrofits, which represent about half of the total investment. The second most expensive ECO is generally hot water heat exchangers; however, the per building cost of hot water heat exchangers is a strong function of building type. Heat meters, which are installed in all buildings, add an additional $\$ 3,000$ per building to the investment requirements.

Investment requirements by building category are summarized in Table E.4. Total institutional sector investment requirements are $\$ 31.1$ million for 7.2 million square meters of floorspace, reflecting a floorspace weighted mean investment level of $\$ 4.31 / \mathrm{m}^{2}$. This investment level reflects a fairly conservative package of ECOs that meet the 5-year simple payback investment requirement at $\$ 22 /$ Gcal for heat costs. The total institutional sector investment represents the investment needed to retrofit only that fraction of the institutional floorspace found to be suitable for inclusion in the World Bank loan package. While additional institutional building floorspace exists, the budget structure and ownership/operation status for these buildings was not considered suitable for inclusion in the loan package. 
Table E.1. Institutional Building Sector Investment Requirements per Building

\begin{tabular}{|c|c|c|c|c|c|c|c|c|c|c|}
\hline \multirow{3}{*}{$\begin{array}{l}\text { Institutional Building } \\
\text { Owner and Category }\end{array}$} & \multicolumn{10}{|c|}{ Investment per Building by Vintage and Size (\$/Bidg.) } \\
\hline & \multicolumn{3}{|c|}{ Pre-1958 } & \multicolumn{3}{|c|}{$1958-1980$} & \multicolumn{3}{|c|}{ Post-1980 } & \multirow{2}{*}{$\begin{array}{c}\text { Average } \\
\text { Investment }\end{array}$} \\
\hline & $<3$ Stories & 3-4 Stories & $>4$ Stories & $<3$ Stories & 3-4 Stories & $>4$ Stories & $<3$ Stories & 3-4 Stories & $>4$ Stories & \\
\hline \multicolumn{11}{|l|}{ Municipal Dept. of Health } \\
\hline Hospitals & 12,151 & 14,460 & 19,920 & 6,726 & 18,105 & 30,314 & 22,405 & 29,305 & 51,948 & 21,719 \\
\hline Polyclinics & 8,077 & 10,137 & 10,785 & 3,929 & 13,534 & 20,722 & 4,207 & 17,912 & 25,873 & 14,143 \\
\hline Administration & 5,203 & 11,445 & 28,532 & 6,269 & 8,092 & 18,553 & 7,154 & 9,667 & 24,589 & 8,309 \\
\hline \multicolumn{11}{|l|}{ Municipal Dept. of Ed. } \\
\hline Kindergartens & 7,426 & 9,519 & & 10,833 & & & 14,225 & 17,692 & & 11,771 \\
\hline Schools & 6,598 & 20,196 & & 6,103 & 26,535 & & 9,661 & 32,280 & & 24,987 \\
\hline & & & & & & & & & & \\
\hline \multicolumn{11}{|l|}{ Ministry of Education } \\
\hline Education Buildings & 21,257 & 26,073 & 24,553 & 10,270 & 25,425 & 30,589 & 13,249 & 33,467 & 38,041 & 27,703 \\
\hline Hostels & 20,820 & 21,403 & 21,500 & 9,166 & 37,418 & 23,507 & & & 27,502 & 23,994 \\
\hline \multicolumn{11}{|l|}{ Municipal Dept. of Culture } \\
\hline Theaters & & 25,135 & 14,112 & 10,867 & & & & & 18,623 & 21,295 \\
\hline Art Galleries/Museums & 7,998 & 11,310 & 32,112 & & & 96,394 & 7,764 & 18,843 & & 12,809 \\
\hline & & & & & & & & & & 10505 \\
\hline Average & & & & & & & & & & 18,505 \\
\hline
\end{tabular}


Table E.2. Institutional Building Sector Investment Requirements per Square Meter

\begin{tabular}{|c|c|c|c|c|c|c|c|c|c|c|}
\hline \multirow{3}{*}{$\begin{array}{l}\text { Institutional Building } \\
\text { Owner and Category }\end{array}$} & \multicolumn{10}{|c|}{ Investment per Square Meter of Buildings by Vintage and Size $\left(\$ / \mathrm{m}^{2}\right)$} \\
\hline & \multicolumn{3}{|c|}{ Pre-1958 } & \multicolumn{3}{|c|}{ 1958-1980 } & \multicolumn{3}{|c|}{ Post-1980 } & \multirow{2}{*}{$\begin{array}{l}\text { Weighted Average } \\
\text { Investment Level }\end{array}$} \\
\hline & $<3$ Stories & 3-4 Stories & $>4$ Stories & <3 Stories & 3-4 Stories & $>4$ Stories & $<3$ Stories & 3-4 Stories & $>4$ Stories & \\
\hline \multicolumn{11}{|l|}{ Municipal Dept. of Health } \\
\hline Hospitals & 8.59 & $\overline{6.43}$ & $\overline{6.43}$ & $\overline{6.49}$ & $\overline{6.49}$ & 4.75 & $\overline{6.49}$ & 4.56 & 4.56 & 5.45 \\
\hline Polyclinics & 8.30 & 8.30 & 8.30 & 5.85 & 5.85 & 4.87 & 5.85 & 4.87 & $\overline{4.45}$ & 5.29 \\
\hline Administration & 9.20 & 9.20 & 9.20 & 8.87 & 4.63 & 4.63 & 8.87 & 4.63 & 3.96 & 6.21 \\
\hline & & & & & & & & & & \\
\hline \multicolumn{11}{|l|}{ Municipal Dept. of Ed. } \\
\hline Kindergartens & 6.67 & 6.67 & & 5.54 & & & 5.04 & 5.04 & & 5.38 \\
\hline Schools & 3.61 & 3.61 & & 3.46 & 3.46 & & 3.38 & 3.38 & & 3.47 \\
\hline & & & & & & & & & & \\
\hline Ministry of Education & & & & & & & & & & $\cdot$ \\
\hline Education Buildings & 4.56 & 4.56 & 4.56 & 4.63 & 4.63 & 3.41 & 4.54 & 4.54 & 3.34 & 3.92 \\
\hline Hostels & 4.77 & 4.77 & 4.77 & 4.77 & 4.77 & 4.22 & & & 4.77 & 4.37 \\
\hline & & & & & & & & & & \\
\hline \multicolumn{11}{|l|}{ Municipal Dept. of Culture } \\
\hline Theaters & & 5.23 & 5.23 & 6.29 & & & & & 5.45 & 5.32 \\
\hline Art Galleries/Museums & 7.42 & 5.97 & 5.97 & & & 4.82 & 6.50 & 6.50 & & 6.08 \\
\hline & & & & & & & & & & \\
\hline All Buildings & & & & & & & & & & 4.31 \\
\hline
\end{tabular}


Table E.3. Institutional Building Sector Total Investment Requirements

\begin{tabular}{|c|c|c|c|c|c|c|c|c|c|c|}
\hline \multirow[b]{3}{*}{$\begin{array}{l}\text { Institutional Building } \\
\text { Owner and Category }\end{array}$} & \multicolumn{10}{|c|}{ Total Investment by Vintage and Size (\$) } \\
\hline & \multicolumn{3}{|c|}{ Pre-1958 } & \multicolumn{3}{|c|}{ 1958-1980 } & \multicolumn{3}{|c|}{ Post-1980 } & \multirow{2}{*}{$\begin{array}{c}\text { Total } \\
\text { Invest- } \\
\text { ment }\end{array}$} \\
\hline & $<3$ Stories & 3-4 Stories & $>4$ Stories & $<3$ Stories & 3-4 Stories & $>4$ Stories & $<3$ Stories & 3-4 Stories & $>4$ Stories & \\
\hline \multicolumn{11}{|l|}{ Municipal Dept. of Health } \\
\hline Hospitals & 498,182 & 375,952 & 99,602 & 80,715 & 398,313 & 909,417 & 67,216 & $\overline{58,610}$ & 987,011 & $\overline{3,475,019}$ \\
\hline Polyclinics & 201,931 & 81,096 & 10,785 & 39,292 & 297,754 & 62,165 & 16,829 & 250,773 & 595,084 & $1,555,709$ \\
\hline Administration & 176,888 & 22,890 & 28,532 & 81,491 & 40,460 & 74,213 & 21,461 & 29,001 & 98,355 & 573,290 \\
\hline Subtotal & 877,002 & 479,938 & 138,919 & 201,499 & 736,527 & $1,045,795$ & 105,506 & 338,383 & \begin{tabular}{|l|}
$1,680,449$ \\
\end{tabular} & $5,604,018$ \\
\hline \multicolumn{11}{|l|}{ Municipal Dept. of Ed. } \\
\hline Kindergartens & 319,309 & 9,519 & 0. & $4,062,210$ & 0 & 0 & $2,176,477$ & 495,371 & 0 & $7,062,886$ \\
\hline Schools & 46,183 & $1,918,577$ & 0 & 67,132 & $4,908,904$ & 0 & 67,625 & $2,711,557$ & 0 & $9,719,980$ \\
\hline Subtotal & 365,492 & $1,928,096$ & 0 & $4,129,342$ & $4,908,904$ & 0 & $2,244,102$ & $3,206,929$ & 0 & $16,782,866$ \\
\hline & & & & & & & & & & \\
\hline \multicolumn{11}{|l|}{ Ministry of Education } \\
\hline Education Buildings & 85,028 & 834,330 & 122,763 & 92,431 & $1,093,260$ & $1,468,286$ & 52,997 & 234,266 & 836,910 & $4,820,270$ \\
\hline Hostels & 41,640 & 128,419 & 150,503 & 18,333 & 187,092 & $2,280,142$ & 0 & 0 & 385,031 & $3,191,160$ \\
\hline Subtotal & 126,668 & 962,748 & 273,267 & 110,763 & $1,280,352$ & $3,748,429$ & 52,997 & 234,266 & $1,221,941$ & $8,011,430$ \\
\hline \multicolumn{11}{|l|}{ Municipal Dept. of Culture } \\
\hline Theaters & 0 & 201,076 & 14,112 & 21,734 & 0 & 0 & 0 & 0 & 18,623 & 255,545 \\
\hline Art Galleries/Museums & 135,971 & 90,480 & 32,112 & 0 & 0 & 96,394 & 23,293 & 18,843 & 0 & 397,093 \\
\hline Subtotal & 135,971 & 291,556 & 46,224 & 21,734 & 0 & 96,394 & 23,293 & 18,843 & 18,623 & 652,638 \\
\hline Total & & & & & & & & & & $31,050,952$ \\
\hline
\end{tabular}


Table E.4. Institutional Buildings Sector Investment Requirements

\begin{tabular}{||l|c|c|c|}
\hline \multirow{2}{*}{\multicolumn{1}{|c|}{ Building Type }} & \multicolumn{3}{|c|}{ Investment Requirements (\$) } \\
\cline { 2 - 4 } & Per Building & ${\text { Per } \mathbf{~ m}^{2}}$ & Total \\
\hline Hospitals & 21,719 & 5.45 & $3,475,019$ \\
\hline Polyclinics & 14,143 & 5.29 & $1,555,709$ \\
\hline Administration & $\mathbf{8 , 3 0 9}$ & 6.21 & 573,290 \\
\hline Kindergartens & 11,771 & 5.38 & $7,062,886$ \\
\hline Schools & 24,987 & 3.47 & $9,719,980$ \\
\hline Higher Education & 27,703 & 3.92 & $4,820,270$ \\
\hline Hostels & 23,994 & 4.37 & $3,191,160$ \\
\hline Theaters & 21,295 & 5.32 & 255,545 \\
\hline Art Galleries/Museums & 12,809 & 6.08 & 397,093 \\
\hline Total & 18,505 & 4.31 & $31,050,952$ \\
\hline
\end{tabular}

\section{E.1.2 Residential Sector}

The investment requirements for the residential sector are shown in Table E.5 by building category. Residential sector investment requirements are more than an order of magnitude greater than institutional sector requirements, due to the large amount of floorspace in the residential sector. As with the institutional buildings sector, substation heat controllers are one of the largest investment requirements, accounting for 30 to $40 \%$ of the total investment. The per building cost to install apartment-level heat meters is comparable to the substation cost, however, accounting for about one third of the total investment. Building heat meter costs are again estimated at $\$ 3,000$ per building.

Table E.5. Residential Building Sector Investment Requirements

\begin{tabular}{||c|c|c|c|}
\hline & \multicolumn{3}{|c|}{ Investment Requirements (\$) } \\
\hline Building Type & Per Building & ${\text { Per } \mathbf{~ m}^{\mathbf{2}}}^{\text {Total (millions) }}$ \\
\hline 2-story & 6,044 & 13.49 & 64.9 \\
\hline 5-story & 32,626 & 4.08 & 68.7 \\
\hline 9-story & 36,844 & 6.64 & 111.8 \\
\hline 14-story & 35,102 & 4.08 & 39.2 \\
\hline Total & 31,939 & 5.92 & 284.5 \\
\hline
\end{tabular}




\section{Appendix F}

Review of Literature 


\section{Appendix F}

\section{Review of Literature}

Four studies that focused some or all of their effort on the buildings sector were reviewed. Key findings of each pertaining to the buildings sector are presented in this section.

Of the four, the TACIS report, provides the most comprehensive assessment of efficiency potential. Information in all the reports focused on the residential buildings sector, but the combined information was helpful in developing the institutional sector efficiency potential in this assessment. Major findings of the studies are discussed below.

\section{F.1 Feasibility Study for Heat Supply and Energy Efficiency Project Kyiv, Ukraine (Ekono Energy 1996)}

In the Ekono Energy report, the absence of heat meters required that design data be used to estimate heat consumption. A number of standards and regulations were used to develop the following persquare-meter design estimates in $\mathrm{W} / \mathrm{m}^{2}$ for Kyiv:

\begin{tabular}{||c|c|c|c||}
\hline \multirow{2}{*}{ Building Height } & \multicolumn{2}{|c|}{ Existing Buildings (W/m $\mathbf{m}^{2}$ ) } & \multirow{2}{*}{ New Buildings } \\
\cline { 2 - 3 } & No Efficiency & Improved Efficiency & 168.8 \\
\hline 1-2 Stories & 208.2 & 196.8 & 93.4 \\
\hline 3-4 Stories & 120.6 & 114.2 & 76.2 \\
\hline$>5$ Stories & 81.8 & 77.8 & . \\
\hline
\end{tabular}

Of the total 1995 building sector heat demand of $7412.1 \mathrm{Gcal} / \mathrm{hr}(8620.2 \mathrm{MW})$, it was estimated that 2406.7 Gcal/hr (2799 MW) were accounted for by public buildings and $5005.4 \mathrm{Gcal} / \mathrm{hr}(5,821.3 \mathrm{MW})$ by residential buildings. The total energy, $6298 \mathrm{Gcal} / \mathrm{hr}$, was used for heat and ventilation, and $1114 \mathrm{Gcal} / \mathrm{hr}$ was used for hot water. The information was provided in terms of peak demand (Gcal/hr), not in terms of calories of consumption.

The discussion focused mainly on the residential sector. It was estimated that there was $\mathbf{4 8 . 6}$ million square meters of residential floorspace in Kyiv in 1995.

With respect to heat loss, the following information was provided. A value of $1.0 \mathrm{~W} / \mathrm{m}^{2} \mathrm{~K}$ (U-value) was used for calculating heat loss through walls. This value was felt to accurately reflect the properties of older brick and concrete construction and the deteriorated condition of sandwich wall construction, 
which theoretically has a heat loss coefficient as low as $0.3 \mathrm{~W} / \mathrm{m}^{2} \mathrm{~K}$ (U-value). Ground floor and roof heat losses were felt to be much higher than the theoretical values 0.7 and 0.6 to $0.8 \mathrm{~W} / \mathrm{m}^{2} \mathrm{~K}$. The assumed U-value of $2.3 \mathrm{~W} / \mathrm{m}^{2} \mathrm{~K}$ of windows was also felt to be much higher due to infiltration around the frames. In addition to infiltration around door frames, closing mechanisms often do not work properly.

Domestic hot water consumption was estimated in the range of 70 to $80 \mathrm{dm}^{3} /$ person/day (liters/person/day), rather than the design value of 105 to $110 \mathrm{dm}^{3} /$ person/day. Heat is usually distributed through radiators at a design temperature of $95 / 70^{\circ} \mathrm{C}\left(105 / 70^{\circ} \mathrm{C}\right.$ in some cases $)$, and there is an absence of controls. In recent years the supply temperature of water has been lower so overheating has not been common.

A number of energy conservation measures were discussed. Control measures included building and radiator-level heat controis, and building-level hot water controls. Other measures were balancing valves (risers), pipe insulation, wall insulation, and weatherstripping. Estimates of the reduction in energy consumption were provided for some of the measures as follows:

\begin{tabular}{||l|l||}
\hline \multicolumn{1}{|c|}{ Controls } & \\
\hline Building Level & $15-20 \%$ \\
\hline Hot Water & N/A \\
\hline Thermostatic Valves & N/A \\
\hline Balancing Valves & $5-7 \%$ \\
\hline Pipe Insulation & N/A \\
\hline Wall Insulation & $15 \%$ \\
\hline Weatherstripping & N/A \\
\hline
\end{tabular}

Pipe insulation and weatherstripping were estimated to have short paybacks, while wall insulation was expected to have long paybacks, though these values were not quantified.

The annual theoretical heat consumption per cubic meter is estimated to be $140.56 \mathrm{kWh}$, and the actual heat consumption per cubic meter in 1995 is estimated to have been 94.87 . This compares to the actual 1994 per cubic meter consumption in Finland of $45.5 \mathrm{kWh}$. Data from the TACIS report estimates annual per cubic meter building sector consumption of 110 to $280 \mathrm{kWh}$ in Kyiv. Annual values provided for the Czech republic ranged from 100 to $130 \mathrm{kWh}$ and $80 \mathrm{kWh}$ for Switzerland.

The building sector efficiency potential was felt to be small in view of the current prices and economic situation. Controls are felt to be the most economically attractive measures, providing significant reductions in energy consumption, but only modest reductions in capacity. It was estimated that reductions in peak capacity requirements of 2 to $4 \%$ could be achieved from a buildings sector efficiency program. 


\section{F.2 Ukraine District Heating Project (JTC 1996)}

The Joseph Technology Corporation report includes information on the distribution of nonresidential buildings and an estimate of the number of residential buildings $(33,320)$ and apartments $(889,440)$. Residential floorspace is estimated at 49 million $\mathrm{m}^{2}$, with $10 \%$ in buildings of 1 to 4 stories, $70 \%$ in buildings of 5 to 9 stories, and $20 \%$ in buildings having more than 9 stories. Projections of population and living space per person are provided: 1995 population of 2.7 million and $18 \mathrm{~m}^{2}$ per person; 2010 population of 3.052 million and $22.7 \mathrm{~m}^{2}$ per person.

Peak demand for the building sector was estimated for 1995 as follows:

\begin{tabular}{||l|c||}
\hline & Peak Demand (Gcal/hr) \\
\hline Heating & 5,472 \\
\hline Ventilation & 581 \\
\hline Hot Water & 1,101 \\
\hline Peak Demand by Customer Class & Peak Demand (Gcal/hr) \\
\hline Industrial & \\
\hline Steam & $1,520(2,535$ tons/hr) \\
\hline Hot Water & 3,465 \\
\hline Buildings & 7,155 \\
\hline Total & 12,140 \\
\hline
\end{tabular}

Forecasts of heat demand are provided for the industrial and buildings sectors. Peak demand is projected to increase from $12,140 \mathrm{Gcal} / \mathrm{hr}$ to $17,290 \mathrm{Gcal} / \mathrm{hr}$.

A number of residential buildings sector efficiency measures were discussed. These were

- External Insulation. Apply polystyrene panels to increase the R-value to 11 or 12 . The estimated cost is $\$ 6 / \mathrm{ft}^{2}$ or $\$ 2,500 /$ apartment.

- Windows. Install double or triple panes and use caulking and weatherstripping. The estimated cost is $\$ 2,000 /$ apartment.

- Weatherstripping. The estimated cost is $\$ 50 /$ apartment.

- Thermostatic Valves. The estimated cost is $\$ 150 /$ apartment.

- Heat Meters. The estimated cost is $\$ 1,500$ per apartment building.

- Domestic Hot Water Taps. The estimated cost is $\$ 20 /$ apartment. 
- Heat Supply Substations. Substation modernization is estimated to be $\$ 32,400$ /substation.

The total estimated cost for 33,320 buildings, 888,440 apartments, and substations at $50 \%$ penetration ( 16,700 buildings, 1,125 substations, and 445,000 apartments) is $\$ 2,172.3$ million. Analysis indicates that supply-side measures are a more cost-effective option than demand-side measures, but a 5 to $6 \%$ reduction in peak demand is considered in the analysis.

\section{F.3 Energy Policies of Ukraine (IEA 1996)}

This report provided an overview of the entire energy sector of Ukraine, which includes technical and policy recommendations. Only those sections that pertain to the technical analysis of the buildings sector are discussed in this review.

The average energy expenses for a typical family of four in Kyiv is estimated as follows:

\begin{tabular}{|l|l|}
\hline Central (district) Heat & 1.4 million KRB $(\$ 8.00)$ \\
\hline Hot Water & 1.6 million KRB $(\$ 9.14)$ \\
\hline Gas (for cooking) & $800,000 \mathrm{KRB}(\$ 4.57)$ \\
\hline Electricity & $(180 \mathrm{kWh}) 900,000 \mathrm{KRB}(\$ 5.14)$ \\
\hline Total Monthly Energy Bill & 4.7 million $\mathrm{KRB}(\$ 26.85)$ \\
\hline Average Monthly Earnings & 14 million KRB $(\$ 80)$ \\
\hline
\end{tabular}

The source for these figures is the Ukrainian Academy of Sciences.

Theoretical heat demand using present building standards is $9.3 \mathrm{MWh} / \mathrm{yr}$ for an apartment with net living area of about $60 \mathrm{~m}^{2}\left(71 \mathrm{~m}^{2}\right.$ gross $)$. Actual consumption is estimated to be 14 to $16 \mathrm{MWh} / \mathrm{yr}$.

Factors that bear upon household implementation of efficiency measures are

- households are not billed for actual consumption, hence they have no incentive to conserve

- households do not have sufficient information about efficiency measures

- equipment/materials are expensive and sometimes difficult to obtain.

Building standards, if enforcement and education were provided, would bring new housing up to Western European levels of consumption. Appliance labeling, scheduled to be implemented in 1996, would also be expected to improve energy efficiency. 
The report notes that the tariffs for district heat are based on production and transmissions costs. Production costs factor in fuel and operating expenses, but not depreciation expenses. Transmission costs are calculated to cover losses of $7 \%$; losses are estimated to range from 10 to $15 \%$. These tariffs are subject to approval by Regional Energy Committees and according to guidelines set by the Ministry of Economy. Tariffs are higher for industrial customers than for residential customers, and the Ministry of Economy provides a subsidy to apartment or homeowners. The average heat tariff is about $\$ 2.60 / \mathrm{GJ}$, about half the economic level. A World Bank estimate is that the marginal cost of heat from a coal-fired plant is about $\$ 10 /$ GJ with 10 to $15 \%$ transmission losses.

In Kyiv, residential customers are estimated to account for about two-thirds of district heat supplied, and the hot water to steam ratio is $85: 15$. Average consumption is estimated at $1.7 \mathrm{GJ} / \mathrm{m}^{2} / \mathrm{yr}$ as compared to about 0.7 to $0.75 \mathrm{GJ} / \mathrm{m}^{2} / \mathrm{yr}$ for countries such as Denmark, Belgium, and Finland.

Transmission and distribution losses are estimated to be $17 \%$, and water losses are estimated to surpass $3 \%$ in some hot water systems and 5 to $10 \%$ in steam systems.

District heat is usually billed on estimated consumption, and legislation is calling for installation of heat meters so consumers can be charged for actual consumption.

Water consumption is estimated to be 328 liters/day as compared to about 150 to 240 liters/day in industrialized countries.

The average cost of water and heat meters is about 700 million KRB per building, and these meters are expected to reduce consumption by about 15 to $20 \%$ initially and 35 to $50 \%$ in the longer term.

Retrofits to provide for metering and control of heat in apartments would require the installation of thermostatic valves, bypasses, and throttle valves. This retrofit is estimated to cost $\$ 300 /$ apartment.

\section{F.4 Study of the Potential for Developing Actions to Improve the Overall Energy Efficiency in the Building Sector in Ukraine (TACIS 1994)}

The TACIS report presents an assessment of potential energy efficiency measures for buildings in Kyiv and the expected energy savings from these measures.

The report provided an extensive discussion of the physical characteristics of the measures, their installation, and implementation in existing and new buildings. The implementation discussion included the human resources available as well as an estimate of the quantity of labor required. An extensive discussion was also provided for the domestic production of insulation and glazing. 


\section{Measures evaluated were}

- Temperature Controls. This consisted of three measures for near-term implementation and two measures for the longer term:

1. Control indoor temperature at $18^{\circ} \mathrm{C}$, and balance system through installation of thermostatic bypass valves at the radiator and balancing valves in the vertical lines.

2. Employ night and weekend setback in public buildings.

3. Install building-level heat meters to enable billing for actual heat consumption.

4. Install hot water circulation pumps and heat exchangers with temperature controls in place of the existing "venturi" systems.

5. Install balancing valves on the building inlets.

- Insulation. This consisted of two classes of measures.

1. Insulate exterior walls, roofs, and attics.

2. Weatherstrip windows and doors.

The study selected a sample of 31 buildings: 18 residential, 3 office, 3 education, 2 hotel, 1 cultural, 1 sport, 1 retail, and 2 other. A number of measures were analyzed by computer analysis, and two residential buildings and the serving substation were metered from 15 October to 15 December 1993. Estimates of the achievable reduction in space heating energy were evaluated for thermostatic regulation, thermostatic regulation with setback, thermostatic valves with setback and wall and roof insulation, and thermostatic valves with setback and wall insulation (note the setback applied only to the nonresidential buildings). The efficiency improvements using an $18^{\circ} \mathrm{C}$ base temperature yielded savings as follows:

\begin{tabular}{||l|c|c|}
\hline & Range & Average \\
\hline Thermostatic Regulation & $14-25 \%$ & $18 \%$ \\
\hline Thermostatic Regulation with Setback & $44-53 \%$ & $50 \%$ \\
\hline Thermostatic Regulation with Setback and W/R Ins. & $17-70 \%$ & \\
\hline Thermostatic Regulation with Setback and Wall Ins. & $20-70 \%$ & \\
\hline
\end{tabular}

An economic analysis was conducted for nine of the residential prototypes and one office building. The economic analysis also provided an estimate of the quantities and costs of equipment, materials, and labor. Using a heat price of $\$ 14.25 / \mathrm{MWh}$, the analysis showed that temperature controls had a payback 
ranging from 0.9 to 5 years, and that the addition of wall and roof insulation increased the payback beyond 5 years for all building types and up to 26.1 years. The office building with setback controls exhibited the shortest payback.

Recommendations were to install regulation equipment on existing buildings. A similar set of measures was examined for new buildings, and both insulation and regulation were generally found to be cost-effective. The energy gains in existing buildings due to regulation and insulation were twice as much as for regulation alone; in new buildings the energy gains were found to be three times that of regulation alone.

Estimates of the efficiency potential were developed for Kyiv; these ranged from a low of $20 \%$ $(987,350 \mathrm{MWh} / \mathrm{yr})$ to a high of $55 \%(2,858,600 \mathrm{MWh} / \mathrm{yr})$.

Domestic manufacture of certain equipment/materials was also assessed for insulating materials, glazing materials, and heat regulation equipment. For each, an estimate of the market size was made along with the necessary investment and associated level of employment. 


\section{Distribution}

No. of

Copies

QFFSITE

2 DOE/Office of Scientific and Technical Information

3 The World Bank

Carolyn Gochenour

Senior Financial Analyst

Infrastructure Operations

Europe and Central Asia

The World Bank

1818 H Street, NW

Washington, DC 20433

Pentti Aro

District Heating Engineer

Infrastructure Operations

Europe and Central Asia

The World Bank

1818 H Street, NW

Washington, DC 20433

Konstantin Skorik

38/44 Pochainynska St.

$2^{\text {nd }}$ and $3^{\text {rd }}$ Floors

Kyiv, 252070

UKRAINE
No. of

Copies

3 U.S. Department of Energy

B. T. Castelli

Chief of Staff, Assistant Secretary for Energy Efficiency and Renewable

Energy

U.S. Department of Energy

Forrestal Building, EE-1

1000 Independence Avenue, S.W.

Washington, DC 20585

G. H. Kats

Special Assistant, Assistant Secretary for Energy Efficiency and Renewable Energy

U.S. Department of Energy

Forrestal Building, EE-1

1000 Independence Avenue, S.W.

Washington, DC 20585

E. A. Arner

Staff Assistant, Office of Utility

Technologies, Assistant Secretary

for Energy Efficiency and Renewable Energy

U.S. Department of Energy

Forrestal Building, EE-10

1000 Independence Avenue, S.W.

Washington, DC 20585

Distr.1 
No. of

Copies

FOREIGN

2 Ukraine State Committee for Energy

Conservation

Sergey Bevz

Director of International Relations

State Committee for Energy Conservation

Gonty St.

Kyiv, 252112

UKRAINE

Georgy Panchenko

Deputy Director of International Relations

State Committee for Energy Conservation

Gonty St.

Kyiv, 252112

UKRAINE

4 Agency for Rational Energy Use and Ecology

Sergey Surnin

ARENA-ECO

P.O. Box 48

1 Laboratorny St.

Kyiv, 252133

UKRAINE

Nikolai Raptsoun

ARENA-ECO

P.O. Box 48

1 Laboratorny St.

Kyiv, 252133

UKRAINE
No. of

Copies

Pavel Shestopal

ARENA-ECO

P.O. Box 48

1 Laboratorny St.

Kyiv, 252133

UKRAINE

Eugene Gagurin

ARENA-ECO

P.O. Box 48

1 Laboratorny St.

Kyiv, 252133

UKRAINE

16 Other

Tord Holmstrom

EnergiPlanerarna $\mathrm{AB}$

Peter Myndes Backe 12, 5 Tr.

11846 Stockholm

SWEDEN

3 Peter Hobson, Principal Banker

Energy Efficiency

European Bank for Reconstruction and

Development

One Exchange Square

London EC2A 2EH

UNITED KINGDOM

2 Lea Swanson, Director

Environmental Development

USAID Regional Mission

19 Nizhniy Val St.

Kyiv, 254071

UKRAINE 
No. of

Copies

10 Andrew Popelka

Tysak Engineering

29 Flint Road

Acton, MA 01720

\section{ONSITE}

226 Pacific Northwest National Laboratory

W. U. Chandler (10)

K4-06

M. Evans

BWO

S. L. Freeman (3)

K8-17

P. E. Killgo (175)

BWO

T. J. Secrest (32)

K5-16

Technical Report Files (5) 
M97054179

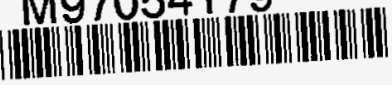

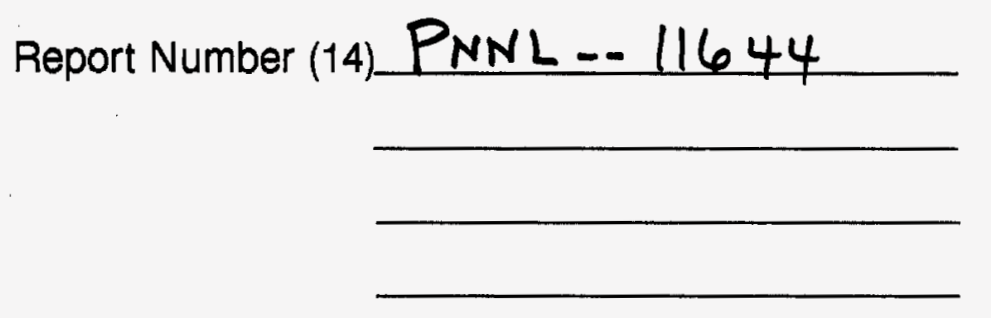

Publ. Date (11) 199708

Sponsor Code (18) DOE/EE , XF

UC Category (19) UC-1600, DDELER

not in RPS, No master necond arrilable

DOE 